NBER WORKING PAPER SERIES

VARIATION IN HEALTH CARE PRICES ACROSS PUBLIC AND PRIVATE PAYERS

Toren L. Fronsdal

Jay Bhattacharya

Suzanne Tamang

Working Paper 27490

http://www.nber.org/papers/w27490

\author{
NATIONAL BUREAU OF ECONOMIC RESEARCH \\ 1050 Massachusetts Avenue \\ Cambridge, MA 02138 \\ July 2020
}

We are grateful to the Foundation for Precision Medicine and to their data contributors, without whom this research would not be possible. Special thanks to Ayin Vala from the Foundation for Precision Medicine. None of the authors received funding for work on this study. All errors are our own. The views expressed herein are those of the authors and do not necessarily reflect the views of the National Bureau of Economic Research.

NBER working papers are circulated for discussion and comment purposes. They have not been peer-reviewed or been subject to the review by the NBER Board of Directors that accompanies official NBER publications.

(C) 2020 by Toren L. Fronsdal, Jay Bhattacharya, and Suzanne Tamang. All rights reserved. Short sections of text, not to exceed two paragraphs, may be quoted without explicit permission provided that full credit, including $\odot$ notice, is given to the source. 
Variation in Health Care Prices Across Public and Private Payers

Toren L. Fronsdal, Jay Bhattacharya, and Suzanne Tamang

NBER Working Paper No. 27490

July 2020

JEL No. G22,I11,I13

\begin{abstract}
$\underline{\text { ABSTRACT }}$
We study a unique all-payer data set spanning 38 states to examine the differences in inpatient reimbursement rates paid by traditional Medicare (TM), Medicare Advantage (MA), Medicaid, and private (under-65) insurers, and the differences in negotiated rates across the 60 largest private insurers. After controlling for enrollee and hospital mix, we find that private insurers pay 37 percent more than TM, and MA pays 10 percent more than TM for the five most common inpatient diagnoses. The correlation in risk-adjusted payments by private insurers and by TM at the same hospital for the same diagnosis is only 0.10 . There is significant variation in negotiated prices within and across private payers. Among the five largest US insurers, the most expensive insurer negotiates prices that are 5-26 percent higher than the mean price for the 20 most common inpatient diagnoses. Additionally, we find a 10 percent increase in insurer market share corresponds to a 7 percent decrease in inpatient negotiated prices and a 10 percent decrease in the standard deviation of prices. This finding suggests that increased insurer market power allows payers to negotiate prospective payment contracts - rather than the more common fee-for-service payments - thereby offloading financial risk to providers.
\end{abstract}

Toren L. Fronsdal

Stanford University

Department of Economics

579 Jane Stanford Way

Stanford, CA 94305-6072

toren@stanford.edu

Jay Bhattacharya

117 Encina Commons

CHP/PCOR

Stanford University

Stanford, CA 94305-6019

and NBER

jay@stanford.edu
Suzanne Tamang

Department of Biomedical Data Science

Stanford University School of Medicine

1265 Welch Road

Stanford, CA 94305-5464

stamang@stanford.edu 


\title{
Variation in Health Care Prices Across Public and Private Payers
}

\author{
Toren L. Fronsdal Jay Bhattacharya Suzanne Tamang *
}

May 2020

\begin{abstract}
We study a unique all-payer data set spanning 38 U.S. states to examine the differences in inpatient reimbursement rates paid by traditional Medicare (TM), Medicare Advantage (MA), Medicaid, and private (under 65) insurers, and the differences in negotiated rates across the 60 largest private insurers. After controlling for enrollee and hospital mix, we find that private insurers pay 37 percent more than TM, and MA pays 10 percent more than TM for the five most common inpatient diagnoses. National MA insurers reimburse hospitals at rates similar to TM, but smaller, regional MA insurers pay more than TM. The correlation in mean risk-adjusted payments by private insurers and by TM at the same hospital for the same diagnosis is only 0.10 . There is also significant variation in negotiated prices within and across private payers. For the five largest U.S. insurers, the least expensive insurer negotiates prices that are 6-27 percent lower on average than the mean price and the most expensive insurer negotiates prices that are 5-26 percent higher than the mean price for the 20 most common inpatient diagnoses. Additionally, we find that a 10 percent increase in insurer market share corresponds to a 7 percent decrease in inpatient negotiated prices. Furthermore, a 10 percent increase in insurer market share is associated with a 10 percent decrease in the standard deviation of inpatient prices paid by the insurer at a given hospital for a specific diagnosis. This finding suggests that increased insurer market power allows payers to negotiate prospective payment contracts - rather than the more common fee-for-service payments - thereby offloading financial risk to providers. (JEL: G22, I11, I13)
\end{abstract}

\section{Introduction}

The prices hospitals negotiate with insurers are shrouded in secrecy. Recently, the Centers for Medicare and Medicaid Services (CMS) introduced regulations compelling hospitals to publish the reimbursement rates they negotiate with private insurers (CMS 2019). The rule is slated to go into effect at the beginning of 2021, but hospitals are appealing the court's decision to uphold the rule, arguing that price transparency violates the First Amendment and may lead to insurer collusion (AHA 2020). Given hospitals' aversion to revealing the secret payer-specific reimbursement rates, there have been little data to date available to the consumers and researchers on the discounts

\footnotetext{
*Fronsdal: Department of Economics, Stanford University (email: toren@stanford.edu); Bhattacharya: School of Medicine, Stanford University and National Bureau of Economic Research (email: jay@stanford.edu); Suzanne Tamang: School of Medicine, Stanford University (email: stamang@stanford.edu). We are grateful to the Foundation for Precision Medicine and to their data contributors, without whom this research would not be possible. Special thanks to Ayin Vala from the Foundation for Precision Medicine. All errors are our own.
} 
resulting from hospital-insurer bargaining. In the past few years, researchers (e.g., Cooper et al. 2019) have taken advantage of new nationwide data on negotiated prices, though these data do not include a representative panel of payers.

In this paper, we analyze newly accessible data - the American Hospital Utilization Database (AHUD) - on the universe of patients from 474 hospitals across 38 U.S. states from 2009 to 2016, accounting for $\$ 1.8$ trillion in hospital charges. This novel data set has a number of unique advantages over previously available data for studying health care prices. Most importantly, the data contain the actual transaction prices and the discounts negotiated by insurers off the hospital's charges. ${ }^{1}$ Additionally, this all-payer database does not obscure the names of private insurers, allowing for an examination of the variation in the negotiated prices for the 60 largest private insurers in the 38 states in the data. To our knowledge, there has been no prior study examining variation in negotiated prices across private insurers with data with a scope greater than the state-level. Lastly, the data set is large, encompassing more than 300 million patient encounters over eight years. Given that much remains unknown about private insurers' negotiated prices, we present descriptive statistics about the variation in negotiated prices across private insurers and compare prices negotiated by private firms to those paid by Medicare and Medicaid. The analysis in this paper is organized into three areas of inquiry.

First, we describe the variation in risk-adjusted inpatient prices across common types of insurance coverage (traditional Medicare, Medicare Advantage, Medicaid, and private insurance). ${ }^{2}$ We find that, on average, Medicare Advantage (MA) pays 10 percent more than traditional Medicare (TM) for the five most common Medicare Severity Diagnosis Related Groups (MS-DRGs), ${ }^{3}$ after controlling for enrollee and provider mix. The disparity in reimbursement rates varies significantly depending on the diagnosis and treatment. Further, for national insurers, MA prices are similar to TM prices, but for smaller, regional insurers, MA prices tend to be higher than TM prices. For instance, for inpatient psychoses cases, the five largest MA insurers pay 6 percent less than TM, while the remaining insurers in the data pay 17 percent more than TM on average.

Private (under 65) plans consistently pay substantially more than both TM and MA for the same services. Private (under 65) insurers pay 37 percent more than TM and 25 percent more than MA on average for the five most common MS-DRGs. The distribution of private payments features high variance, driven by large outlier payments. This is consistent with the fact that many private insurers negotiate prices based on a percentage of hospital charges, rather than negotiating prospective payment contracts, in which insurers pay a fixed amount for each diagnosis. The distribution of Medicare Advantage negotiated prices, however, does not exhibit a similarly long

\footnotetext{
${ }^{1}$ Payers rarely pay the standard charges billed by hospitals; nearly always, payers will negotiate their own reimbursement rates with hospitals.

${ }^{2}$ In this paper, private insurance will refer to insurance covering enrollees under the age of 65 with group or individual coverage.

${ }^{3}$ MS-DRG codes are a system for classifying inpatient hospital claims based on diagnoses, procedures, and/or treatment; severity; and comorbidities. They are used for Medicare's prospective payment system as the main method of reimbursing inpatient care.
} 
right tail. This suggests that private insurers tend to negotiate the structure of MA contracts with hospitals as a percentage of Medicare reimbursements (a prospective payment system), partially offloading the risk of outlier payments onto the provider. The correlation in mean risk-adjusted prices for private (under 65) and MA across hospitals ranges from 0.60 to 0.67 for the five most common MS-DRGs, after controlling for patient severity. For TM and Medicaid, the correlation ranges from -0.11 to 0.34 for different diagnoses.

Second, we examine the between-payer price variation for the 60 largest private insurers. ${ }^{4}$ For the five largest U.S. insurers, the least expensive insurer negotiates prices that are 6-27 percent lower on average than the mean price and the most expensive insurer negotiates prices that are 5-26 percent higher than the mean price for the 20 most common MS-DRGs. We find there exists high variation in negotiated prices across insurers within the same hospital. For instance, for vaginal deliveries, the bivariate correlations between each of the five largest private U.S. insurance companies within the same hospital range from -0.57 to 0.70. For hip and knee replacements, these correlations range from 0.04 to 0.82 . For the 60 largest insurers and for the 20 most common MSDRGs, the between-payer coefficient of variation ranges from 8 percent to 24 percent. Further, we find that within-hospital variation in prices is sizable for both inpatient and outpatient care. For inpatient care, within-hospital variation is primarily explained by differences in negotiated prices across insurers. For outpatient care, however, insurer contracts do not explain much of the withinhospital variation. These findings imply that contracts between insurers and providers are more prospective for inpatient care than for outpatient care.

Third, we add to the literature on the determinants of negotiated health care prices by investigating the relationship between insurer market share and negotiated reimbursement rates. While there has been ample research on other determinants of health care prices (including hospital market concentration), lack of accessible data has constrained research on the relationship between insurer market concentration and negotiated prices. We find that a 10 percent increase in insurer market share is associated with a 6-7 percent decrease in negotiated prices. In addition, we explore the relationship between insurer market share and the extent to which hospitals and insurers bear risk in their negotiated price contracts. There is an inverse relationship between insurer market share and the variance in payments for services treating a given diagnosis. This finding implies that, when insurers hold greater market power, they are more likely to be able to negotiate prospective payment contracts, paying providers based on the diagnosis rather than the actual treatments the patient receives.

The paper proceeds as follows. In Section 2, we give an overview of the existing literature on health care prices. In Section 3, we describe the data, variable construction, sample selection, and provide descriptive statistics. In Section 4, we compare the price of care received by the privatelyinsured and publicly-insured and examine the variation in prices negotiated by different private payers. In Section 5, we examine the association between insurer market share and negotiated

\footnotetext{
${ }^{4}$ For a complete list of the private insurers examined in this paper, consult Appendix Table 17.
} 
prices. Section 6 concludes.

\section{Background}

\subsection{Comparisons of Public and Private Payer Prices}

Public and private payers reimburse providers for their services using different methods of payments. Traditional Medicare's inpatient payments are set administratively by the Centers for Medicare and Medicaid Services (CMS), and are organized according to Medicare Severity Diagnosis Related Groups (MS-DRGs). Some adjustments to MS-DRG reimbursement rates are made based on geographic marketplace and hospital type, with additional outlier payments reimbursing providers for especially costly patients. In contrast, Medicaid payment structures vary widely across states, with most Medicaid programs using fee-for-service or prospective payments to reimburse providers. Private prices are primarily market-driven and are set based on complex contract negotiations between each provider-insurer pair. The negotiated prices may be set based on a share of a hospital's chargemaster price, or prospectively as a percentage of Medicare reimbursements. These contract structures, and the actual private negotiated prices, have historically remained highly confidential and are considered trade secrets.

Surprisingly little is known about the variation in prices across types of insurance coverage. The Congressional Budget Office reports that MA plans pay slightly more than TM plans (CBO 2013). Recently, using data from three national insurers provided by the Health Care Cost Institute (HCCI) ${ }^{5}$ researchers have been able to compare inpatient prices for MA and TM nationwide. Baker et al. (2016), Maeda and Nelson (2018), Pelech (2018), and Curto et al. (2019) all use the HCCI data to compare prices, utilization, or spending differences between TM and MA. Baker et al. find that, from 2009 to 2012, MA plans paid 5.6 percent less for hospital services than TM plans. Maeda and Nelson estimate that MA and TM prices are roughly equal for hospital services and Pelech finds that this is also true for physician service payments. Similarly, Curto et al. find that MA plans pay only about 1 percent more than TM on average. These findings run counter to conventional wisdom, which suggests that MA would pay significantly higher prices than TM given the ability of the public sector's monopsony power to constrain prices.

In a survey of senior hospital and health plan executives, Berenson et al. (2015) find that commercial plans pay significantly more than MA plans, which, in turn, tend to pay 100-105 percent of TM rates. Pelech (2018) and White and Whaley (2019) also find that average commercial prices are substantially higher than traditional Medicare prices for physician and hospital services, respectively. Using the IBM MarketScan data, Romley et al. (2015) find that a 10 percent lower commercial price is associated with 3 percent higher Medicare spending per member. Using a large administrative change in TM reimbursement rates for surgical versus medical care, Clemens and

\footnotetext{
${ }^{5}$ See Subsection 3.1 for more details on the HCCI data.
} 
Gottlieb (2017) find that, for BCBS of Texas, private negotiated prices tend to be tied to TM reimbursements, although Clemens, Gottlieb, and Molnár (2017) show that these prices deviate when there is significant value at stake.

\subsection{Variation in Private Payer Prices}

Recent literature has focused on the variation in health care prices for the privately-insured across geographic markets and across providers (e.g., Cooper et al. 2019). However, there has been little examination of between-payer price variation. The HCCI data on private prices does not differentiate between insurers and therefore does not allow for cross-payer comparisons. The prices negotiated by private payers have a significant effect on consumer welfare and thus are of immense importance to employers and consumers. Save for the few states that have established all-payer databases, however, these negotiated prices cannot be observed by outsiders. Even in states with all-payer databases, these data are unlikely to be decipherable to the average consumer. Higher negotiated prices may be passed on to consumers in the form of out-of-pocket costs and, potentially, higher premiums. Given the rise of high-deductible plans and increased cost-sharing via coinsurance, the prices negotiated by insurers are especially relevant to customers. Ceteris paribus, in the presence of perfect information on prices, consumers would prefer to be insured by insurance firms negotiating lower prices with providers.

A significant portion of the variation in prices can be attributed to market dynamics based on hospital monopoly power and insurer monopsony power. The past two decades have been characterized by increasing consolidation on both sides of this market. There is strong evidence documenting the positive relationship between provider market power and negotiated prices (e.g., Brooks, Dor, and Wong 1997; Town and Vistnes 2001; Ginsburg 2010; Robinson 2011) and the inverse relationship between insurer market power and negotiated prices (e.g., Wu 2009; Moriya, Vogt, and Gaynor 2010; Melnick, Shen, and Wu 2011; McKellar et al. 2013; Scheffler and Arnold 2017). An insurer's ability to control the flow of patients to specific providers also tends to result in lower negotiated prices (Staten, Umbeck, and Dunkelberg 1987, 1988; Pauly 1998; Cutler, McClellan, and Newhouse 2000; Sorenson 2003). Cooper et al. (2019) find that, even within hospitals, there is significant variation in payments for a given procedure, and hypothesize that this can be primarily attributed to differences in negotiated prices across insurers. Using Massachusetts's All-Payer Claims Database, Craig, Ericson, and Starc (2018) provide the first picture of variation in prices across private payers, focusing on Blue Cross Blue Shield of MA, Tufts Health Plan, and Harvard Pilgrim. Their study finds substantial variation in prices paid by different payers to the same hospitals for the same service in Massachusetts. Further, they present a model of provider-insurer negotiations in which consumer response to negotiated provider prices is a crucial determinant of payers' negotiation efforts. 


\subsection{New Contributions}

This paper leverages a novel proprietary data set that allows researchers to lift the veil of secrecy surrounding provider-insurer negotiations. Building off the recent HCCI findings, we expand the scope of private insurers studied from UnitedHealthcare, Aetna, and Humana (insurers in the HCCI studies) to 60 of the largest U.S. insurers. The findings presented here differ in some notable ways from the HCCI findings, especially since these three national insurers are not representative of the private insurance market as a whole, as we show in Subsection 4.2. Other than the HCCI and MarketScan data, no data has previously allowed for a comparative analysis of MA and private (under 65) negotiated prices across the U.S. The analysis of the data in this paper allows for a descriptive study of prices negotiated by private insurers that captures the universe of insurers at a given provider. Additionally, this paper provides a look at between-payer variation for private negotiated prices across the country. To our knowledge, between-payer variation has only been examined in Massachusetts. Understanding of variation in prices across private payers is important in the context of the federal government's proposed health care price transparency laws. Lastly, the paper contributes to a growing literature on the determinants of private prices by examining the relationship between insurer market power and hospital-insurer negotiations.

\section{Data and Variables}

\subsection{American Hospital Utilization Database}

The data for this study come from the American Hospital Utilization Database (AHUD), which consists of electronic medical record (EMR) data provided by a large healthcare services company. This paper is the first analysis of the AHUD data examining health care pricing. The data come from 474 providers in 38 U.S. states using this service. Included in the data are encounter-level claims for inpatient and outpatient services. The proprietary data span 2009 to 2016 (inclusive) and document over 300 million patient encounters with providers from over 80 million individual patients. 278 million of the encounters are outpatient visits and 25 million are inpatient visits. These encounters come from patients of all insurance types (i.e., traditional Medicare, Medicare Advantage, Medicaid, CHIP, private, no insurance). The mix of hospitals consists of large and small facilities in both urban (87 percent) and rural (13 percent) locations. Roughly 98 percent of providers submit both inpatient and outpatient data. The vast majority of facilities in the data are hospitals but the data also includes skilled nursing facilities, home health, and clinics.

The unique aspect of the AHUD data is the inclusion of the actual reimbursement paid by the insurer and patient, the provider's billed charges for the encounter, and the negotiated discount and contractual adjustments for the insurer. The data also include the estimated cost for the encounter based on the cost-to-charge ratio for that hospital from the Centers for Medicare and Medicaid Services (CMS) hospital cost reports. Some providers report the amount of the payment that is 
the patient's responsibility, including the patient's copay and deductible amounts.

Figure 1: States in the AHUD Data

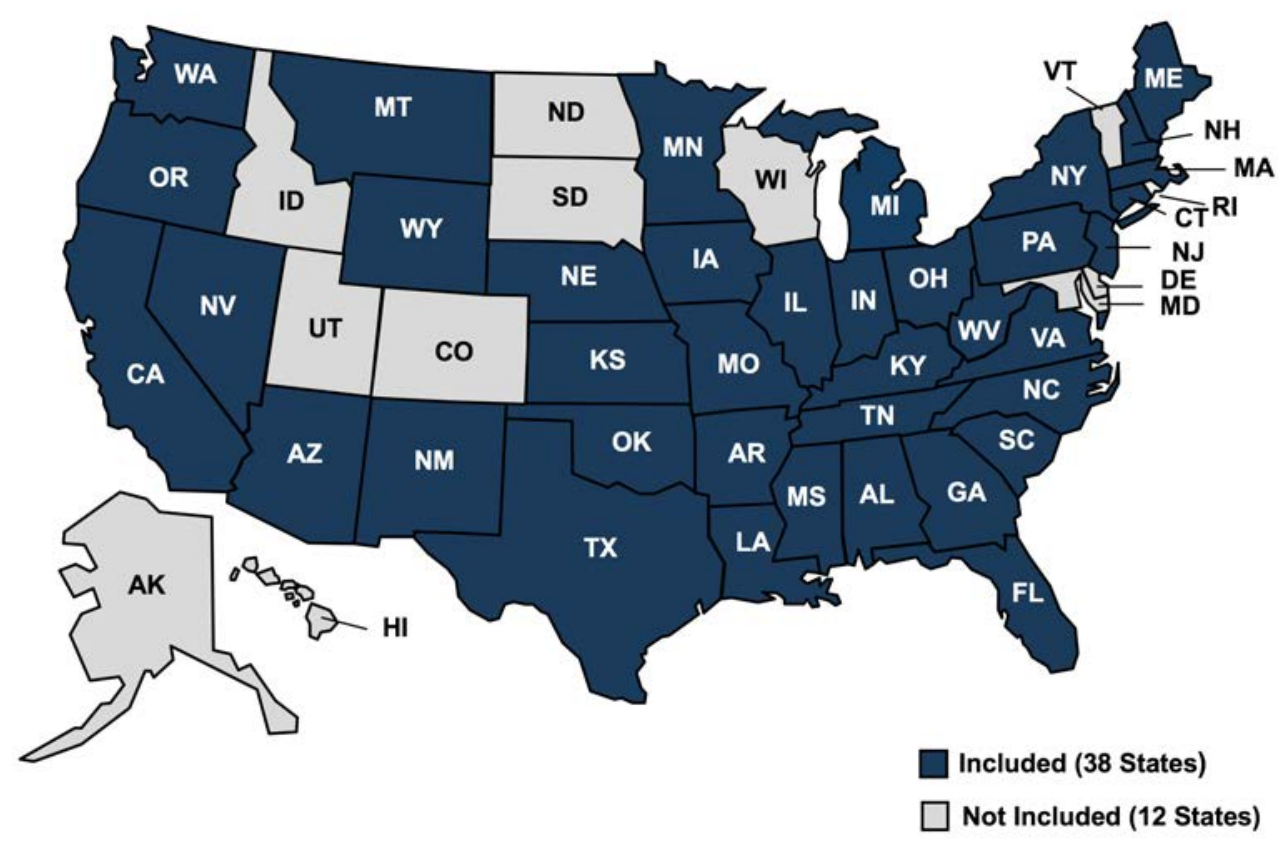

To our knowledge, there are only two other alternative data sources available to researchers that are larger than the state level and include prices negotiated by private insurers. One is the Health Care Cost Institute (HCCI) data. ${ }^{6}$ HCCI provides claims-level data for employersponsored insurance from UnitedHealthcare, Aetna, and Humana (masking the individual insurers) and contains 42 to 46 million lives per year (Cooper et al. 2019). The other alternative data source is the IBM MarketScan Commercial Database. The MarketScan data come primarily from large employers, but also contain some data from mid-size and smaller employers as well as health plans. It contains several million individuals, encompassing employees and their dependents who are covered by employer-sponsored private insurance. Unlike the HCCI and MarketScan data, the AHUD data are sourced from the providers rather than employers or health plans. This allows for one distinct advantage over the other two data sources. Namely, the AHUD data contain people with all types of insurance (public and private) and with no insurance, rather than strictly employer-sponsored insurance. Within private claims, HCCI and MarketScan only have data on a handful of insurers and obscure any connection between a specific payer and a claim, while AHUD contains claims-level data for hundreds of insurers and identifies the payer for each claim.

To de-identify the data, all protected health information (PHI) elements are removed except for the admission and discharge dates, which are reported on a monthly, rather than daily, basis. Furthermore, patient zip codes are truncated to three digits and reported only if the population

\footnotetext{
${ }^{6}$ https://healthcostinstitute.org/data
} 
of the three-digit zip code was greater than 20,000 as reported in the 2010 Census. Ages greater than 89 are truncated to 90 for reporting purposes. Patient characteristics included in the data are age, gender, and employment status. For each patient encounter, the AHUD data include a list of primary and secondary diagnoses from ICD-9 and ICD-10 codes; procedures, treatments, and prescriptions from ICD, CPT, and HCPCS codes; length of stay; and whether or not the patient died during hospitalization. In addition, the data contain information submitted in UB92/UB04 billing forms, including admission source, admission type, and discharge status. For inpatient visits, we also include CMS Medicare Severity Diagnosis Related Groups (MS-DRGs).

For the analysis comparing public and private prices, we classify payers as traditional Medicare, Medicare Advantage, private (under 65), and Medicaid and CHIP. For more information on the classification of payers, consult Appendix C and Appendix D. Within the private (under 65) category, we identify claims from the 60 largest private insurance firms and their subsidiaries. A list of the private insurance firms we study with the AHUD data is provided in Appendix Table 17.

\subsection{Sample Selection}

We include only patient encounters for which there are data on the actual price received by the hospital for the encounter. Unless otherwise specified, we include only inpatient admissions. For the analysis of private and Medicare Advantage prices, we restrict the sample to encounters covered by the 60 largest insurers in the data. In the analysis comparing prices by public and private payers, we restrict the sample to the five most common MS-DRGs that are not related to births, so as to include data from the elderly population for MA and TM. For the examination of private (under $65)$ prices, we restrict the analysis to the 20 most common MS-DRGs for patients between 18 and 65 years old.

\subsection{Limitations of Data}

The data are not nationally representative of hospitals. Hospitals in the AHUD data tend to be larger and in more populated areas. According to the American Hospital Association's 2017 Annual Survey, 64 percent of U.S. hospitals are in urban locations. In the AHUD data, 83 percent of hospitals are in urban locations. In addition, 44 percent of U.S. hospitals have 100 or more beds, while in the AHUD data, 78 percent of hospitals have 100 or more beds. Hospitals in the South are overrepresented in the AHUD data. The data also only include providers using an EMR system. Further, there may be selection bias in providers that employ the healthcare services company from which the data are sourced (e.g., hospitals in wealthier areas). However, overall demographic information including the distribution of patient ages and gender and pricing data including average charges and average costs are nearly identical to nationally representative data. ${ }^{7}$

\footnotetext{
${ }^{7}$ We compare the AHUD inpatient data to the HCUP National Inpatient Sample in Appendix B.
} 
While AHUD has information on the payer for a patient's encounter with a provider, it does not provide any further information about the type of plan the patient has (e.g., HMO, PPO, or PFFS). Additionally, patient and hospital location data is not fine-grain. The location of a patient's residence is only provided at the three-digit zip code level, which is a relatively broad geographic area. ${ }^{8}$ While distinct hospitals are identifiable in the data, they can not be linked to more detailed external hospital data. Therefore, only rough approximations of a hospital's local market share can be estimated with these data. While other data sets include both claims and denominator populations (eligible enrollees), the denominator population is not available in the AHUD data. Lastly, five of the 38 states in the data only have data from one provider. Thus, we avoid any state-level analysis and comparisons in prices between states.

\subsection{Constructing Risk- and Hospital-Adjusted Prices}

Differences in reimbursement rates across payers may indicate differences in the enrollee mix (e.g., MA beneficiaries may be more healthy on average compared to TM beneficiaries). Further, differences in reimbursement rates could be driven by differences in the geographic locations and the hospitals at which the payer covers patients. Thus, we control for these differences across payers by constructing hospital- and risk-adjusted prices that remove variation due to patient characteristics and comorbidities as well as any year- and hospital-specific variation.

We estimate the hospital- and risk-adjusted prices paid by each payer for a number of highvolume MS-DRGs. Each of MS-DRG is defined by a particular set of patient attributes, including principal diagnosis, specific secondary diagnoses, procedures, sex, and discharge status. MS-DRGs are used to code the payment of inpatient services for Medicare beneficiaries.

We construct the adjusted price estimate in two stages. First, we estimate the following equation separately for each MS-DRG:

$$
p_{i, j, h, t}=\mathbf{X}_{i} \beta+\gamma_{h, t}+\epsilon_{i, j, h, t}
$$

where $p_{i, j, h, t}$ is price paid for patient encounter $i$ covered by payer $j$ at hospital $h$ in year $t . \mathbf{X}_{i}$ is a vector of patient-specific characteristics: age, an indicator for male, length of stay, and indicators for the 17 comorbid conditions defining the Charlson comorbidity index. $\gamma_{h, t}$ is a vector of yearspecific hospital fixed effects. Lastly, $\epsilon_{i, j, h, t}$ is a vector of the residuals accounting for all variation in $p_{i, j, h, t}$ not explained by $\mathbf{X}_{i}$ and $\gamma_{h, t}$.

From equation (1), we obtain the vector of residuals from the model, $\hat{\epsilon}_{i, j, h, t}$. These residuals can be interpreted as the variation in price not explained by age, gender, comorbidities, year, or the hospital which the patient visited. A positive residual means the payment for the encounter was higher than expected, conditional on these covariates.

\footnotetext{
${ }^{8}$ For reference, California has 58 three-digit zip codes.
} 
We then obtain hospital- and risk-adjusted prices, $\tilde{p}_{i, j, h, t}$ :

$$
\tilde{p}_{i, j, h, t}=\bar{p}+\hat{\epsilon}_{i, j, h, t}
$$

where $\bar{p}$ is simply a constant across all observations and scales the residual to match the mean of the data for the given MS-DRG. The only term that differentially affects $\tilde{p}_{i, j, h, t}$ is $\hat{\epsilon}_{i, j, h, t}$. The mean hospital- and risk-adjusted price for each payer is then given by $\overline{\tilde{p}}_{j}=1 / N \sum_{i=1}^{N} \tilde{p}_{i, h, t}$ where $N$ is the number of enrollees in plans by payer $j$. This price measure allows for an analysis of prices paid by different payers after controlling for observable differences in enrollee mix, encounter severity, and hospital-specific differences.

For certain analyses, such as those presented in Table 4 and Table 6, we also construct measures of risk-adjusted prices using the method described above that do not control for differences across providers ( $\gamma$ is now a vector of year fixed effects, rather than year-specific hospital fixed effects). This allows for a comparison of risk-adjusted prices paid by payers within the same hospital.

The interpretation of this adjusted price relies on the assumption that there are no unobservable differences in the average patient severity or level of treatment for each payer. Unlike some other DRG classifications, MS-DRGs indicate the presence and severity of comorbidities and complications. Thus, the stratification across MS-DRGs further controls for differences in patient severity.

We estimate several different versions of risk-adjusted and hospital- and risk-adjusted prices. For the analysis in Subsection 4.1, $j$ indexes the type of coverage a patient receives (TM, MA, Medicaid and CHIP, and private). For the analysis in Subsection 4.2, we first subset the data to only the encounters covered by the largest 60 private insurers for patients under 65 years of age. In this analysis, the prices are constructed such that $j$ indexes the private insurers (e.g., Anthem). Further, we also construct risk-adjusted and hospital- and risk-adjusted discounts for payers, as measured by the percent discount off the chargemaster price for the encounter. The adjusted prices and adjusted percent discounts track each other closely. To further evaluate the adjusted price measures, we run versions of equations (1) and (2) where the outcome variable is the hospital's billed charges, rather than the price. With this outcome measure, we observe little variation across private payers, implying that the adjusted price measures are likely not biased by any unobserved differences in patient severity or level of care across payers.

\subsection{Descriptive Statistics}

Table 1 displays summary statistics for the hospitals in the data. Table 2 presents summary statistics describing patient characteristics. We also compare the AHUD data to the Healthcare Cost and Utilization Project (HCUP) National Inpatient Sample, a nationally representative sample, in Appendix B. The levels and trends in inpatient charges and costs are similar between the AHUD and HCUP data. Further, the distribution of patient ages is nearly identical for the AHUD and HCUP data. The AHUD has 9 percent more hospitals in the South Atlantic region and 8 percent 
more in the West South Central region relative to the geographic distribution of U.S. hospitals.

Table 1: Hospital Characteristics

\begin{tabular}{|c|c|c|c|c|}
\hline & \multirow[b]{2}{*}{$\mathrm{N}$} & \multirow[b]{2}{*}{ Percent } & \multicolumn{2}{|c|}{ Cost to charge ratio } \\
\hline & & & Mean & Std. Dev. \\
\hline \multicolumn{5}{|l|}{ Teaching Status } \\
\hline Non-Teaching & 302 & $64 \%$ & 0.26 & 0.08 \\
\hline Teaching & 152 & $32 \%$ & 0.26 & 0.06 \\
\hline Unknown & 20 & $4 \%$ & 0.27 & 0.07 \\
\hline \multicolumn{5}{|l|}{ Number of Beds } \\
\hline Less Than 100 Beds & 106 & $22 \%$ & 0.28 & 0.09 \\
\hline 100-199 Beds & 125 & $26 \%$ & 0.25 & 0.08 \\
\hline 200-299 Beds & 64 & $14 \%$ & 0.25 & 0.08 \\
\hline 300-499 Beds & 87 & $18 \%$ & 0.25 & 0.07 \\
\hline 500 or More Beds & 70 & $15 \%$ & 0.24 & 0.06 \\
\hline Unknown & 22 & $5 \%$ & 0.27 & 0.07 \\
\hline \multicolumn{5}{|c|}{ Urban or Rural Status } \\
\hline Rural & 62 & $13 \%$ & 0.29 & 0.08 \\
\hline Urban & 392 & $83 \%$ & 0.25 & 0.08 \\
\hline Unknown & 20 & $4 \%$ & 0.27 & 0.07 \\
\hline \multicolumn{5}{|l|}{ Region } \\
\hline East North Central & 56 & $12 \%$ & 0.29 & 0.08 \\
\hline East South Central & 25 & $5 \%$ & 0.25 & 0.06 \\
\hline Middle Atlantic & 37 & $8 \%$ & 0.22 & 0.07 \\
\hline Mountain & 13 & $3 \%$ & 0.29 & 0.07 \\
\hline New England & 19 & $4 \%$ & 0.36 & 0.11 \\
\hline Pacific & 64 & $14 \%$ & 0.23 & 0.08 \\
\hline South Atlantic & 140 & $30 \%$ & 0.25 & 0.06 \\
\hline West North Central & 24 & $5 \%$ & 0.27 & 0.08 \\
\hline West South Central & 96 & $20 \%$ & 0.25 & 0.07 \\
\hline
\end{tabular}

Table 2: Patient Characteristics

\begin{tabular}{ccc}
\hline & $\mathrm{N}$ & Percent \\
\hline Patient Type & & \\
Outpatient & $278,271,652$ & 91.66 \\
Inpatient & $25,326,425$ & 8.34 \\
Patient Age & & \\
Age $<$ 18 & $40,160,935$ & 13.23 \\
Age 18-24 & $19,390,300$ & 6.39 \\
Age 25-34 & $31,727,338$ & 10.45 \\
Age 35-44 & $32,228,165$ & 10.62 \\
Age 45-54 & $43,596,816$ & 14.36 \\
Age 55-64 & $48,782,047$ & 16.07 \\
Age $>$ 65 & $87,458,066$ & 28.81 \\
Unknown & 254,410 & 0.08 \\
Gender & & \\
Male & $117,170,775$ & 38.59 \\
Female & $186,427,302$ & 61.41 \\
Length of Stay & & \\
1 & $249,345,370$ & 82.13 \\
2 & $15,036,230$ & 4.95 \\
3 & $7,925,148$ & 2.61 \\
4 & $5,422,263$ & 1.79 \\
5 & $3,122,377$ & 1.03 \\
$>5$ & $22,746,683$ & 7.49 \\
\hline
\end{tabular}




\section{Variation in Hospital-Insurer Negotiated Prices}

\subsection{Variation Across Public and Private Plans}

In this section, we examine the variation in prices paid to providers by traditional Medicare, Medicaid and CHIP, Medicare Advantage insurers, and private (under 65) insurers. For the analysis of prices across public and private insurers, we first compare the mean hospital- and risk-adjusted price for each of the five most common MS-DRGs. We present the results in Table 3. Private (under 65) insurers pay significantly more than all other types of coverage, MA pays slightly more than TM, and Medicaid and CHIP pay significantly less than TM. The average discount off the chargemaster price negotiated by private insurers ranges from 52 to 62 percent. Figure 2 presents prices as a percent of traditional Medicare's reimbursement for the five most common MS-DRGs. Medicaid pays 21.1 percent less than TM on average. In contrast, private (under 65) insurers pay 37.4 percent more than TM and 24.5 percent more than MA on average.

Medicare Advantage (MA) pays 10.4 percent more than traditional Medicare (TM) on average for the five most common Medicare Severity Diagnosis Related Groups (MS-DRGs), after controlling for enrollee and provider mix. However, the disparity in reimbursement rates varies significantly depending on the diagnosis and treatment. For cases with diagnoses of psychoses, MA payers only pay 6.9 percent more than TM. For hip and knee replacements, MA payers pay 15.2 percent more than TM.

The finding that MA pays more than TM stands differs from the findings analyzing HCCI data (Baker et al. 2016; Maeda and Nelson 2018; Pelech 2018; Curto et al. 2019), which all find that MA pays providers similar or lower rates on average relative to TM. These HCCI studies examine data from UnitedHealthcare, Aetna, and Humana - three of the five largest insurers in the U.Swhereas we examine data from the 60 largest insurers. Indeed, when we consider only these three large insurers with the AHUD data, the results are largely consistent with the HCCI studies. On average across the five most common MS-DRGs, the HCCI insurers pay only 2.1 percent more for MA than TM, while the remaining 57 non-HCCI insurers pay 17.5 percent more than TM (see Appendix Figure 8 and Appendix Figure 9). These findings suggest that the HCCI data is not representative of the insurance market as a whole. It is possible that these three national insurers are able to extract significantly higher discounts relative to smaller, regional insurers. In fact, the five largest U.S. insurers (Aetna, Anthem, Cigna, Humana, and UnitedHealthcare) pay only 5.6 percent more for MA than TM on average, while the remaining 55 insurers in the data pay 15.5 percent more than TM (see Appendix Figure 10 and Appendix Figure 11). 
Table 3: Adjusted Prices by Payer Type for Five Most Common MS-DRGs

\begin{tabular}{|c|c|c|c|c|c|c|c|c|c|c|}
\hline \multirow[b]{3}{*}{$\begin{array}{l}\text { Medicare Severity } \\
\text { Diagnosis Related Group }\end{array}$} & \multirow[b]{3}{*}{ Payer } & \multicolumn{4}{|c|}{ Price } & \multicolumn{4}{|c|}{ Percent Discount off Charge } & \multirow[b]{3}{*}{$\mathrm{N}$} \\
\hline & & \multicolumn{2}{|c|}{ Mean } & \multirow[b]{2}{*}{ Std. Dev. } & \multirow[b]{2}{*}{$\mathrm{CV}$} & \multicolumn{2}{|c|}{ Mean } & \multirow[b]{2}{*}{ Std. Dev } & \multirow[b]{2}{*}{$\mathrm{CV}$} & \\
\hline & & Residuals & Adj. Price & & & Residuals & Adj. Discount & & & \\
\hline \multirow{4}{*}{$\begin{array}{l}\text { Esophagitis, gastroent \& } \\
\text { misc digest disorders w/o } \\
\text { MCC }\end{array}$} & Private (under 65) & $1,386.04$ & $6,799.49$ & $6,222.33$ & 0.92 & -5.43 & 61.94 & 35.88 & 0.58 & 37,971 \\
\hline & Medicare Advantage & -99.85 & $5,313.60$ & $3,236.45$ & 0.61 & -0.19 & 67.19 & 20.07 & 0.30 & 9,871 \\
\hline & Medicare & -613.43 & $4,800.02$ & $2,584.58$ & 0.54 & 1.78 & 69.15 & 69.72 & 1.01 & 42,523 \\
\hline & Medicaid and CHIP & $-1,591.30$ & $3,822.16$ & $9,342.85$ & 2.44 & 8.23 & 75.61 & 37.47 & 0.50 & 15,981 \\
\hline \multirow{4}{*}{$\begin{array}{l}\text { Major joint replacement or } \\
\text { reattachment of lower } \\
\text { extremity w/o MCC }\end{array}$} & Private (under 65) & $3,717.41$ & $20,067.30$ & $10,028.17$ & 0.50 & -7.26 & 59.55 & 22.57 & 0.38 & 51,593 \\
\hline & Medicare Advantage & 312.12 & $16,662.02$ & $7,252.81$ & 0.44 & -1.69 & 65.11 & 175.84 & 2.70 & 27,910 \\
\hline & Medicare & $-1,885.35$ & $14,464.54$ & $4,436.95$ & 0.31 & 4.08 & 70.89 & 70.37 & 0.99 & 87,936 \\
\hline & Medicaid and CHIP & $-7,704.18$ & $8,645.71$ & $7,476.77$ & 0.86 & 13.85 & 80.65 & 17.62 & 0.22 & 4,507 \\
\hline \multirow{4}{*}{ Cellulitis w/o MCC } & Private (under 65) & $1,409.01$ & $7,391.65$ & $5,687.21$ & 0.77 & -6.20 & 55.41 & 31.39 & 0.57 & 21,357 \\
\hline & Medicare Advantage & 37.96 & $6,020.60$ & $3,781.47$ & 0.63 & -0.26 & 61.35 & 24.44 & 0.40 & 5,852 \\
\hline & Medicare & -564.38 & $5,418.26$ & $2,607.51$ & 0.48 & 1.44 & 63.05 & 36.29 & 0.58 & 26,929 \\
\hline & Medicaid and CHIP & $-1,235.40$ & $4,747.24$ & $18,359.61$ & 3.87 & 7.78 & 69.39 & 66.66 & 0.96 & 12,213 \\
\hline \multirow{4}{*}{$\begin{array}{l}\text { Septicemia or severe sepsis } \\
\text { w/o mv } 96+\text { hours w MCC }\end{array}$} & Private (under 65) & $7,193.09$ & $21,392.51$ & $27,017.28$ & 1.26 & -8.90 & 52.25 & 50.38 & 0.96 & 17,111 \\
\hline & Medicare Advantage & 323.73 & $14,523.16$ & $10,276.53$ & 0.71 & 1.58 & 62.73 & 41.24 & 0.66 & 20,577 \\
\hline & Medicare & -735.27 & $13,464.15$ & $6,294.04$ & 0.47 & 0.42 & 61.57 & 130.70 & 2.12 & 98,646 \\
\hline & Medicaid and CHIP & $-4,261.54$ & $9,937.88$ & $14,204.46$ & 1.43 & 5.85 & 67.00 & 417.08 & 6.23 & 13,406 \\
\hline \multirow{4}{*}{ Psychoses } & Private (under 65) & 630.68 & $6,990.26$ & $5,186.54$ & 0.74 & -3.63 & 58.53 & 36.81 & 0.63 & 38,807 \\
\hline & Medicare Advantage & 354.05 & $6,713.63$ & $5,266.15$ & 0.78 & -1.41 & 60.75 & 151.81 & 2.50 & 3,710 \\
\hline & Medicare & -77.10 & $6,282.48$ & $4,091.06$ & 0.65 & 2.29 & 64.45 & 83.03 & 1.29 & 56,626 \\
\hline & Medicaid and CHIP & -468.88 & $5,890.70$ & $3,702.53$ & 0.63 & 0.27 & 62.43 & 315.79 & 5.06 & 44,737 \\
\hline
\end{tabular}

Notes: A unit of analysis is an inpatient admission. Prices and percent discounts are adjusted using equations (1) and (2) to control for differences

in patient severity and year-specific hospital effects. 
Figure 2: Prices as a Percent of Medicare Reimbursements

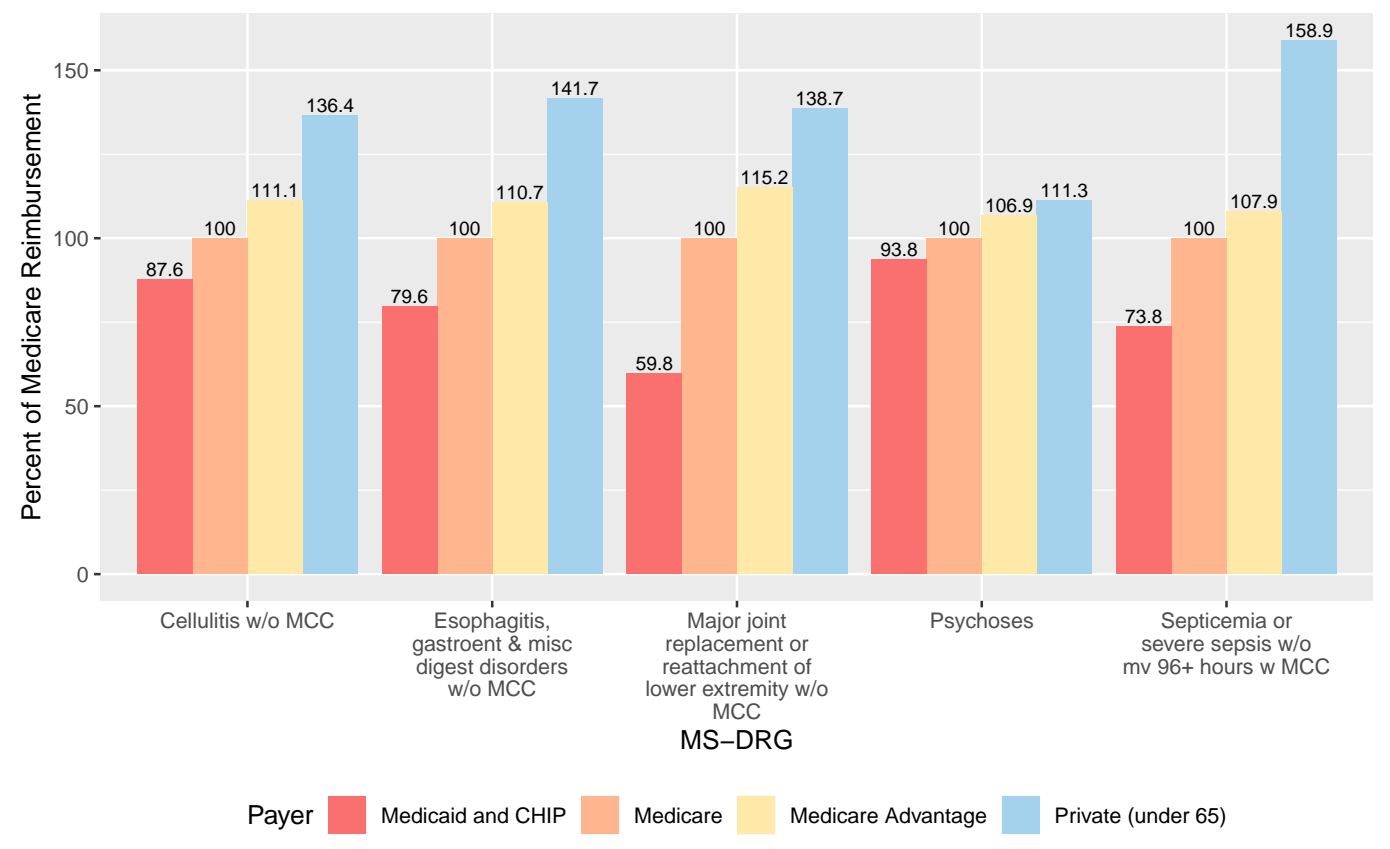

Figure 3 shows that the high mean prices negotiated by private payers and the high variation in prices exhibited in Table 3 are driven primarily by large outlier payments. This is expected given that commercial plans tend to pay providers a share of the billed charges. Interestingly, the distribution of MA prices does not have the long right tail present for the private (under 65) prices. This suggests that MA plans tend to not make payments as a share of charges, but instead they pay prospectively based on diagnosis, following TM.

As shown in Table 3, the coefficient of variation for private prices is substantially larger relative to that of traditional Medicare and Medicare Advantage. However, the coefficient of variation for the percent discount off the chargemaster price is smaller in all cases than that of traditional Medicare. Medicare's prospective payment system reimburses providers independently of the providers' billed charges. In contrast, private payers tend to pay providers a share of the billed charge. Thus, for many MS-DRG-payer-provider combinations, the percent discount is relatively constant, explaining the smaller variation relative to Medicare. Medicaid's reimbursement methodology and rates vary by state, explaining why Medicaid tends to exhibit the highest coefficient of variation of all types of insurance coverage.

Lastly, we compare payments by MA, TM, Medicaid, and private (under 65) insurers at the same provider with the same MS-DRG to examine the correlation between payments across these types of insurance coverage within a provider. The unit of analysis for this analysis is the mean risk-adjusted payment for admissions covered by a type of insurance at a specific hospital for a specific MS-DRG. Table 4 presents the bivariate correlations in mean inpatient risk-adjusted price 
Figure 3: Density Plots of Adjusted Prices by Payer Type and MS-DRG

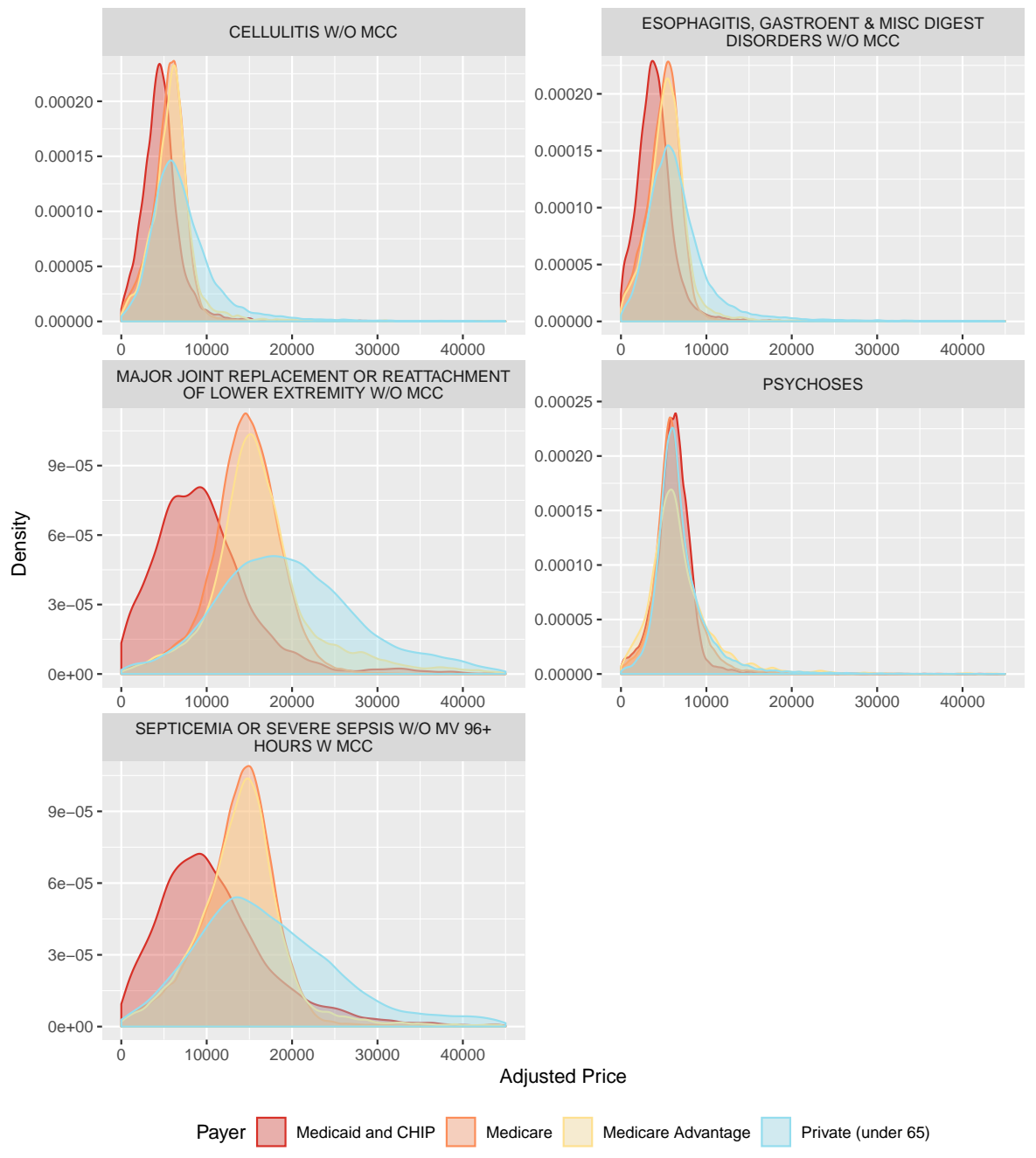

residuals between MA, TM, Medicaid, and private insurers. Note that here we use the price residuals obtained from equation (1) rather than the residuals linearly-transformed by the mean price for each MS-DRG from (2), allowing for the correlations to be unaffected by differences in the average price level of each of the MS-DRGs. We find a low correlation (0.10) between the prices paid by private insurers and traditional Medicare. Medicare Advantage is similarly correlated with private plans (0.55) and traditional Medicare (0.53). Risk-adjusted prices for Medicaid are, perhaps surprisingly, more correlated with private and MA plans than with TM. The correlation between TM and Medicaid prices for the same MS-DRG at the same hospital is only 0.12. Notably, for hip and knee replacements, the correlation between TM and Medicaid prices across hospitals is -0.11 . The correlation matrices for specific MS-DRGs are presented in Appendix Table 23. 
Table 4: Pearson Correlation in Mean Inpatient Risk-Adj. Price Residuals between Types of Coverage

(Observations at MS-DRG-provider-payer level)

\begin{tabular}{lccc}
\hline & $\begin{array}{c}\text { Private } \\
\text { (under 65) }\end{array}$ & Medicare & $\begin{array}{c}\text { Medicare } \\
\text { Advantage }\end{array}$ \\
\hline Medicare & $0.10^{* * *}$ & & \\
Medicare Advantage & $0.55^{* * *}$ & $0.53^{* * *}$ & \\
Medicaid and CHIP & $0.39^{* * *}$ & $0.12^{* * *}$ & $0.33^{* * *}$ \\
\hline
\end{tabular}

Notes: ${ }^{*} \mathrm{p}<0.1 ;{ }^{* *} \mathrm{p}<0.05 ;{ }^{* * *} \mathrm{p}<0.01$. The $\mathrm{p}$-values are reported for a two-tailed test. A unit of analysis is a MS-DRG-provider-payer. Price residuals are obtained by equation (1), which removes variation in prices due to differences in observable patient severity and year-specific hospital effects. Includes the five most common MS-DRGs.

\subsection{Variation Across Private Payers}

As both prior studies and the descriptive analysis in Subsection 4.1 have shown, prices paid to hospitals by private health care plans vary widely. While it is well documented that, across hospitals, private insurers pay drastically different prices, little is known about the differences in prices paid by different private payers within the same hospital. In this section, we help to fill this gap in the literature by describing the variation in health care prices across private payers and decomposing the variation in negotiated prices.

Table 5: Private-Payer Negotiated Prices and Discounts

\begin{tabular}{|c|c|c|c|c|c|c|c|c|}
\hline \multirow[b]{3}{*}{ Payer } & \multicolumn{3}{|c|}{ Price } & \multicolumn{4}{|c|}{ Percent Discount from Charge } & \multirow[b]{3}{*}{$\mathrm{N}$} \\
\hline & \multicolumn{2}{|c|}{ Mean } & \multirow[b]{2}{*}{ Std. Dev. } & \multicolumn{3}{|c|}{ Mean } & \multirow[b]{2}{*}{ Std. Dev } & \\
\hline & Residuals & Adj. Price & & Residuals & Adj. & Discount & & \\
\hline \multicolumn{9}{|c|}{ Vaginal delivery $w / o$ complicating diagnoses } \\
\hline Insurer D & 488.96 & $5,856.40$ & $2,992.38$ & -4.62 & & 51.66 & 18.95 & 12,085 \\
\hline Insurer $\mathrm{C}$ & 413.78 & $5,781.21$ & $2,491.09$ & -4.21 & & 52.06 & 28.84 & 21,748 \\
\hline Insurer B & 190.07 & $5,557.51$ & $3,486.34$ & 0.71 & & 56.99 & 31.51 & 28,933 \\
\hline Insurer $\mathrm{E}$ & 24.16 & $5,391.60$ & $2,071.24$ & -0.17 & & 56.11 & 18.86 & 2,255 \\
\hline Insurer A & -129.52 & $5,237.92$ & $2,447.21$ & 0.42 & & 56.70 & 18.83 & 35,166 \\
\hline \multicolumn{9}{|c|}{ Cesarean section w/o $C C / M C C$} \\
\hline Insurer D & $1,067.14$ & $9,133.76$ & $3,885.97$ & -5.18 & & 54.45 & 15.68 & 5,627 \\
\hline Insurer $\mathrm{C}$ & 470.58 & $8,537.21$ & $3,175.87$ & -3.57 & & 56.06 & 47.78 & 9,678 \\
\hline Insurer B & -54.03 & $8,012.60$ & $3,852.42$ & 1.83 & & 61.46 & 14.98 & 11,514 \\
\hline Insurer $\mathrm{E}$ & -59.88 & $8,006.74$ & $3,297.94$ & -0.19 & & 59.45 & 17.47 & 1,018 \\
\hline Insurer A & -266.66 & $7,799.97$ & $3,349.32$ & 0.61 & & 60.25 & 24.92 & 14,277 \\
\hline \multicolumn{9}{|c|}{ Cesarean section $w C C / M C C$} \\
\hline Insurer D & $1,280.62$ & $12,086.97$ & $10,003.82$ & -2.88 & & 51.82 & 78.98 & 3,122 \\
\hline Insurer $\mathrm{C}$ & 556.38 & $11,362.74$ & $7,923.13$ & -2.23 & & 52.47 & 82.05 & 5,370 \\
\hline Insurer B & -26.45 & $10,779.90$ & $11,024.82$ & 2.59 & & 57.29 & 27.58 & 6,756 \\
\hline Insurer $\mathrm{E}$ & -267.83 & $10,538.52$ & $10,490.19$ & 5.02 & & 59.72 & 116.32 & 657 \\
\hline Insurer A & -426.58 & $10,379.77$ & $35,202.02$ & -3.09 & & 51.61 & 595.58 & 8,415 \\
\hline
\end{tabular}


Table 5: Private-Payer Negotiated Prices and Discounts (continued)

\begin{tabular}{|c|c|c|c|c|c|c|c|c|}
\hline \multirow[b]{3}{*}{ Payer } & \multicolumn{3}{|c|}{ Price } & \multicolumn{4}{|c|}{ Percent Discount from Charge } & \multirow[b]{3}{*}{$\mathrm{N}$} \\
\hline & \multicolumn{2}{|c|}{ Mean } & \multirow[b]{2}{*}{ Std. Dev. } & \multicolumn{3}{|c|}{ Mean } & \multirow[b]{2}{*}{ Std. Dev } & \\
\hline & Residuals & Adj. Price & & Residuals & Adj. & Discount & & \\
\hline \multicolumn{9}{|c|}{ Major joint replacement or reattachment of lower extremity w/o MCC } \\
\hline Insurer D & $3,591.56$ & $27,179.60$ & $10,666.88$ & -4.91 & & 48.07 & 17.69 & 3,404 \\
\hline Insurer $\mathrm{C}$ & $2,291.69$ & $25,879.73$ & $9,225.60$ & -4.42 & & 48.56 & 17.07 & 5,411 \\
\hline Insurer B & -663.92 & $22,924.11$ & $8,878.84$ & 1.79 & & 54.77 & 14.86 & 8,516 \\
\hline Insurer A & -682.58 & $22,905.46$ & $9,052.46$ & 1.23 & & 54.21 & 30.76 & 8,152 \\
\hline Insurer $\mathrm{E}$ & $-4,140.69$ & $19,447.35$ & $11,894.92$ & 7.90 & & 60.88 & 27.30 & 1,887 \\
\hline \multicolumn{9}{|l|}{ Psychoses } \\
\hline Insurer C & $1,021.55$ & $7,027.73$ & $6,061.38$ & -6.61 & & 48.69 & 35.88 & 3,579 \\
\hline Insurer B & 47.23 & $6,053.41$ & $6,687.59$ & 0.81 & & 56.11 & 27.05 & 5,474 \\
\hline Insurer D & -261.50 & $5,744.68$ & $5,257.46$ & 3.24 & & 58.54 & 24.25 & 2,578 \\
\hline Insurer A & $-1,002.98$ & $5,003.20$ & $3,183.45$ & 8.56 & & 63.85 & 19.00 & 7,445 \\
\hline Insurer $\mathrm{E}$ & $-1,195.32$ & $4,810.86$ & $4,940.73$ & 8.75 & & 64.05 & 27.01 & 1,423 \\
\hline
\end{tabular}

Notes: The unit of analysis is an inpatient admission. Prices and percent discounts are adjusted using equations (1) and (2) to control for differences in patient severity and year-specific hospital effects. Insurers A-E mask the names of the five largest U.S. private insurers (Aetna, Anthem, Cigna, Humana, and UnitedHealthcare). The data use agreement enabling our access to the AHUP data does not permit us to uniquely identify insurers by name.

Table 5 presents statistics on the negotiated price and discounts by Aetna, Anthem, Cigna, Humana, and UnitedHealthcare for the five most common MS-DRGs for patients between ages 18 and 65. The names of the insurers are masked randomly as Insurers A-E. These prices are adjusted by equations (1) and (2), which control enrollee mix and year-specific hospital fixed effects. For the five major U.S. insurers, the least expensive insurer negotiates prices that are 6-27 percent lower on average than the mean price and the most expensive insurer negotiates prices that are 5-26 percent higher than the mean price for the 20 most common MS-DRGs. It is clear that certain insurers are able to consistently negotiate lower reimbursement rates across MS-DRGs. In four of the five diagnoses presented in Table 5, Cigna has the highest negotiated prices. For the most common MS-DRG, vaginal delivery without complicating diagnoses, the discounts range from 51.66 to 56.99 percent off the chargemaster price on average. For a diagnosis of psychoses, the percent discount ranges from 48.69 percent to 64.05 percent. The adjusted prices and adjusted discounts track each other closely. The discount measure is more robust to unobserved differences across insurers that are not captured by the risk- and hospital-adjustments. However, the high correlation between discount and price suggests that the adjusted prices are not meaningfully biased by unobserved differences across insurers.

For the corresponding tables for the five most common MS-DRGs with all 60 insurers in the data, consult Appendix E.1. As is evident in these extended tables, the variation in prices negotiated by the five largest national insurers does not capture the extent of the variation in prices across all insurers. For instance, for a hip or knee replacement without major complicating conditions, 
Figure 4: Histograms of Mean Adjusted Residuals for Private Payers (Observations at payer-provider level)

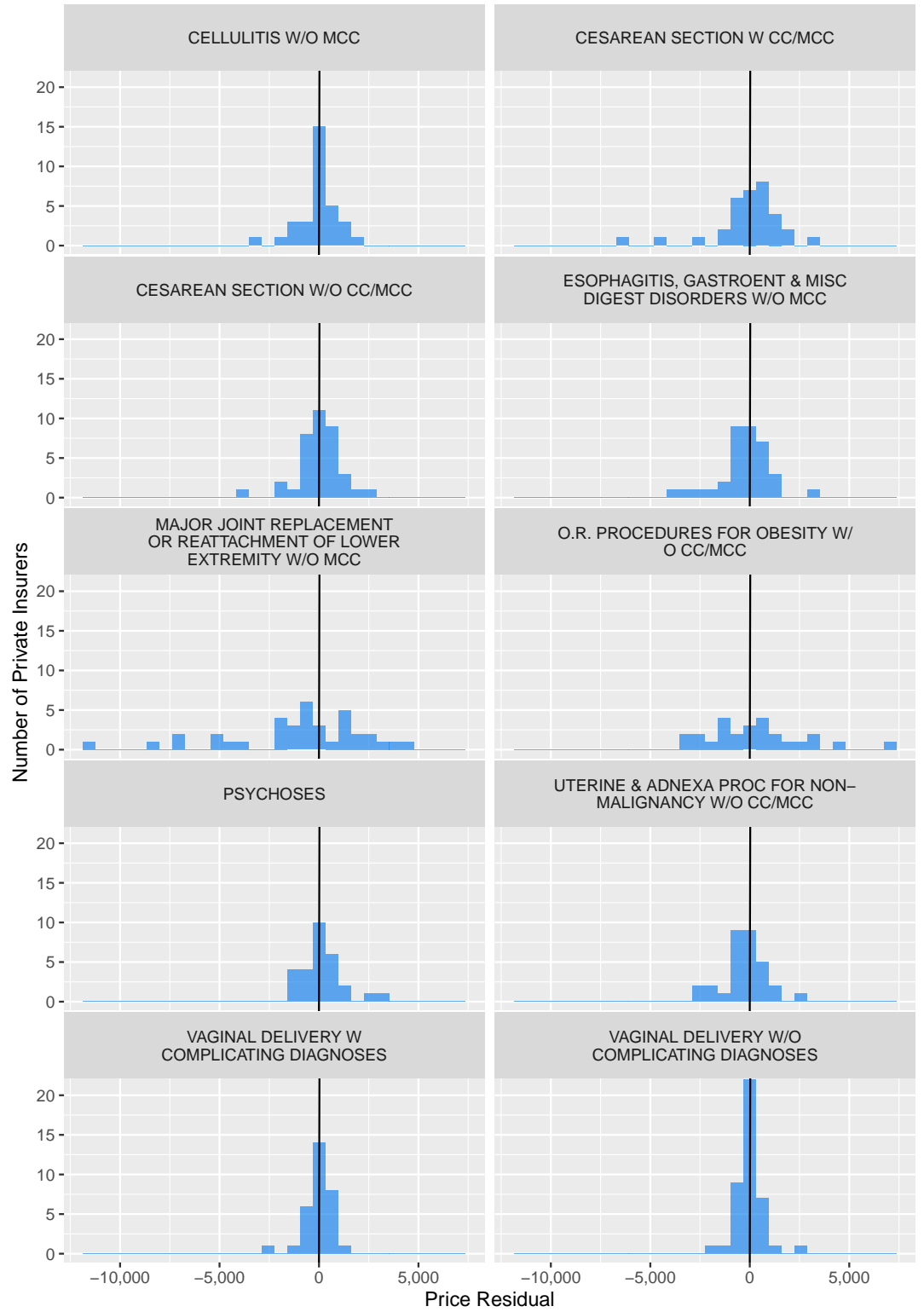

Notes: Unit of analysis is a payer-provider. Price residuals are obtained by equation (1), which removes variation in prices due to differences in observable patient severity and year-specific hospital effects.

WellCare negotiates a price of $\$ 11,766$ (73 percent discount) on average while Harvard Pilgrim Health Care negotiates an average price of $\$ 27,786$ (39 percent discount). Figure 4 presents a histogram of the mean risk- and hospital-adjusted price residuals for all insurers in the data for the 10 most common MS-DRGs. Here, it is clear that, when comparing all 60 insurers, there is relatively large variation in average negotiated price across insurers. For the 20 most common 
Table 6: Pearson Correlation in Mean Inpatient Risk-Adj. Price Residuals between Private (under 65) Payers

(Observations at MS-DRG-provider-payer level)

\begin{tabular}{lcccc}
\hline & Insurer A & Insurer B & Insurer C & Insurer D \\
\hline Insurer B & $0.54^{* * *}$ & & & \\
Insurer C & $0.49^{* * *}$ & $0.43^{* * *}$ & & \\
Insurer D & $0.40^{* * *}$ & $0.33^{* * *}$ & $0.60^{* * *}$ & \\
Insurer E & 0.01 & $0.48^{* * *}$ & $0.45^{* * *}$ & 0.10 \\
\hline
\end{tabular}

Notes: ${ }^{*} \mathrm{p}<0.1 ;{ }^{* *} \mathrm{p}<0.05 ;{ }^{* * *} \mathrm{p}<0.01$. The $\mathrm{p}$-values are reported for a two-tailed test. A unit of analysis is a MS-DRG-providerpayer. Price residuals are obtained by equation (1), which removes variation in prices due to differences in observable patient severity and year-specific hospital effects. Insurers A-E mask the names of the five largest U.S. private insurers (Aetna, Anthem, Cigna, Humana, and UnitedHealthcare). Includes the 20 most common MS-DRGs.

MS-DRGs, the between-payer coefficient of variation ranges from 5 percent to 17 percent, after controlling for enrollee and provider mix, for the five largest insurers. For all 60 insurers studied, the between-payer coefficient of variation ranges from 8 percent to 24 percent. For comparison, the between-provider coefficient of variation ranges from 24 percent to 48 percent.

Overall, Table 5 suggests that the prices negotiated by national insurers tend to be relatively similar on average, after controlling for hospital and enrollee mix (although this is not the case for regional insurers). However, this does not necessarily imply that these large insurers are getting similar discounts at each hospital, only that the discounts on average are relatively similar. To examine the within-hospital variation in payments across insurers, we compare insurers' mean risk-adjusted prices at the hospital level.

Table 6 presents the bivariate correlations between the mean risk-adjusted prices negotiated by the five largest national insurers - Aetna, Anthem, Cigna, Humana, and UnitedHealthcare - for a specific MS-DRG at a given provider. Included are the 20 most common MS-DRGs for privatelyinsured patients between ages 18 and 65 . Note again that here we use the price residuals obtained from equation (1) rather than the residuals linearly-transformed by the mean price for each MSDRG from (2), allowing for the correlations to not be affected by differences in the mean price level of each of the MS-DRGs. The correlations in risk-adjusted price residuals for the bivariate comparisons between the five largest insurers range from 0.01 to 0.60 . These results are also presented for specific MS-DRGs in Appendix Table 24. The correlation in risk-adjusted prices varies significantly across insurers and across MS-DRGs. For vaginal deliveries without complicating diagnoses, the bivariate correlations between each of the five largest private U.S. insurers range from -0.57 to 0.70 . For hip and knee replacements, these correlations range from 0.04 to 0.82 . This evidence suggests that, while large insurers tend to negotiate similar prices on average, the prices different large insurers negotiate at any given hospital tend to vary considerably. 


\subsubsection{Decomposition of Variation in Private Prices}

Recently, researchers have found that within-hospital variation in private negotiated prices is high, and speculated that the differences in prices must be driven in no small part by significant differences in insurer-hospital contracts across insurers. However, the extent to which differences in insurer-hospital negotiations explains the variation in within-hospital prices has not previously been measured due to lack of data.

To further investigate the extent to which the variation in prices is explained by variation across private payers at a hospital, we extend the method Cooper et al. (2019) employ to decompose the variation within-markets and within-hospitals. We decompose the variation further to the withinhospital-payer level. To examine the variation explained at different levels, we iteratively add various combinations of control variables, and observe the subsequent changes to the $R^{2}$. The outcome variable is $p_{i, j, h, t}$, the price of a procedure for patient encounter $i$, covered by payer $j$, at hospital $h$, in year $t$. Table 7 presents the $R^{2}$ from five regressions, each with an additional control included. In column 1, only patient age, an indicator for male, and year-month fixed effects are included. In column 2, we add encounter-specific controls including dummies for each comorbid condition defining the Charlson comorbidity index, length of stay, and a dummy if the MS-DRG indicates a diagnosis with complications or comorbidities (for inpatient procedures only). Column 3 adds year-month-specific provider fixed effects and column 4 adds year-month-specific payerprovider fixed effects. Lastly, in column 5, we include the total charges that the hospital billed for the encounter to further control for the patient-specific amount of care provided at the encounter.

One potential criticism of the analysis thus far is that it examines differences in prices across MS-DRG codes, rather than specific procedures. There may be multiple different services provided within an MS-DRG. For instance, the MS-DRG code 471 includes both hip and knee joint replacements. Thus, here we look at specific high-volume procedures as defined by ICD-9 procedure and diagnosis codes. This restricts the sample to only encounters occurring prior to October 1, 2015 to avoid differences in coding resulting from the switch to ICD-10 codes. Using ICD-9 codes also allows for an analysis of both inpatient and outpatient prices, whereas MS-DRGs only classify inpatient visits.

As shown in column 1 of Table 7, we find that patient characteristics explain very little of the differences in prices for each procedure. Adding the encounter-specific controls for length of stay, comorbidities, and complications has varying effects on $R^{2}$ across procedures. For colonoscopies, adding these controls results in an $R^{2}$ of 0.519 , while for knee replacements, the $R^{2}$ only rises to 0.074. For outpatient procedures, as one would expect, these controls explain very little variation. The addition of month-specific provider fixed effects raises the $R^{2}$ to between 0.492 (cesarean section) and 0.770 (colonoscopy) for inpatient procedures and to between 0.304 (routine medical examination) and 0.444 (screening mammogram) for outpatient procedures. 
Table 7: Decomposition of Private-Payer Health Care Prices

\begin{tabular}{|c|c|c|c|c|c|c|c|c|}
\hline & \multicolumn{5}{|c|}{$R^{2}$} & \multirow{2}{*}{$\begin{array}{c}\text { Percent of variance } \\
\text { unexplained within } \\
\text { payer-provider- } \\
\text { month }\end{array}$} & \multirow{2}{*}{$\begin{array}{c}\text { Num. Obs. } \\
(7)\end{array}$} & \multirow{2}{*}{$\begin{array}{c}\begin{array}{c}\text { Within payer } \\
\text { provider- } \\
\text { month } \\
\text { CV }\end{array} \\
(8)\end{array}$} \\
\hline & $(1)$ & $(2)$ & $(3)$ & $(4)$ & $(5)$ & & & \\
\hline \multicolumn{9}{|l|}{ Inpatient Procedures } \\
\hline Colonoscopy & 0.039 & 0.519 & 0.770 & 0.855 & 0.876 & 0.124 & 26,944 & 0.264 \\
\hline Manually Assisted Delivery NEC & 0.074 & 0.139 & 0.495 & 0.707 & 0.714 & 0.286 & 87,166 & 0.206 \\
\hline Low Cervical C-Section & 0.069 & 0.169 & 0.492 & 0.727 & 0.730 & 0.270 & 86,836 & 0.203 \\
\hline Total Knee Replacement & 0.065 & 0.074 & 0.602 & 0.828 & 0.869 & 0.131 & 23,535 & 0.151 \\
\hline Total Hip Replacement & 0.071 & 0.078 & 0.686 & 0.916 & 0.922 & 0.078 & 12,785 & 0.119 \\
\hline Packed Cell Transfusion & 0.012 & 0.400 & 0.670 & 0.843 & 0.869 & 0.131 & 14,337 & 0.536 \\
\hline PTCA or Coronary Atherectomy & 0.054 & 0.153 & 0.528 & 0.814 & 0.840 & 0.160 & 20,549 & 0.257 \\
\hline \multicolumn{9}{|l|}{ Outpatient Diagnoses/Procedures } \\
\hline Routine Medical Examination & 0.004 & 0.005 & 0.304 & 0.490 & 0.698 & 0.302 & 176,552 & 0.507 \\
\hline Screening Mammogram NEC & 0.017 & 0.018 & 0.444 & 0.647 & 0.726 & 0.274 & 756,366 & 0.220 \\
\hline Routine Gynecological Examination & 0.039 & 0.044 & 0.309 & 0.477 & 0.709 & 0.291 & 137,502 & 0.474 \\
\hline Screening Malignant Neoplasm-Cervix & 0.082 & 0.083 & 0.349 & 0.469 & 0.722 & 0.278 & 126,601 & 0.412 \\
\hline Patient characteristics & Yes & Yes & Yes & Yes & Yes & & & \\
\hline Encounter controls & No & Yes & Yes & Yes & Yes & & & \\
\hline Provider-month fixed effects & No & No & Yes & - & - & & & \\
\hline Payer-provider-month fixed effects & No & No & No & Yes & Yes & & & \\
\hline Control for charges & No & No & No & No & Yes & & & \\
\hline
\end{tabular}

Notes: Columns 1-5 report the $R^{2}$ of OLS regressions in which the outcome variable is an insurer's negotiated price and the independent variables are specified in the lower rows. A unit of observation is a patient encounter. All regressions include month-year dummies. Patient characteristics include age and gender. Encounter controls include dummies for each Charlson comorbid condition, length of stay, and a dummy if the MS-DRG indicates CC or MCC (for inpatient procedures only) to further adjust for any complications or comorbidities. Column $6=1$ - column 5 . Column 8 presents the within-payer-provider-month coefficient of variation, averaged across payer-provider-months. 
At the within-hospital level, Cooper et al. (2019) find overall lower variation than we find here. For instance, for a knee replacement, they find 27 percent of variation is unexplained. In contrast, we find that, at the within-hospital level, 40 percent of price variation is still unexplained. There are two potential differences in our analyses that could explain this discrepancy. First, Cooper et al. also include a control for plan type (HMO, PPO, etc.), which is not observable in the AHUD data. However, this explanation is unlikely as Cooper et al. find that plan type only accounts for around 3 percent of variation in prices. Second, Cooper et al. use the HCCI data, which includes claims from three large, national insurers: UnitedHealthcare, Aetna, and Humana. In contrast, we study 60 insurers, many of which are regional or statewide insurance firms. Thus, the most plausible explanation for the discrepancy between our findings and those of Cooper et al. is the differences in insurers. Indeed, we found above that smaller payers exhibit significantly more variation in negotiated prices. When we restrict our analysis to only include UnitedHealthcare, Aetna, and Humana, our results for the within-hospital level are similar to Cooper et al. When we observe encounters covered by all 60 insurers, the percent of within-hospital variation unexplained increases from roughly 17-36 percent (for only the HCCI insurers) to 23-51 percent for the seven inpatient procedures studied. Thus, Cooper et al.'s estimates report within-hospital variation for three large insurers. The variation for a broader set of insurers at the hospital level is substantially higher than they estimate.

The addition of the month-specific provider-payer fixed effects in column 4 is the novel component of this analysis. Prior studies could not decompose to this level as the data did not allow for identification of individual payers. Decomposing to the provider-payer-month level leaves very little unexplained variation for most inpatient procedures. For hip replacements, only 8 percent of the variation in prices at this level is left unexplained. However, for cesarean sections and manually-assisted deliveries, 27 percent and 29 percent of variation remain unexplained within a payer-provider-month, respectively, after controlling for patient characteristics and patient severity. For outpatient procedures, even more variation is left unexplained at the payer-provider-month level.

Overall, this finding confirms anecdotal reports that the majority of within-hospital variation in prices can be attributed to differences in prices across insurers. For some procedures, there still remains a relatively large amount of variation unexplained within a payer-provider-month. This variation could potentially be explained by measurement error, contract negotiations that are updated in the middle of a month, or by fee-for-service or outlier payments that are not based on observable patient severity.

In column 5, we add total charges as a control variable, which leaves 8 to 29 percent of variation unexplained for inpatient procedures and 27 to 30 percent of variation unexplained for outpatient procedures. The minimal effect of the addition of total charges underscores the lack of correlation between billed charges and the transaction price that insurers pay for inpatient care. For outpatient care, however, including the charges as an independent variable has a sizable influence on the $R^{2}$. 
This suggests that outpatient visits are more likely to be reimbursed as a share of charges for any services rendered during the visit.

\section{Monopsony Power and Hospital-Insurer Bargaining}

The sizable cross-payer variation in prices at the same hospital for the same procedure may be attributable to differences in leverage in hospital-insurer negotiations. In this section, we examine the relationship between insurer market power and the contracts that insurers negotiate with providers. There are two plausible effects of market power on hospital-insurer negotiations: increased insurer market share may lead to (1) lower negotiated prices and (2) different payment systems that are favorable to insurers. To examine the relationship between insurer market share and negotiated prices, we employ the following specification:

$$
\ln \left(p_{i, d, j, h, t}\right)=\text { ashare }_{j, h, t}+\mathbf{X}_{i} \beta+\delta_{d}+\gamma_{h}+\tau_{t}+\epsilon_{i, d, j, h, t}
$$

where $p_{i, d, j, h, t}$ is the negotiated inpatient price for patient encounter $i$, with MS-DRG $d$, insured by payer $j$, at hospital $h$, in year $t$. The market share of insurer $j$ at hospital $h$ in year $t$ is measured by share $_{j, h, t}$, and $\alpha$ is the coefficient of interest. $\mathbf{X}_{i}$ is a vector of patient-encounter characteristics including age, an indicator for male, length of stay, and indicators for the 17 comorbidities defining the Charlson comorbidity index. $\delta_{d}, \gamma_{h}$, and $\tau_{t}$ are MS-DRG, hospital, and year fixed effects, respectively. The sample for this analysis includes all privately-insured patient encounters for the 20 most common MS-DRGs for patients between 18 and 65 years old. The results from this main regression are presented in column 4 of Table 8 Panel A. In addition, as a sensitivity analysis, we also run a version of the regression where the outcome is the risk-adjusted price, as estimated in Section 4. In this specification, $\mathbf{X}_{i}$ is omitted from the equation, given it is controlled for in the risk-adjustment. The results for this specification are presented in column 4 of Table 8 Panel B. One potential criticism of this approach is that it does not capture the actual procedures being provided, only the diagnosis as defined by the MS-DRG. Thus, we also run the aforementioned specifications with the inclusion of ICD-9/10 code fixed effects rather than MS-DRG fixed effects. ${ }^{9}$ The results for these regressions are presented in Appendix Table 25.

Given the lack of transparency surrounding negotiated prices, it is difficult to know what type of reimbursements payers are negotiating with providers. The second effect of increased market share may be that insurers are able to adopt prospective payment systems, similar to that of Medicare, rather than paying a percentage of the hospital's charges. Under a prospective payment contract structure, insurers reimburse based on the expected costs for clinically defined episodes of care, typically some form of a DRG classification system for inpatient claims. When an insurer pays a share of hospital charges, all of the risks of the varying level of intensity of care fall on the insurer.

\footnotetext{
${ }^{9}$ There are 3,191 ICD 9/10 codes corresponding to the 20 MS-DRGs used in the analysis.
} 
In contrast, under prospective payment, insurers share the risk with providers by agreeing to pay a predetermined payment for a given diagnosis, regardless of the intensity of care. Thus, while risk-averse insurers may prefer prospective payments, hospitals may prefer fee-for-service and only agree to prospective payments when the insurers have significant leverage.

The extent to which private insurers use prospective payment systems has long remained a mystery, given the lack of available data. Recently, with the availability of new data sources, such as the HCCI data, researchers have begun studying the structure of private insurer payments. Burns and Pauly (2018) find a low prevalence of prospective payment models, and Baker et al. (2019) find that commercial insurance payments are less prospective than Medicare payments. Clemens and Gottlieb (2017) and Clemens, Gottlieb, and Molnár (2017) find that BCBS of Texas uses Medicare fee-for-services prices for physician services for simplicity but abandons it when sufficient value is at stake.

To examine the association between insurer market share and type of inpatient payment contract, we estimate the following regression:

$$
\ln \left(s_{d, j, h, t}^{p}\right)=\alpha \operatorname{share~}_{j, h, t}+\delta_{d}+\gamma_{h}+\tau_{t}+\epsilon_{d, j, h, t}
$$

where $s_{d, j, h, t}^{p}$ is the standard deviation of prices for MS-DRG $d$ paid by private insurer $j$ at hospital $h$ in year $t$. All other variables and parameters retain their meanings from equation (3). The results of this main specification - as well as one where the outcome variable measures $s^{p}$ rather than its natural logarithm - are presented in Table 8 Panel C.

In Table 8, we find a strong inverse relationship between insurer market share and negotiated inpatient prices. When the outcome variable is log negotiated price, a 10 percent increase in market share is associated with a $6\left(=10 \cdot 100\left[e^{0.006}-1\right]\right)$ percent decrease in negotiated prices. When the outcome variable is log risk-adjusted negotiated price, a 10 percent increase in market share is associated with a 7 percent decrease in price. Both of these point estimates are statistically significant at the 1 percent level. Additionally, Panel C shows that a 10 percent increase in insurer market share is associated with a 10 percent decrease in the standard deviation of prices paid by the insurer. This finding is also significant at the 1 percent level. This suggests that, when an insurer has more bargaining power, they are able to offload some of their financial risk to hospitals for inpatient care.

The findings presented here on the relationship between insurer market share and prices are consistent with prior studies examining single-state all-payer databases. There is a relatively large body of research that finds larger insurers are able to negotiate greater discounts from hospitals. ${ }^{10}$ However, the only other paper to study the association between insurer market share and the type of payment contract is Cooper et al. (2019), which uses the collective share of Aetna, UnitedHealthcare, and Humana as a measure of insurer market share, rather than the market shares of

\footnotetext{
${ }^{10}$ For a review of this literature, see Gaynor and Town (2011).
} 
Table 8: Relationship between Insurer's Market Share and Insurer-Hospital Bargaining

\begin{tabular}{|c|c|c|c|c|}
\hline \multirow[b]{3}{*}{ Panel A } & \multicolumn{4}{|c|}{ Dependent variable: } \\
\hline & \multicolumn{2}{|c|}{ Price } & \multicolumn{2}{|c|}{$\log ($ Price) } \\
\hline & $(1)$ & $(2)$ & $(3)$ & $(4)$ \\
\hline Insurer's Market Share & $\begin{array}{c}-66.351^{* * *} \\
(19.229)\end{array}$ & $\begin{array}{c}-78.837^{* * *} \\
(19.873)\end{array}$ & $\begin{array}{c}-0.004^{* *} \\
(0.002)\end{array}$ & $\begin{array}{c}-0.006^{* * *} \\
(0.002)\end{array}$ \\
\hline Age & $\begin{array}{l}-3.606 \\
(7.532)\end{array}$ & $\begin{array}{c}1.163 \\
(3.860)\end{array}$ & $\begin{array}{c}0.003^{* * *} \\
(0.001)\end{array}$ & $\begin{array}{l}0.003^{* * *} \\
(0.0004)\end{array}$ \\
\hline Male & $\begin{array}{c}216.455^{* * *} \\
(69.228)\end{array}$ & $\begin{array}{c}185.848^{* * *} \\
(62.471)\end{array}$ & $\begin{array}{c}0.005 \\
(0.004)\end{array}$ & $\begin{array}{c}0.002 \\
(0.004)\end{array}$ \\
\hline Length of Stay & $\begin{array}{c}1,253.091^{* * *} \\
(158.958)\end{array}$ & $\begin{array}{c}1,244.524^{* * *} \\
(159.959)\end{array}$ & $\begin{array}{c}0.065^{* * *} \\
(0.007)\end{array}$ & $\begin{array}{c}0.063^{* * *} \\
(0.007)\end{array}$ \\
\hline Charlson comorbidity dummies & Yes & Yes & Yes & Yes \\
\hline MS-DRG fixed effects & Yes & Yes & Yes & Yes \\
\hline Year fixed effects & Yes & Yes & Yes & Yes \\
\hline Provider fixed effects & No & Yes & No & Yes \\
\hline Observations & 526,663 & 526,663 & 526,663 & 526,663 \\
\hline & 0.461 & 0.505 & 0.505 & 0.592 \\
\hline \multirow[t]{2}{*}{ Adjusted $\mathrm{R}^{2}$} & 0.461 & 0.505 & 0.505 & 0.592 \\
\hline & \multicolumn{4}{|c|}{ Dependent variable: } \\
\hline Panel B & \multicolumn{2}{|c|}{ Risk-Adj. Price } & \multicolumn{2}{|c|}{$\log ($ Risk-Adj. Price $)$} \\
\hline Insurer's Market Share & $\begin{array}{c}-67.531^{* * *} \\
(18.873)\end{array}$ & $\begin{array}{c}-79.830^{* * *} \\
(19.458)\end{array}$ & $\begin{array}{c}-0.005^{* * *} \\
(0.002)\end{array}$ & $\begin{array}{c}-0.007^{* * *} \\
(0.002)\end{array}$ \\
\hline MS-DRG fixed effects & Yes & Yes & Yes & Yes \\
\hline Year fixed effects & Yes & Yes & Yes & Yes \\
\hline Provider fixed effects & No & Yes & No & Yes \\
\hline Observations & 526,663 & 526,663 & 518,038 & 518,038 \\
\hline & 0.408 & 0.457 & 0.467 & 0.564 \\
\hline \multirow[t]{2}{*}{ Adjusted $\mathrm{R}^{2}$} & 0.408 & 0.457 & 0.467 & 0.563 \\
\hline & \multicolumn{4}{|c|}{ Dependent variable: } \\
\hline Panel C & \multicolumn{2}{|c|}{ Std. Dev. of Price } & \multicolumn{2}{|c|}{$\log ($ Std. Dev. of Price $)$} \\
\hline Insurer's Market Share & $\begin{array}{c}-63.904^{* *} \\
(28.438)\end{array}$ & $\begin{array}{c}-67.098^{* * *} \\
(17.495)\end{array}$ & $\begin{array}{c}-0.011^{* * *} \\
(0.004)\end{array}$ & $\begin{array}{c}-0.010^{* * *} \\
(0.003)\end{array}$ \\
\hline Year fixed effects & Yes & Yes & Yes & Yes \\
\hline MS-DRG fixed effects & Yes & Yes & Yes & Yes \\
\hline Provider fixed effects & No & Yes & No & Yes \\
\hline Observations & 4,460 & 4,460 & 4,460 & 4,460 \\
\hline $\mathrm{R}^{2}$ & 0.166 & 0.261 & 0.354 & 0.615 \\
\hline Adjusted $\mathrm{R}^{2}$ & 0.162 & 0.223 & 0.351 & 0.595 \\
\hline
\end{tabular}

Notes: ${ }^{*} \mathrm{p}<0.1 ;{ }^{* *} \mathrm{p}<0.05 ;{ }^{* * *} \mathrm{p}<0.01$

OLS regression results for equations (3) and (4). For Panels A and B, a unit of observation is an inpatient admission. For Panel C, a unit of observation is a MS-DRG-payer-provider-year. 
individual insurers. Our findings are consistent with Cooper et al. and show that the association does not exist only for the three large insurers and for employer-sponsored insurance, but also across private plans from many insurers.

On the other side of the market, there is more evidence that provider market share is associated with higher prices and more contracts in which prices are paid as a share of charges. Town, Feldman, and Kralewski (2011) examine physician groups that were in the network for one of Minnesota Blue Cross's plans and find that the share of revenue from capitation is positively associated with physicians' self-reported assessments of their market power. Using the HCCI data, Baker et al. (2019) find that differences in prospective payment across hospitals are positively associated with the extent of hospital competition.

An important limitation of this analysis is that it does not control for differences in the makeup and competitiveness of the other side of the hospital-insurer market. Unfortunately, since the AHUD data cannot be linked to external data on hospitals, there is no way to include more information on providers (e.g., hospital market share or metrics of hospital quality). However, the inclusion of provider fixed effects, as in equations (3) and (4), should control for any differences across hospitals, including hospital market share.

The link between insurer market share and negotiated prices presented here is a correlation; nevertheless the results suggest that insurers may be able to leverage higher market consolidation to improve their position in hospital-insurer bargaining.

\section{Conclusion}

In this paper, we document the variation in payments across public and private payers. For all MS-DRGs studied, on average, private (under 65) payers pay significantly more than Medicare Advantage payers and traditional Medicare, which both pay substantially more than Medicaid. Large, national MA insurers reimburse at a rate similar to TM, while smaller, regional MA insurers tend to pay more than TM. Both private and Medicaid prices vary much more than MA and TM prices for a given diagnosis. The distribution of Medicare Advantage payments mirrors that of traditional Medicare, though Medicare Advantage plans tend to pay more on average. Most notably, this paper provides, for the first time, a look at variation in negotiated prices across private payers at the national level. Average negotiated prices paid by the largest national insurers do not vary much, but average negotiated prices paid by smaller, regional insurers vary substantially. Further, while average prices for large insurers are similar, within a given hospital, the prices paid by these large insurers vary considerably. For vaginal deliveries, the bivariate correlations between each of the five largest private U.S. insurance companies range from -0.57 to 0.70 . For hip and knee replacements, these correlations range from 0.04 to 0.82 . Lastly, we find an inverse relationship between insurer market share and negotiated prices. A 10 percent increase in insurer market share is associated with a 7 percent decrease in negotiated prices. Additionally, a 10 percent increase in 
insurer market share is associated with a 10 percent decrease in the standard deviation of negotiated prices at a provider. This suggests that insurers with greater market share are able to negotiate favorable payment structures that offload financial risk to the providers. 


\section{A Detailed Descriptive Statistics for AHUD Data}

Table 9: Charlson Comorbidity Index by Payer and Patient Type

\begin{tabular}{llrr}
\hline \multirow{2}{*}{ Patient Type } & \multicolumn{2}{c}{ Charlson Index } \\
\cline { 3 - 4 } & Payer & Mean & Std. Dev. \\
\hline \multirow{3}{*}{ Inpatient } & Medicaid & 0.730 & 1.593 \\
& Medicare & 2.208 & 2.175 \\
& Medicare Advantage & 2.096 & 2.174 \\
& Private & 0.704 & 1.558 \\
\hline \multirow{3}{*}{ Outpatient } & Medicaid & 0.195 & 0.728 \\
& Medicare & 0.438 & 1.080 \\
& Medicare Advantage & 0.405 & 1.061 \\
& Private & 0.179 & 0.738 \\
\hline
\end{tabular}




\section{A.1 Summary Statistics by State}

Table 10: Summary Statistics by State - All Patients

\begin{tabular}{|c|c|c|c|c|c|c|c|c|}
\hline \multirow[b]{2}{*}{ State } & \multicolumn{3}{|c|}{ Number } & \multicolumn{5}{|c|}{ Mean } \\
\hline & Visits & Patients & Providers & Age & Length of Stay & Payment & Urban & $\mathrm{CCR}^{*}$ \\
\hline $\mathrm{TX}$ & $27,509,533$ & $7,980,364$ & 56 & 43.65 & 2.06 & $1,645.13$ & 0.90 & 0.26 \\
\hline VA & $25,632,352$ & $6,552,306$ & 30 & 49.70 & 3.02 & $1,280.25$ & 0.93 & 0.25 \\
\hline $\mathrm{NC}$ & $24,596,382$ & $5,634,027$ & 34 & 47.94 & 2.67 & $2,078.34$ & 0.89 & 0.27 \\
\hline $\mathrm{CA}$ & $20,726,620$ & $6,551,277$ & 44 & 43.76 & 3.26 & $2,395.55$ & 0.96 & 0.20 \\
\hline GA & $19,885,480$ & $5,634,430$ & 21 & 48.47 & 4.06 & $1,823.33$ & 0.84 & 0.23 \\
\hline FL & $16,091,559$ & $5,610,300$ & 32 & 47.18 & 2.65 & $2,376.17$ & 0.98 & 0.21 \\
\hline $\mathrm{SC}$ & $14,812,639$ & $3,608,239$ & 20 & 46.25 & 2.87 & $1,795.21$ & 0.86 & 0.25 \\
\hline WA & $14,639,697$ & $3,297,106$ & 12 & 48.53 & 2.04 & $1,279.48$ & 1.00 & 0.32 \\
\hline $\mathrm{PA}$ & $12,944,454$ & $3,042,214$ & 16 & 53.96 & 2.58 & $1,464.17$ & 1.00 & 0.22 \\
\hline NJ & $12,915,384$ & $2,916,555$ & 13 & 48.13 & 4.01 & $2,194.67$ & 0.99 & 0.18 \\
\hline LA & $12,578,527$ & $3,274,394$ & 14 & 48.58 & 2.19 & $1,198.30$ & 1.00 & 0.27 \\
\hline $\mathrm{OH}$ & $10,200,204$ & $2,365,651$ & 18 & 50.69 & 3.42 & $1,633.59$ & 1.00 & 0.26 \\
\hline IN & $8,773,689$ & $1,493,333$ & 17 & 51.02 & 2.13 & $2,051.81$ & 0.91 & 0.27 \\
\hline MI & $8,260,455$ & $2,279,119$ & 8 & 47.51 & 1.30 & 528.68 & 0.22 & 0.38 \\
\hline $\mathrm{TN}$ & $7,502,752$ & $1,683,218$ & 7 & 46.70 & 2.40 & $2,304.89$ & 0.82 & 0.26 \\
\hline NY & $6,133,303$ & $1,305,587$ & 7 & 49.76 & 1.96 & $1,014.37$ & 1.00 & 0.27 \\
\hline $\mathrm{CT}$ & $5,870,907$ & $1,419,052$ & 6 & 47.79 & 1.49 & $1,437.24$ & 1.00 & 0.24 \\
\hline $\mathrm{MO}$ & $5,518,023$ & $1,081,677$ & 5 & 52.92 & 1.97 & $3,406.57$ & 0.87 & 0.28 \\
\hline KY & $5,423,821$ & $1,849,116$ & 9 & 46.75 & 1.96 & $\mathrm{NA}$ & 0.94 & 0.24 \\
\hline OK & $5,160,937$ & $1,915,902$ & 18 & 48.93 & 2.71 & $2,070.81$ & 0.85 & 0.25 \\
\hline $\mathrm{AL}$ & $5,094,017$ & $1,270,015$ & 7 & 49.29 & 2.41 & $1,252.85$ & 0.99 & 0.23 \\
\hline MA & $4,790,115$ & 937,566 & 7 & 52.23 & 2.02 & $1,043.45$ & 1.00 & 0.40 \\
\hline $\mathrm{AZ}$ & $4,482,249$ & $1,014,600$ & 5 & 39.25 & 2.04 & $4,731.86$ & 1.00 & 0.25 \\
\hline $\mathrm{NH}$ & $4,424,105$ & 543,252 & 3 & 53.39 & 3.07 & $\mathrm{NA}$ & 0.21 & 0.34 \\
\hline $\mathrm{NE}$ & $3,776,924$ & $2,166,965$ & 7 & 49.55 & 2.32 & $1,875.79$ & 1.00 & 0.26 \\
\hline IL & $3,698,031$ & $1,173,964$ & 9 & 45.95 & 2.78 & $1,303.32$ & 1.00 & 0.27 \\
\hline OR & $2,948,598$ & $1,107,718$ & 8 & 48.84 & 2.33 & $1,744.43$ & 0.91 & 0.34 \\
\hline KS & $1,480,557$ & 511,152 & 5 & 44.92 & 2.76 & $2,375.73$ & 0.51 & 0.25 \\
\hline WV & $1,285,329$ & 152,208 & 1 & 52.65 & 1.91 & 961.02 & 1.00 & 0.42 \\
\hline MT & $1,106,127$ & 296,910 & 3 & 52.10 & 3.30 & $16,885.74$ & 1.00 & 0.34 \\
\hline $\mathrm{AR}$ & $1,100,146$ & 322,217 & 2 & 48.30 & 1.96 & $1,651.93$ & 1.00 & 0.21 \\
\hline IA & 909,221 & 591,846 & 2 & 51.25 & 2.38 & 934.67 & 1.00 & 0.28 \\
\hline $\mathrm{MN}$ & 908,300 & 328,904 & 3 & 49.85 & 2.77 & $1,428.53$ & 0.84 & 0.32 \\
\hline NM & 712,184 & 171,657 & 2 & 54.31 & 5.11 & $1,149.78$ & 1.00 & 0.28 \\
\hline MS & 695,196 & 195,180 & 1 & 36.51 & 2.01 & NA & 1.00 & 0.27 \\
\hline ME & 491,243 & 117,252 & 1 & 56.35 & 2.48 & 834.84 & 1.00 & 0.53 \\
\hline NV & 274,089 & 126,014 & 1 & 49.90 & 2.87 & $2,537.92$ & 1.00 & 0.21 \\
\hline WY & 207,257 & 47,836 & 1 & 49.16 & 1.87 & NA & 0.00 & 0.43 \\
\hline
\end{tabular}

CCR stands for cost-to-charge ratio for a hospital. 
Table 11: Summary Statistics by State - Traditional Medicare Patients

\begin{tabular}{|c|c|c|c|c|c|c|c|c|}
\hline \multirow[b]{2}{*}{ State } & \multicolumn{3}{|c|}{ Number } & \multicolumn{5}{|c|}{ Mean } \\
\hline & Visits & Patients & Providers & Age & Length of Stay & Payment & Urban & $\mathrm{CCR}^{*}$ \\
\hline $\mathrm{CA}$ & $4,306,843$ & 848,852 & 39 & 71.85 & 2.77 & $2,308.38$ & 0.95 & 0.19 \\
\hline VA & $3,337,721$ & 800,606 & 26 & 72.12 & 2.42 & 825.55 & 1.00 & 0.25 \\
\hline $\mathrm{NC}$ & $3,153,617$ & 552,685 & 12 & 68.55 & 2.25 & $1,872.77$ & 0.98 & 0.27 \\
\hline GA & $3,098,593$ & 581,515 & 14 & 70.44 & 4.34 & $1,411.82$ & 0.95 & 0.23 \\
\hline $\mathrm{TX}$ & $2,622,324$ & 580,260 & 50 & 66.46 & 2.77 & $2,069.22$ & 0.80 & 0.25 \\
\hline NJ & $2,572,981$ & 433,559 & 11 & 72.12 & 3.59 & $2,069.30$ & 0.99 & 0.17 \\
\hline FL & $1,998,556$ & 546,865 & 19 & 72.09 & 3.44 & $2,163.22$ & 1.00 & 0.21 \\
\hline IN & $1,622,036$ & 194,627 & 14 & 71.23 & 1.70 & $1,266.14$ & 0.88 & 0.27 \\
\hline $\mathrm{PA}$ & $1,550,145$ & 313,796 & 12 & 71.99 & 2.54 & $1,534.24$ & 1.00 & 0.25 \\
\hline LA & $1,485,871$ & 286,870 & 10 & 69.90 & 1.69 & $1,029.64$ & 1.00 & 0.25 \\
\hline OK & $1,427,908$ & 420,534 & 18 & 68.64 & 3.02 & $2,156.98$ & 0.79 & 0.26 \\
\hline $\mathrm{SC}$ & $1,421,897$ & 242,682 & 11 & 67.15 & 2.02 & $1,459.91$ & 0.95 & 0.28 \\
\hline $\mathrm{OH}$ & $1,145,718$ & 214,937 & 11 & 68.81 & 2.99 & $1,533.45$ & 1.00 & 0.26 \\
\hline MA & $1,094,531$ & 162,106 & 7 & 70.49 & 2.19 & $1,287.64$ & 1.00 & 0.40 \\
\hline NY & 710,547 & 91,037 & 6 & 72.49 & 2.38 & 961.97 & 1.00 & 0.30 \\
\hline $\mathrm{NE}$ & 565,511 & 466,980 & 6 & 71.96 & 2.61 & $1,400.27$ & 1.00 & 0.29 \\
\hline WA & 541,558 & 107,379 & 3 & 73.65 & 2.94 & $1,119.23$ & 1.00 & 0.28 \\
\hline WV & 410,880 & 33,851 & 1 & 72.18 & 1.90 & 963.54 & 1.00 & 0.42 \\
\hline MI & 381,892 & 212,423 & 6 & 69.76 & 1.43 & 388.21 & 0.33 & 0.39 \\
\hline $\mathrm{AR}$ & 345,453 & 63,289 & 2 & 71.08 & 2.19 & $1,403.75$ & 1.00 & 0.21 \\
\hline $\mathrm{AL}$ & 339,718 & 61,048 & 2 & 69.06 & 2.13 & $1,686.07$ & 1.00 & 0.22 \\
\hline $\mathrm{CT}$ & 301,650 & 62,764 & 4 & 73.76 & 2.18 & $1,131.73$ & 1.00 & 0.23 \\
\hline OR & 286,912 & 70,704 & 5 & 69.78 & 2.78 & $1,678.54$ & 1.00 & 0.35 \\
\hline IA & 230,624 & 183,507 & 1 & 71.10 & 2.25 & 809.79 & 1.00 & 0.30 \\
\hline IL & 228,922 & 57,764 & 8 & 66.89 & 2.91 & $1,712.24$ & 1.00 & 0.34 \\
\hline $\mathrm{ME}$ & 218,288 & 31,213 & 1 & 68.52 & 2.54 & 550.50 & 1.00 & 0.53 \\
\hline $\mathrm{TN}$ & 179,900 & 66,025 & 5 & 68.80 & 4.95 & $2,855.05$ & 1.00 & 0.28 \\
\hline $\mathrm{AZ}$ & 147,842 & 40,676 & 1 & 73.50 & 2.27 & $2,848.37$ & 1.00 & 0.37 \\
\hline $\mathrm{NH}$ & 137,583 & 20,809 & 2 & 71.63 & 1.47 & NA & 0.00 & 0.33 \\
\hline KY & 135,376 & 59,340 & 5 & 68.11 & 2.46 & NA & 0.83 & 0.21 \\
\hline $\mathrm{NV}$ & 72,408 & 27,937 & 1 & 69.41 & 3.15 & $2,842.18$ & 1.00 & 0.21 \\
\hline $\mathrm{MO}$ & 70,666 & 23,434 & 1 & 68.54 & 2.28 & $3,354.67$ & 1.00 & 0.18 \\
\hline KS & 45,355 & 11,711 & 1 & 72.25 & 3.26 & $2,497.21$ & 0.00 & 0.29 \\
\hline NM & 25,454 & 9,244 & 2 & 68.91 & 2.23 & 872.71 & 1.00 & 0.23 \\
\hline MT & 20,941 & 11,340 & 2 & 71.87 & 3.61 & $8,874.65$ & 1.00 & 0.32 \\
\hline $\mathrm{MN}$ & 10,000 & 3,720 & 2 & 71.74 & 2.31 & $1,310.00$ & 1.00 & 0.25 \\
\hline
\end{tabular}

CCR stands for cost-to-charge ratio for a hospital. 
Table 12: Summary Statistics by State - Medicare Advantage Patients

\begin{tabular}{|c|c|c|c|c|c|c|c|c|}
\hline \multirow[b]{2}{*}{ State } & \multicolumn{3}{|c|}{ Number } & \multicolumn{5}{|c|}{ Mean } \\
\hline & Visits & Patients & Providers & Age & Length of Stay & Payment & Urban & $\mathrm{CCR}^{*}$ \\
\hline PA & $1,457,931$ & 235,043 & 15 & 75.60 & 3.12 & $1,409.56$ & 1.00 & 0.24 \\
\hline LA & $1,166,894$ & 272,299 & 14 & 75.39 & 2.44 & $1,412.76$ & 1.00 & 0.26 \\
\hline $\mathrm{TX}$ & $1,124,732$ & 317,760 & 53 & 72.77 & 2.41 & $2,222.95$ & 0.81 & 0.25 \\
\hline $\mathrm{OH}$ & 801,948 & 179,538 & 18 & 74.51 & 3.99 & $1,647.19$ & 1.00 & 0.25 \\
\hline $\mathrm{NC}$ & 799,909 & 206,418 & 27 & 73.22 & 3.23 & $2,127.23$ & 0.97 & 0.27 \\
\hline $\mathrm{CA}$ & 788,914 & 261,159 & 41 & 74.15 & 3.14 & $3,453.24$ & 0.87 & 0.20 \\
\hline VA & 777,842 & 233,296 & 29 & 73.28 & 3.10 & $1,448.58$ & 0.99 & 0.24 \\
\hline NJ & 718,085 & 175,719 & 13 & 74.95 & 4.69 & $2,543.07$ & 1.00 & 0.18 \\
\hline GA & 710,187 & 206,423 & 21 & 72.41 & 4.00 & $1,968.62$ & 0.91 & 0.23 \\
\hline FL & 638,386 & 210,384 & 27 & 74.38 & 3.29 & $3,603.37$ & 1.00 & 0.19 \\
\hline MI & 524,019 & 181,208 & 8 & 74.56 & 1.31 & 572.46 & 0.33 & 0.38 \\
\hline IN & 422,882 & 74,942 & 14 & 74.04 & 2.02 & $1,939.21$ & 0.94 & 0.27 \\
\hline WA & 418,385 & 106,133 & 11 & 72.56 & 2.48 & $1,694.03$ & 1.00 & 0.31 \\
\hline $\mathrm{SC}$ & 404,963 & 108,652 & 19 & 72.59 & 3.01 & $1,804.78$ & 0.85 & 0.24 \\
\hline MA & 398,061 & 65,834 & 7 & 74.84 & 2.06 & $1,130.10$ & 1.00 & 0.39 \\
\hline $\mathrm{TN}$ & 374,386 & 87,691 & 7 & 72.84 & 2.41 & $3,160.68$ & 0.90 & 0.26 \\
\hline OR & 306,190 & 78,488 & 6 & 75.69 & 2.52 & $1,757.57$ & 0.92 & 0.35 \\
\hline CT & 236,676 & 50,506 & 6 & 73.00 & 1.56 & $1,466.58$ & 1.00 & 0.23 \\
\hline OK & 213,065 & 69,513 & 18 & 73.19 & 3.16 & $2,617.95$ & 0.87 & 0.22 \\
\hline $\mathrm{NE}$ & 202,792 & 160,735 & 7 & 77.11 & 2.63 & $1,742.84$ & 1.00 & 0.28 \\
\hline $\mathrm{AL}$ & 183,751 & 45,496 & 7 & 72.60 & 2.59 & $1,567.33$ & 1.00 & 0.23 \\
\hline KY & 178,899 & 56,518 & 9 & 72.60 & 1.97 & NA & 0.91 & 0.24 \\
\hline NY & 177,603 & 26,404 & 6 & 75.93 & 2.22 & $1,199.98$ & 1.00 & 0.31 \\
\hline $\mathrm{MO}$ & 162,217 & 54,278 & 4 & 83.42 & 1.58 & $3,321.15$ & 1.00 & 0.28 \\
\hline IL & 123,169 & 37,718 & 9 & 72.87 & 3.03 & $1,728.95$ & 1.00 & 0.28 \\
\hline WV & 117,367 & 12,587 & 1 & 74.37 & 2.13 & $1,048.64$ & 1.00 & 0.42 \\
\hline IA & 66,963 & 51,833 & 2 & 77.12 & 2.49 & $1,015.63$ & 1.00 & 0.29 \\
\hline $\mathrm{AR}$ & 63,297 & 15,429 & 2 & 73.45 & 2.28 & $1,842.17$ & 1.00 & 0.21 \\
\hline $\mathrm{AZ}$ & 42,351 & 17,283 & 5 & 73.37 & 3.88 & $6,842.87$ & 1.00 & 0.29 \\
\hline NM & 41,148 & 10,230 & 2 & 73.11 & 6.34 & $1,068.58$ & 1.00 & 0.28 \\
\hline $\mathrm{NH}$ & 16,730 & 3,277 & 3 & 70.20 & 1.30 & NA & 0.94 & 0.31 \\
\hline $\mathrm{ME}$ & 14,716 & 4,285 & 1 & 71.98 & 2.81 & $1,060.38$ & 1.00 & 0.53 \\
\hline $\mathrm{MN}$ & 13,827 & 4,174 & 3 & 75.45 & 2.91 & $1,922.81$ & 0.29 & 0.41 \\
\hline NV & 10,563 & 5,200 & 1 & 72.67 & 3.39 & $3,373.22$ & 1.00 & 0.21 \\
\hline KS & 7,831 & 2,973 & 5 & 70.20 & 5.24 & $3,424.21$ & 0.26 & 0.26 \\
\hline MT & 6,378 & 3,058 & 3 & 72.58 & 2.14 & $7,559.98$ & 1.00 & 0.37 \\
\hline WY & 2,075 & 456 & 1 & 75.26 & 2.21 & NA & 0.00 & 0.43 \\
\hline
\end{tabular}

${ }^{*}$ CCR stands for cost-to-charge ratio for a hospital.

${ }^{1}$ Patients 65 years of age or older with Medicare Advantage plans from the 60 largest insurers in the AHUD data. 
Table 13: Summary Statistics by State - Private (under 65) Patients

\begin{tabular}{|c|c|c|c|c|c|c|c|c|}
\hline \multirow[b]{2}{*}{ State } & \multicolumn{3}{|c|}{ Number } & \multicolumn{5}{|c|}{ Mean } \\
\hline & Visits & Patients & Providers & Age & Length of Stay & Payment & Urban & $\mathrm{CCR}^{*}$ \\
\hline GA & $6,357,239$ & $2,502,358$ & 21 & 40.03 & 3.94 & $2,585.33$ & 0.92 & 0.23 \\
\hline TX & $5,621,813$ & $2,252,150$ & 54 & 39.22 & 1.94 & $2,612.13$ & 0.87 & 0.25 \\
\hline CA & $5,170,674$ & $2,098,097$ & 42 & 37.46 & 2.84 & $3,327.51$ & 0.93 & 0.20 \\
\hline NJ & $4,699,899$ & $1,549,162$ & 13 & 33.68 & 3.19 & $2,246.59$ & 0.99 & 0.18 \\
\hline VA & $4,324,696$ & $1,728,394$ & 29 & 39.39 & 2.47 & $2,032.16$ & 0.99 & 0.26 \\
\hline $\mathrm{NC}$ & $3,872,629$ & $1,191,476$ & 27 & 40.93 & 2.61 & $2,967.23$ & 0.98 & 0.27 \\
\hline WA & $3,694,299$ & $1,096,533$ & 11 & 40.34 & 1.75 & $1,449.76$ & 1.00 & 0.32 \\
\hline LA & $3,591,584$ & $1,240,940$ & 14 & 42.10 & 1.96 & $1,634.91$ & 1.00 & 0.27 \\
\hline PA & $3,198,536$ & 966,338 & 16 & 43.77 & 1.87 & $1,408.60$ & 1.00 & 0.24 \\
\hline $\mathrm{SC}$ & $2,969,462$ & 944,044 & 20 & 40.03 & 2.46 & $2,504.02$ & 0.89 & 0.26 \\
\hline $\mathrm{OH}$ & $2,880,539$ & 986,661 & 18 & 43.12 & 2.82 & $2,202.99$ & 1.00 & 0.24 \\
\hline $\mathrm{TN}$ & $2,666,145$ & 771,431 & 7 & 33.96 & 2.05 & $2,127.67$ & 0.81 & 0.27 \\
\hline IN & $2,366,744$ & 579,112 & 14 & 42.34 & 1.96 & $2,897.25$ & 0.95 & 0.27 \\
\hline FL & $2,302,238$ & $1,017,862$ & 28 & 40.69 & 2.12 & $2,795.80$ & 0.98 & 0.21 \\
\hline MI & $2,112,058$ & 746,630 & 8 & 39.35 & 1.20 & 811.64 & 0.22 & 0.38 \\
\hline MA & $1,692,891$ & 451,725 & 7 & 42.15 & 1.92 & 826.22 & 1.00 & 0.39 \\
\hline $\mathrm{CT}$ & $1,664,805$ & 514,826 & 6 & 40.52 & 1.34 & $1,646.29$ & 1.00 & 0.24 \\
\hline $\mathrm{NE}$ & $1,360,423$ & 921,080 & 7 & 36.75 & 2.10 & $2,316.00$ & 1.00 & 0.26 \\
\hline OK & $1,311,455$ & 611,498 & 18 & 42.65 & 2.38 & $2,600.89$ & 0.84 & 0.25 \\
\hline $\mathrm{AL}$ & $1,243,970$ & 421,811 & 7 & 41.29 & 1.83 & 871.08 & 1.00 & 0.23 \\
\hline IL & $1,008,641$ & 398,806 & 9 & 40.33 & 2.14 & $1,333.99$ & 1.00 & 0.26 \\
\hline KY & 946,827 & 355,343 & 9 & 42.00 & 1.61 & $\mathrm{NA}$ & 0.99 & 0.24 \\
\hline $\mathrm{MO}$ & 825,165 & 227,263 & 5 & 39.54 & 1.73 & $3,571.82$ & 0.99 & 0.27 \\
\hline OR & 613,952 & 291,983 & 6 & 38.18 & 2.23 & $2,447.68$ & 0.95 & 0.35 \\
\hline NY & 603,712 & 192,845 & 6 & 42.28 & 1.83 & $1,259.33$ & 1.00 & 0.28 \\
\hline $\mathrm{AZ}$ & 413,922 & 174,903 & 5 & 38.13 & 2.66 & $7,196.89$ & 1.00 & 0.28 \\
\hline WV & 357,319 & 67,061 & 1 & 38.99 & 1.83 & $1,140.08$ & 1.00 & 0.42 \\
\hline AR & 315,114 & 131,672 & 2 & 38.37 & 1.98 & $1,888.21$ & 1.00 & 0.21 \\
\hline IA & 256,372 & 181,982 & 2 & 41.31 & 2.43 & $1,170.95$ & 1.00 & 0.28 \\
\hline NH & 247,725 & 72,037 & 3 & 41.14 & 1.29 & NA & 0.89 & 0.32 \\
\hline ME & 196,505 & 71,506 & 1 & 42.86 & 2.35 & $1,126.91$ & 1.00 & 0.53 \\
\hline NM & 165,045 & 58,886 & 2 & 44.38 & 4.28 & $1,820.30$ & 1.00 & 0.28 \\
\hline KS & 142,398 & 59,909 & 5 & 40.18 & 2.92 & $2,402.23$ & 0.23 & 0.26 \\
\hline NV & 72,327 & 42,363 & 1 & 39.78 & 2.53 & $2,878.49$ & 1.00 & 0.21 \\
\hline $\mathrm{MN}$ & 68,338 & 31,249 & 3 & 35.13 & 3.06 & $1,333.66$ & 0.43 & 0.38 \\
\hline MT & 61,229 & 33,266 & 3 & 39.94 & 1.63 & $9,657.85$ & 1.00 & 0.38 \\
\hline WY & 8,318 & 3,858 & 1 & 33.47 & 1.58 & NA & 0.00 & 0.43 \\
\hline
\end{tabular}

${ }^{*}$ CCR stands for cost-to-charge ratio for a hospital.

${ }^{1}$ Patients younger than 65 years of age with private plans from the 60 largest insurers in the AHUD data. 
Table 14: Summary Statistics by State - Medicaid Patients

\begin{tabular}{|c|c|c|c|c|c|c|c|c|}
\hline \multirow[b]{2}{*}{ State } & \multicolumn{3}{|c|}{ Number } & \multicolumn{5}{|c|}{ Mean } \\
\hline & Visits & Patients & Providers & Age & Length of Stay & Payment & Urban & $\mathrm{CCR}^{*}$ \\
\hline $\mathrm{CA}$ & $4,219,974$ & $1,619,940$ & 41 & 25.46 & 2.92 & $1,253.90$ & 1.00 & 0.20 \\
\hline TX & $3,813,730$ & $1,159,642$ & 51 & 24.76 & 1.84 & 738.14 & 0.88 & 0.26 \\
\hline $\mathrm{NC}$ & $2,043,293$ & 556,145 & 20 & 24.50 & 2.44 & $1,201.66$ & 0.97 & 0.28 \\
\hline GA & $1,731,304$ & 525,317 & 20 & 27.08 & 3.06 & $1,017.41$ & 0.79 & 0.24 \\
\hline FL & $1,314,472$ & 527,324 & 24 & 21.75 & 1.86 & $1,143.35$ & 0.99 & 0.21 \\
\hline LA & $1,294,896$ & 469,162 & 14 & 24.25 & 1.92 & 534.91 & 1.00 & 0.27 \\
\hline $\mathrm{SC}$ & $1,283,144$ & 332,178 & 16 & 20.71 & 3.19 & $1,435.33$ & 0.89 & 0.27 \\
\hline MI & $1,091,191$ & 378,000 & 8 & 24.46 & 1.39 & 233.26 & 0.16 & 0.38 \\
\hline $\mathrm{OH}$ & $1,053,661$ & 323,844 & 17 & 35.16 & 2.87 & $1,088.97$ & 1.00 & 0.24 \\
\hline OK & $1,018,249$ & 428,071 & 17 & 24.41 & 2.39 & 972.52 & 0.87 & 0.24 \\
\hline VA & $1,010,273$ & 415,085 & 30 & 27.86 & 2.70 & $1,082.27$ & 0.94 & 0.25 \\
\hline WA & 944,007 & 300,868 & 10 & 33.19 & 2.25 & 786.45 & 1.00 & 0.31 \\
\hline IN & 753,439 & 169,575 & 14 & 26.77 & 2.15 & $1,475.49$ & 0.95 & 0.27 \\
\hline NJ & 718,461 & 264,517 & 13 & 28.53 & 5.18 & $1,542.04$ & 0.99 & 0.18 \\
\hline $\mathrm{CT}$ & 648,837 & 191,101 & 6 & 33.49 & 1.52 & $1,414.51$ & 1.00 & 0.25 \\
\hline MO & 570,070 & 116,975 & 5 & 45.57 & 1.61 & $1,410.89$ & 0.82 & 0.29 \\
\hline $\mathrm{AL}$ & 518,291 & 157,436 & 7 & 25.89 & 2.93 & $1,588.51$ & 1.00 & 0.23 \\
\hline IL & 479,725 & 183,959 & 8 & 27.90 & 2.89 & 341.55 & 1.00 & 0.33 \\
\hline $\mathrm{TN}$ & 355,412 & 77,728 & 7 & 25.47 & 2.31 & $1,017.68$ & 0.96 & 0.22 \\
\hline PA & 348,831 & 137,375 & 16 & 34.53 & 2.26 & $1,877.26$ & 1.00 & 0.20 \\
\hline NY & 288,303 & 92,077 & 6 & 32.29 & 2.64 & 585.20 & 1.00 & 0.26 \\
\hline MA & 280,077 & 88,804 & 7 & 36.34 & 1.62 & 762.73 & 1.00 & 0.41 \\
\hline $\mathrm{NE}$ & 276,822 & 192,030 & 7 & 32.80 & 2.83 & $1,101.96$ & 1.00 & 0.24 \\
\hline OR & 197,391 & 96,912 & 6 & 36.77 & 2.06 & 920.75 & 0.99 & 0.35 \\
\hline $\mathrm{AR}$ & 138,611 & 53,048 & 2 & 20.41 & 1.61 & $1,038.99$ & 1.00 & 0.21 \\
\hline IA & 127,853 & 109,528 & 2 & 25.63 & 1.90 & 613.26 & 1.00 & 0.30 \\
\hline KY & 94,615 & 41,937 & 8 & 40.68 & 2.33 & NA & 0.99 & 0.20 \\
\hline WV & 81,959 & 17,793 & 1 & 34.62 & 1.94 & 500.95 & 1.00 & 0.42 \\
\hline NH & 61,930 & 16,744 & 3 & 34.27 & 2.33 & NA & 0.65 & 0.33 \\
\hline NM & 61,694 & 24,728 & 2 & 29.92 & 2.23 & 780.62 & 1.00 & 0.25 \\
\hline NV & 54,918 & 23,678 & 1 & 33.84 & 2.59 & 810.93 & 1.00 & 0.21 \\
\hline KS & 48,173 & 19,115 & 4 & 31.81 & 2.65 & 848.66 & 0.55 & 0.25 \\
\hline $\mathrm{AZ}$ & 42,960 & 26,384 & 4 & 26.47 & 2.44 & $4,038.49$ & 1.00 & 0.28 \\
\hline MT & 36,847 & 15,636 & 3 & 23.67 & 1.96 & NA & 1.00 & 0.39 \\
\hline WY & 23,104 & 6,414 & 1 & 23.76 & 1.64 & NA & 0.00 & 0.43 \\
\hline $\mathrm{MN}$ & 17,980 & 8,386 & 3 & 30.73 & 2.27 & 795.04 & 0.52 & 0.37 \\
\hline MS & 982 & 704 & 1 & 14.87 & 2.01 & NA & 1.00 & 0.27 \\
\hline ME & 442 & 302 & 1 & 38.76 & 3.17 & $2,394.98$ & 1.00 & 0.53 \\
\hline
\end{tabular}

CCR stands for cost-to-charge ratio for a hospital. 


\section{B Comparison of AHUD Data to Nationally Representative Data}

We compare AHUD inpatient data used in this paper to weighted national estimates from the Healthcare Cost and Utilization Project (HCUP) National Inpatient Sample, provided by the Agency for Healthcare Research and Quality. The HCUP NIS has roughly 7 million inpatient hospital stays each year, while AHUD has roughly 2-4 million inpatient stays each year. Weighted, the NIS estimates more than 35 million hospitalizations nationally.

Figure 5: Trends in Inpatient Charges and Costs in AHUD and HCUP Data

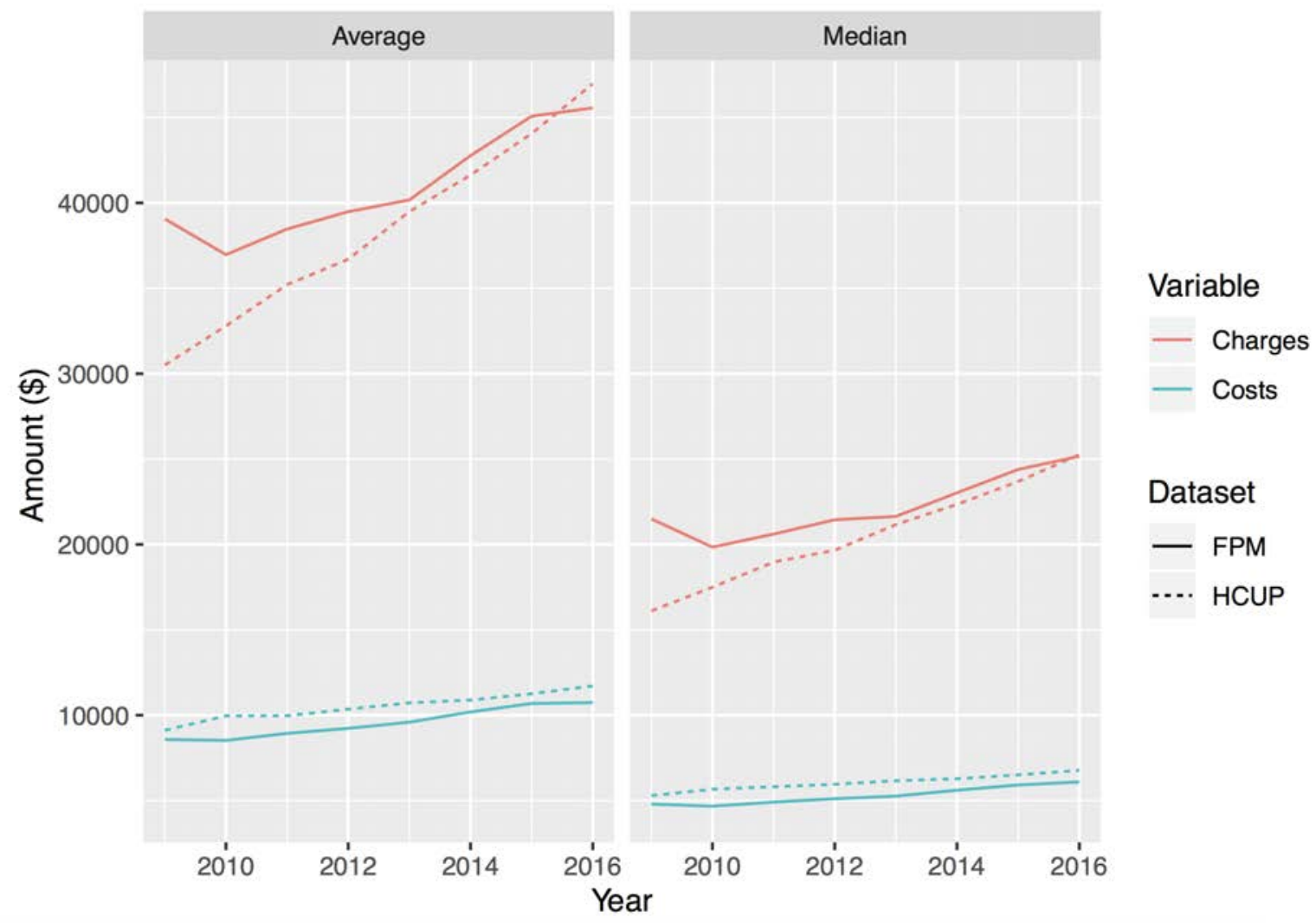

Notes: Costs are an estimate of the actual costs of providing care. They are estimated by multiplying the charge by cost-to-charge ratios from CMS hospital cost reports. Charges are what the hospital bills for its services, before adjusting for negotiated discounts and other contractual adjustments. The HCUP data do not contain information on actual payments hospitals receive after these discounts so there is no way to compare the actual price data from the AHUD data set. 
Table 15: Comparison of AHUD and HCUP Inpatient Data, 2016

\begin{tabular}{|c|c|c|c|}
\hline & \multicolumn{2}{|c|}{ Percent } & \multirow[b]{2}{*}{ Difference } \\
\hline & AHUD & HCUP & \\
\hline \multicolumn{4}{|l|}{ Patient Age } \\
\hline Age $<1$ & 11.49 & 11.82 & -0.33 \\
\hline Age 1-17 & 3.94 & 3.54 & 0.4 \\
\hline Age 18-44 & 25.24 & 24.41 & 0.83 \\
\hline Age $45-64$ & 24.67 & 24.62 & 0.05 \\
\hline Age $65-84$ & 26.64 & 27.63 & -0.99 \\
\hline Age $>85$ & 7.93 & 7.96 & -0.03 \\
\hline Unknown & 0.1 & 0.02 & 0.08 \\
\hline \multicolumn{4}{|l|}{ Patient Gender } \\
\hline Male & 41.85 & 43.25 & -1.4 \\
\hline Female & 58.15 & 56.69 & 1.46 \\
\hline Unknown & 0.00 & 0.06 & -0.06 \\
\hline \multicolumn{4}{|l|}{ Payer* } \\
\hline Medicare & 19.72 & 39.57 & -19.85 \\
\hline Medicaid & 11.63 & 23.1 & -11.47 \\
\hline Private & 19.19 & 30.05 & -10.86 \\
\hline Self-pay & 1.89 & 4.18 & -2.29 \\
\hline Other & 23.93 & 2.97 & 20.96 \\
\hline \multicolumn{4}{|l|}{ Census Division } \\
\hline East North Central & 11.81 & 15.33 & -3.52 \\
\hline East South Central & 5.27 & 6.84 & -1.57 \\
\hline Middle Atlantic & 7.81 & 13.87 & -6.06 \\
\hline Mountain & 2.74 & 6.23 & -3.49 \\
\hline New England & 4.01 & 4.63 & -0.62 \\
\hline Pacific & 13.5 & 13.74 & -0.24 \\
\hline South Atlantic & 29.54 & 20.6 & 8.94 \\
\hline West North Central & 5.06 & 6.91 & -1.85 \\
\hline West South Central & 20.25 & 11.85 & 8.4 \\
\hline
\end{tabular}

* For the AHUD data, our method of classifying payers (see Appendix D) leaves 24 percent of inpatient admissions unclassified. This explains the discrepancy between HCUP and AHUD for this metric. 


\section{Variable Construction}

In the data, information on payers and insurance plan descriptions is as entered by providers. This entry procedure is not standardized across providers and often is not standardized within providers (e.g., "BCBSMA" and "Mass. BlueCross BlueShield" are both used to describe the same insurer). Below we discuss how we classify public and private payers.

Classifying public payers - Only plans that contained the name "Medicare" or some variant (e.g,. "MCARE") were classified as Medicare plans. Similarly, Medicaid plans were identified from plan names that contained the name "Medicaid" or some variant (e.g., "MCD"). However, the classification of Medicaid plans was more involved than that of Medicare given that most states have their own names for their respective Medicaid and CHIP programs (e.g., the SoonerCare is Oklahoma's Medicaid plan and PeachCare for Kids is Georgia's CHIP plan). We include Medicaid and CHIP plan names for all 38 states in the AHUD data, based on information from the U.S. Department of Health \& Human Services (2009), the American Council of Aging (2017), the U.S. Centers for Medicare \& Medicaid Services (2020), and from our review of state Medicaid websites. For a list of all Medicaid and CHIP names by state included in the classification see Appendix Table 16.

Classifying private payers - For this analysis, we classify only a subset of the largest health insurance companies. In order to determine the largest private payers, we used data on the market share of insurers in each state from the Kaiser Family Foundation (KFF). The selection mechanism is as follows: insurers with a market share of over 10 percent in either the large-group market or the individual market in each state in the AHUD data which were one of the three largest insurers in that state in 2011. In addition, we include all relevant subsidiaries for each of these insurers (e.g., UniCare, RightCHOICE, Empire Blue Cross Blue Shield, Blue Cross of California, Blue Cross Blue Shield of Georgia, Comp-Care, and CareMore are all subsidiaries of Anthem). ${ }^{11}$ Furthermore, we include any other BCBS affiliated company (e.g., BCBS's Federal Employee Program). This resulted in a total of 60 insurance firms. For a complete list of private insurers and their subsidiaries included in the analysis, see Appendix Table 17. The distinction between Medicare Advantage plans and other private plans is made by simply classifying private plans as Medicare Advantage if the patient's age at the time of the encounter is 65 or older and as a standard private plan otherwise. This procedure introduces a misclassificaiton error that will tend to reduce measured differences between private and public plans. For more information on the procedure of classifying private insurers, see Appendix D.

Charlson comorbidity index - To classify comorbidities, we rely on the methodology described in Quan et al. (2005). Quan et al. define an "Enhanced ICD-9" coding scheme for deriving Charlson comorbidities from ICD-9 billing codes. We implement the computation of both Enhanced ICD-9

\footnotetext{
${ }^{11}$ Relevant subsidiaries are defined as subsidiaries that sold health insurance in the states present in the AHUD data and that were wholly owned by the company between 2009 and 2016 according to U.S. Securities and Exchange Commission Form 10-K filings.
} 
codes (for all diagnoses prior to October 1, 2015) and ICD-10 codes (for all diagnoses starting on October 1, 2015).

\section{Details on Construction of Payer Variables}

In order to classify the payer for each patient encounter, we account for a certain degree of human error or other variation in the hospital's identification of the insurance plan names. To do so, we include multiple variations of an insurer's name. As an example, let us consider the insurance firm GuideWell and its subsidiary, Blue Cross and Blue Shield of Florida (also operating under the name Florida Blue). We classify any patient encounter as being covered by GuideWell if the insurance plan name or payer name entered by the hospital contains any of the following phrases: "GUIDEWELL"; "GUIDE WELL"; "GUIDE-WELL"; ("FLORIDA" or "FL") and ("BLUE", "BCBS", "BC BS", or "BC AND BS"). Note that the classification of insurance firms is case insensitive.

\section{D.1 Public Payers}

Table 16: Included State Public Plan Names

\begin{tabular}{lll} 
State & Medicaid Plans & CHIP Plans \\
\hline \multirow{2}{*}{ Alabama } & Medicaid & Alabama ALL Kids \\
Arizona & Arizona Health Care Cost Contain- & AHCCCS-KidsCare \\
& ment System (AHCCCS) & \\
Arkansas & Medicaid & ARKids First \\
& TEFRA & \\
California & Medi-Cal & Medi-Cal \\
Connecticut & HUSKY Health & HUSKY B \\
Florida & Statewide Medicaid Managed Care & Florida KidCare \\
& Program & \\
Georgia & Medical Assistance & PeachCare for Kids \\
Illinois & Medical Assistance & Illinois All Kids \\
Indiana & Hoosier Healthwise & Hoosier Healthwise Package C \\
& Hoosier Care Connects & \\
& M.E.D. Works & \\
Iowa & Health Indiana Plan (HIP) & Healthy and Well Kids in Iowa \\
Kansas & IA Health Link & (Hawk-I) \\
& MediPASS & CHIP \\
KanCare Medical Assistance Pro- & \\
& gram & Kentucky Children's Health Insur- \\
& HealthWave & ance Program (KCHIP)
\end{tabular}




\begin{tabular}{|c|c|c|}
\hline Louisiana & $\begin{array}{l}\text { HealthyLouisiana } \\
\text { Bayou Health }\end{array}$ & $\begin{array}{l}\text { Louisiana Children's Health Insur- } \\
\text { ance Program (LaCHIP) }\end{array}$ \\
\hline Maine & MaineCare & CubCare \\
\hline Massachusetts & MassHealth & MassHealth \\
\hline Michigan & $\begin{array}{l}\text { MI Choice } \\
\text { Michigan Dept. of Health and Hu- } \\
\text { man Services }\end{array}$ & Michigan MIChild \\
\hline Minnesota & MinnesotaCare & CHIP \\
\hline Mississippi & $\begin{array}{l}\text { Mississippi Coordinated Access } \\
\text { Network (MississippiCAN) }\end{array}$ & CHIP \\
\hline Missouri & MO HealthNet & MO HealthNet for Kids \\
\hline Montana & & Healthy Montana Kids \\
\hline Nebraska & ACCESSNebraska & CHIP \\
\hline Nevada & Medicaid & Nevada Check Up \\
\hline New Hampshire & Medicaid & Healthy Kids \\
\hline New Jersey & Medicaid & NJ FamilyCare \\
\hline New Mexico & Centennial Care & New Mexi-Kids \\
\hline New York & Medicaid Managed Care & Child Health Plus \\
\hline \multirow[t]{3}{*}{ North Carolina } & Division of Medical Assistance & Health Choice \\
\hline & $(\mathrm{DMA})$ & Health Check \\
\hline & $\begin{array}{l}\text { Community Care of North Car- } \\
\text { olina/Carolina Access }\end{array}$ & \\
\hline Ohio & Medicaid & Healthy Start \\
\hline \multirow[t]{2}{*}{ Oklahoma } & SoonerCare & SoonerCare \\
\hline & & Soon-To-Be-Sooners \\
\hline Oregon & Oregon Health Plan & Oregon Health Plan \\
\hline Pennsylvania & Medical Assistance & CHIP \\
\hline South Carolina & Healthy Connections & Healthy Connections Children \\
\hline Tennessee & TennCare & CoverKids \\
\hline \multirow[t]{2}{*}{ Texas } & STAR Medicaid Managed Care & CHIP \\
\hline & & TexCare \\
\hline \multirow[t]{2}{*}{ Virginia } & Medicaid & Family Access to Medical Insurance \\
\hline & & Security (FAMIS) \\
\hline Washington & Apple Health & Apple Health for Kids \\
\hline West Virginia & Mountain Health Choices & $\begin{array}{l}\text { West Virginia Children's Health In- } \\
\text { surance Program (WVCHIP) }\end{array}$ \\
\hline Wyoming & EqualityCare & Kid Care CHIP \\
\hline
\end{tabular}




\section{D.2 Private Payers}

Table 17: Included Private Insurers and Subsidiaries

\begin{tabular}{|c|c|}
\hline Private Insurance Company & Included Subsidiaries and Products ${ }^{1}$ \\
\hline \multirow[t]{10}{*}{ UnitedHealth } & TouchPoint Care \\
\hline & Oxford Health Plans \\
\hline & PacifiCare \\
\hline & Sierra Health \\
\hline & Evercare \\
\hline & AmeriChoice \\
\hline & Mid Atlantic Medical Services \\
\hline & Ovation \\
\hline & Unison Health Plan \\
\hline & Arnett HealthPlans \\
\hline \multirow[t]{7}{*}{ WellPoint/Anthem } & UniCare \\
\hline & RightCHOICE \\
\hline & Empire Blue Cross Blue Shield \\
\hline & Blue Cross of California \\
\hline & Blue Cross Blue Shield of Georgia \\
\hline & Comp-Care \\
\hline & CareMore \\
\hline \multicolumn{2}{|l|}{ Aetna } \\
\hline \multirow[t]{2}{*}{ Cigna } & Allegiance \\
\hline & Great-West Healthcare \\
\hline \multirow[t]{4}{*}{ Humana } & Solicare Health Plans \\
\hline & CarePlus Health Plans \\
\hline & Cariten Healthcare \\
\hline & Emphesys \\
\hline \multirow[t]{2}{*}{ Centene } & Ambetter \\
\hline & Allwell Health Net \\
\hline \multicolumn{2}{|l|}{ Molina } \\
\hline \multicolumn{2}{|l|}{ WellCare } \\
\hline \multirow[t]{5}{*}{ Health Care Service Corporation (HCSC) } & Blue Cross and Blue Shield of Illinois \\
\hline & Blue Cross and Blue Shield of New Mexico \\
\hline & Blue Cross and Blue Shield of Oklahoma \\
\hline & Blue Cross and Blue Shield of Texas \\
\hline & Blue Cross and Blue Shield of Montana \\
\hline HealthSpring & BravoHealth \\
\hline \multirow[t]{7}{*}{ Coventry } & First Health \\
\hline & Advantra \\
\hline & Altius Health Plans \\
\hline & HealthAmerica Pennsylvania \\
\hline & HealthCare USA of Missouri \\
\hline & HealthCare USA of Tennessee \\
\hline & WellPath of South Carolina \\
\hline
\end{tabular}




\author{
Amerigroup \\ Kaiser \\ EmblemHealth \\ Harvard Pilgrim \\ Tufts Health Plan \\ HealthPartners \\ Medica \\ PacificSource \\ Assurant \\ Cambia Health Solutions
}

Highmark

Blue Cross and Blue Shield of Alabama

Blue Cross and Blue Shield of Arizona

Blue Cross and Blue Shield of Arkansas

QualChoice

Blue Shield of California

GuideWell

Advantage Health Solutions

Wellmark BCBS

Blue Cross and Blue Shield of Kansas City

Blue Cross and Blue Shield of Kansas

Louisiana Health Service

HealthMarkets

Blue Cross and Blue Shield of Massachusetts

Blue Cross and Blue Shield of Minnesota

Blue Cross and Blue Shield of Michigan

Henry Ford Health System

Spectrum Health Group

Mississippi Insurance Group

New West Health Services

Blue Cross and Blue Shield of Maine

Horizon Blue Cross Blue Shield of New Jersey

Aegon

Presbyterian Health Plan

Ardent Health Services

Lifetime Healthcare Companies

Blue Cross and Blue Shield of North Carolina Medical Mutual of $\mathrm{OH}$
Regence

Asuris Northwest Health

BridgeSpan Health

LifeMap

Blue Cross and Blue Shield of Oregon

Blue Shield of Idaho

Blue Shield of Washington

Blue Cross of Northeastern Pennsylvania

Blue Cross and Blue Shield of West Virginia

Florida Blue (Blue Cross and Blue Shield of Florida)

Blue Cross and Blue Shield of Iowa

Blue Cross and Blue Shield of Louisiana

Health Alliance Plan (HAP)

Priority Health

Excellus BlueCross BlueShield

Univera Healthcare 
CommunityCare

Providence

Independence Blue Cross

Capital Blue Cross

Blue Cross and Blue Shield of South Carolina

Blue Cross and Blue Shield of Tennessee

Tennessee Rural Health Group

CareFirst

Premera Blue Cross

Blue Cross and Blue Shield of Wyoming

Blue Cross and Blue Shield Federal

Blue Cross and Blue Shield (Unclassified)
Keystone Health Plan East

Keystone Health Plan Central

Farm Bureau Health Plans

\footnotetext{
${ }^{1}$ Subsidiaries that sold health insurance in the states present in the AHUD data and that were wholly owned by the company between 2009 and 2016 based on SEC Form 10-K filings.
} 


\section{E Additional Tables and Figures}

Figure 6: Density Plots for Adjusted Discount by Payer Type and MS-DRG

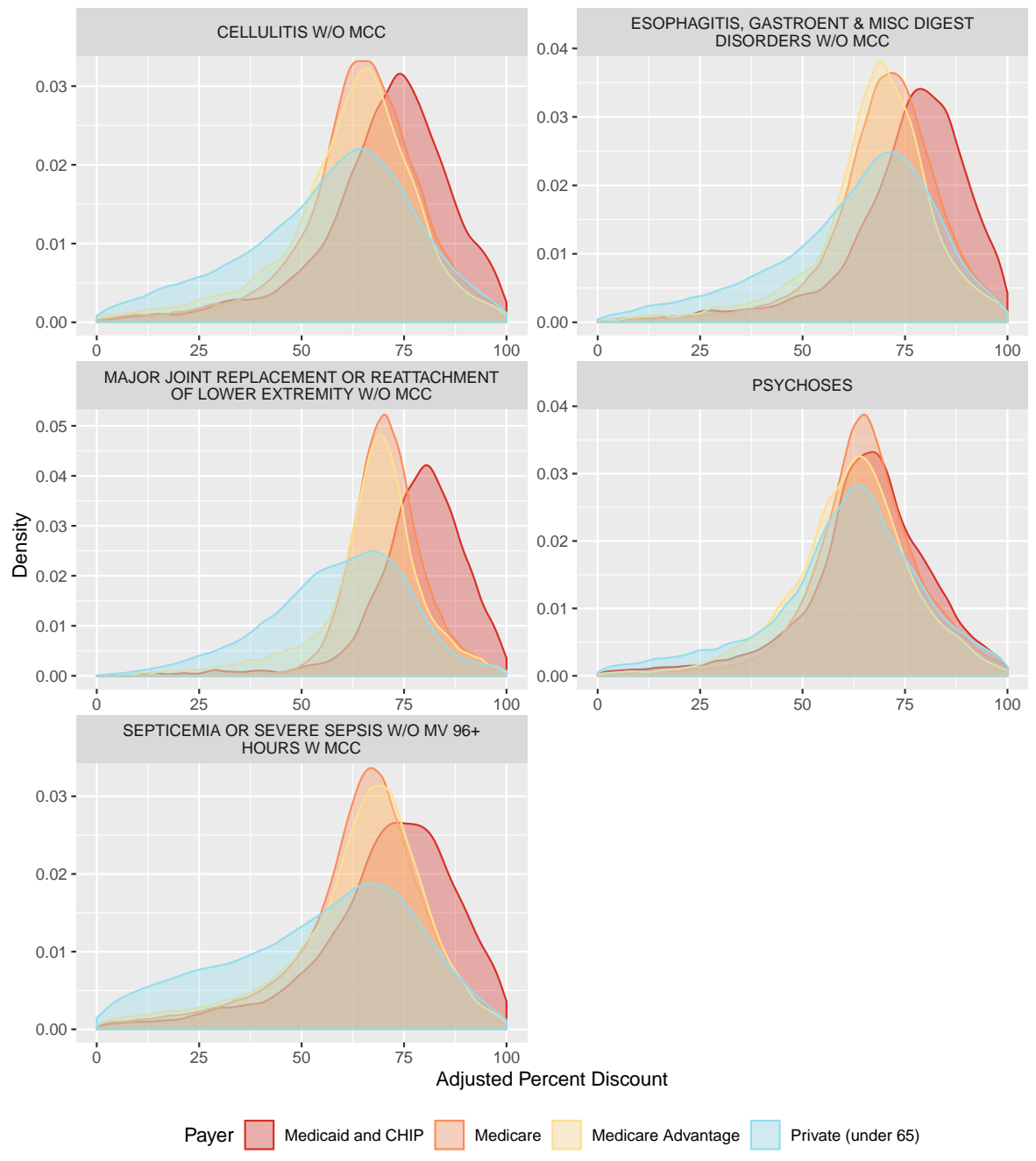


Figure 7: Conditional Density Plots for Adjusted Discount by Payer Type and MS-DRG
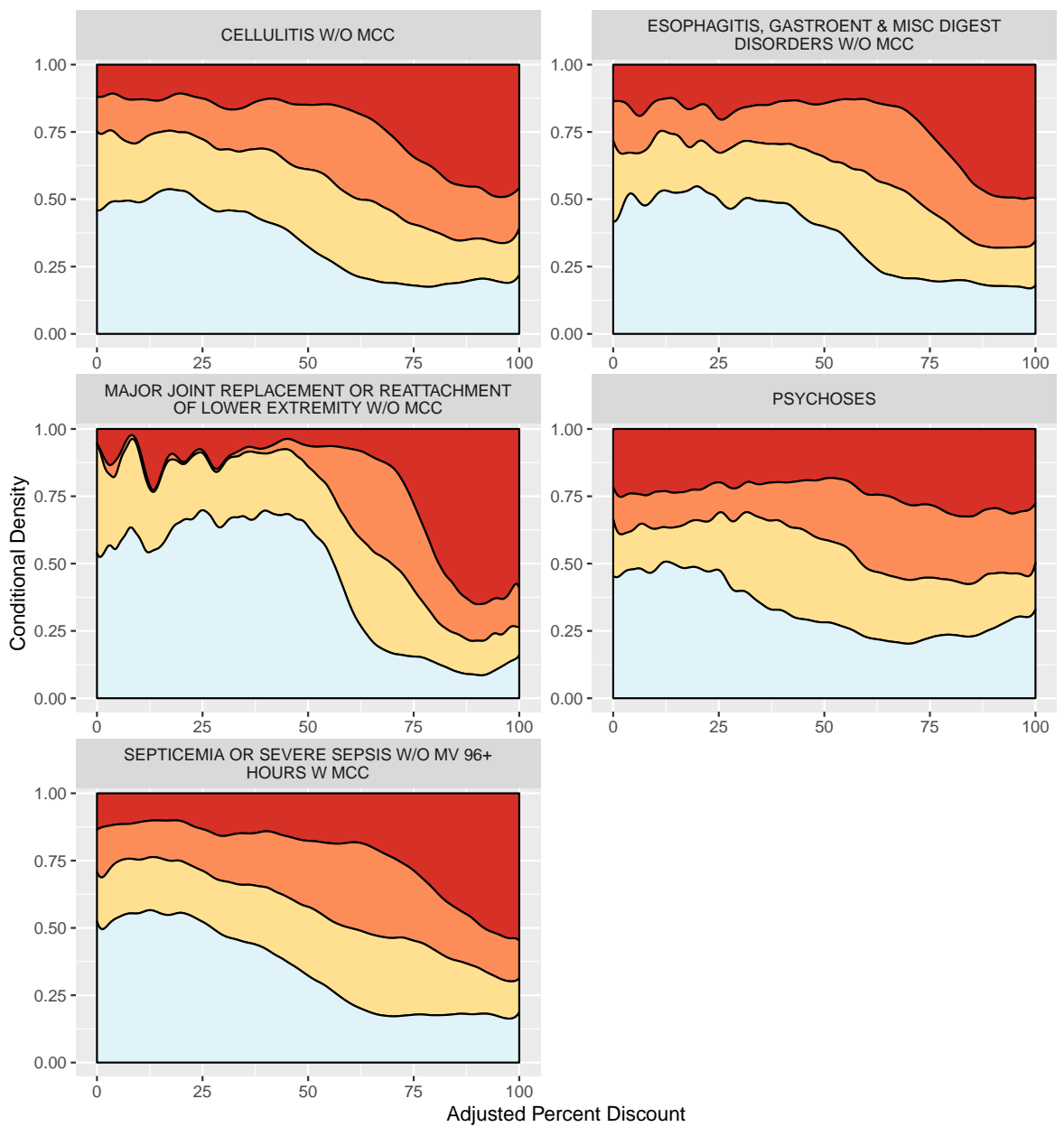

Payer $\square$ Medicaid and CHIP $\square$ Medicare $\square$ Medicare Advantage $\square$ Private (under 65) 
Figure 8: Prices as a Percent of Medicare Reimbursements - HCCI Insurers

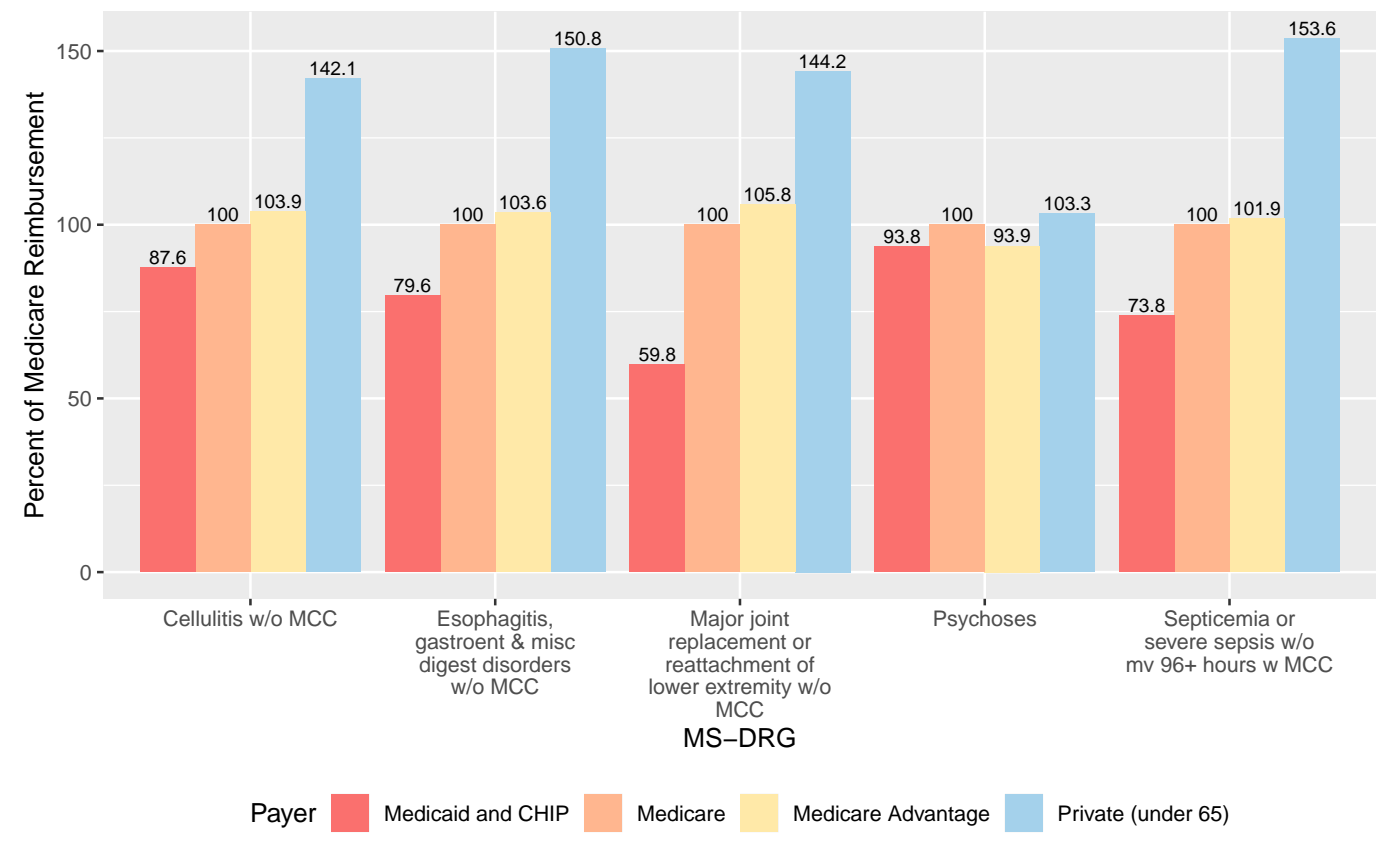

Figure 9: Prices as a Percent of Medicare Reimbursements - Non-HCCI Insurers

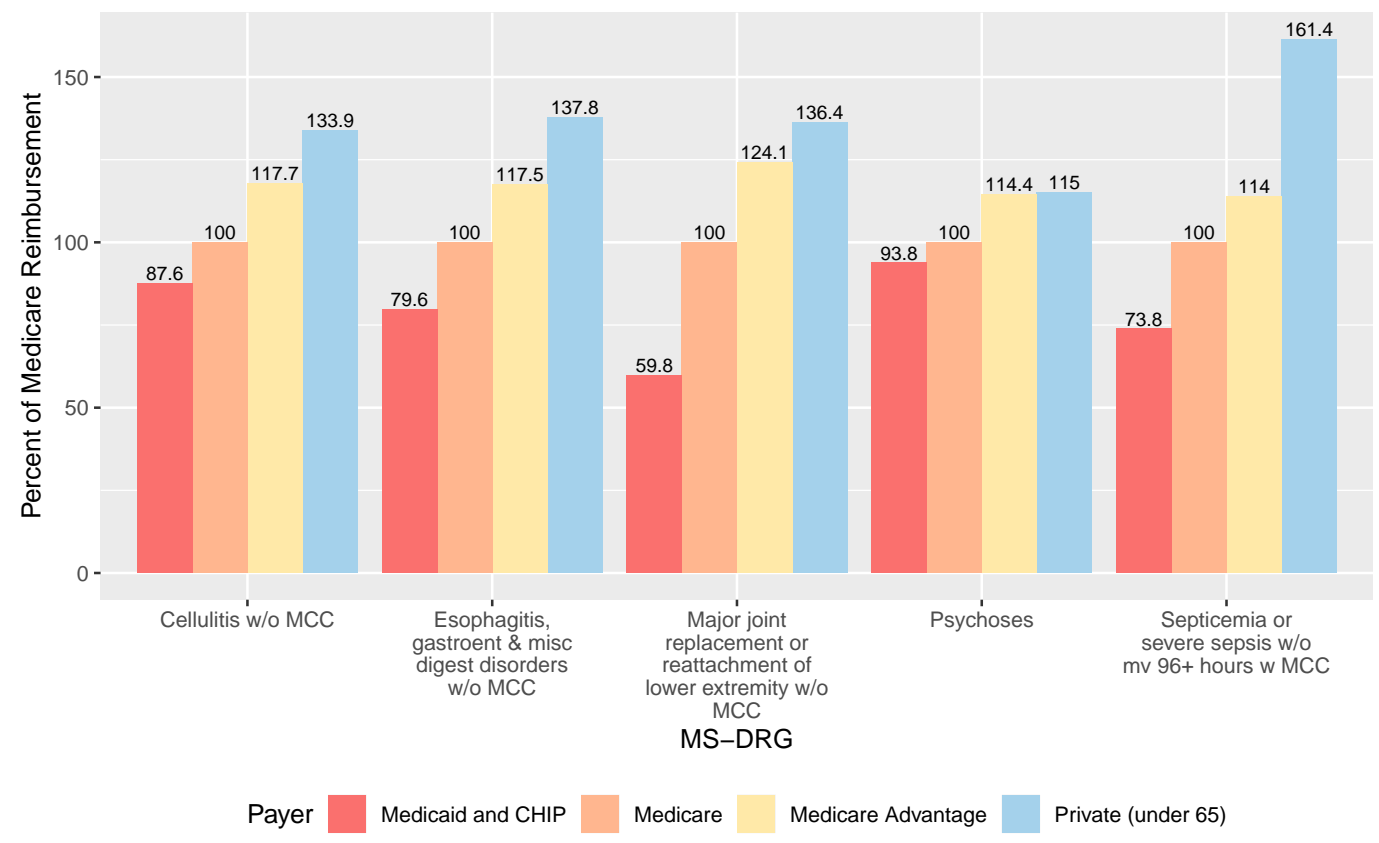


Figure 10: Prices as a Percent of Medicare Reimbursements - Top 5 Insurers

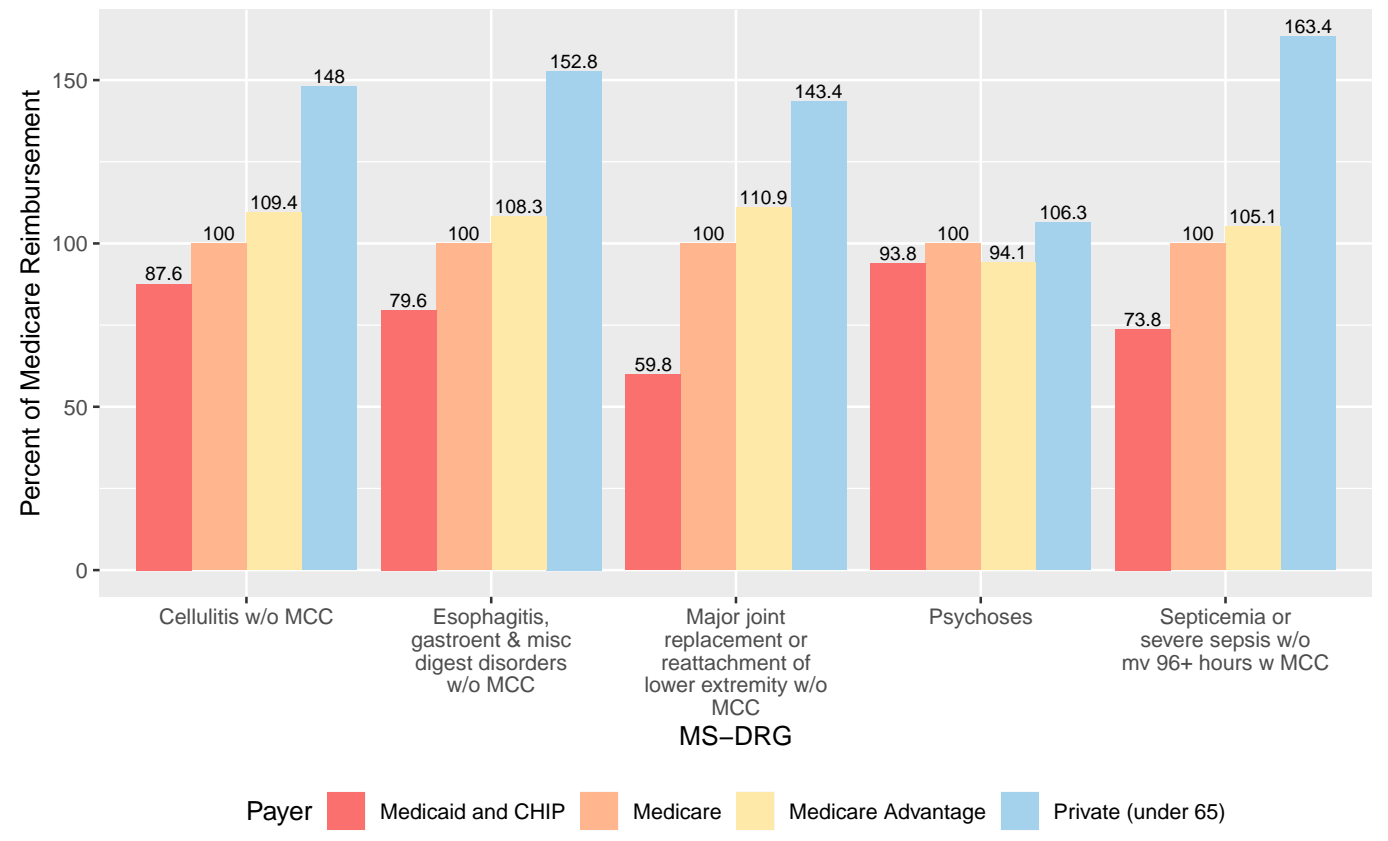

Figure 11: Prices as a Percent of Medicare Reimbursements - Bottom 55 Insurers

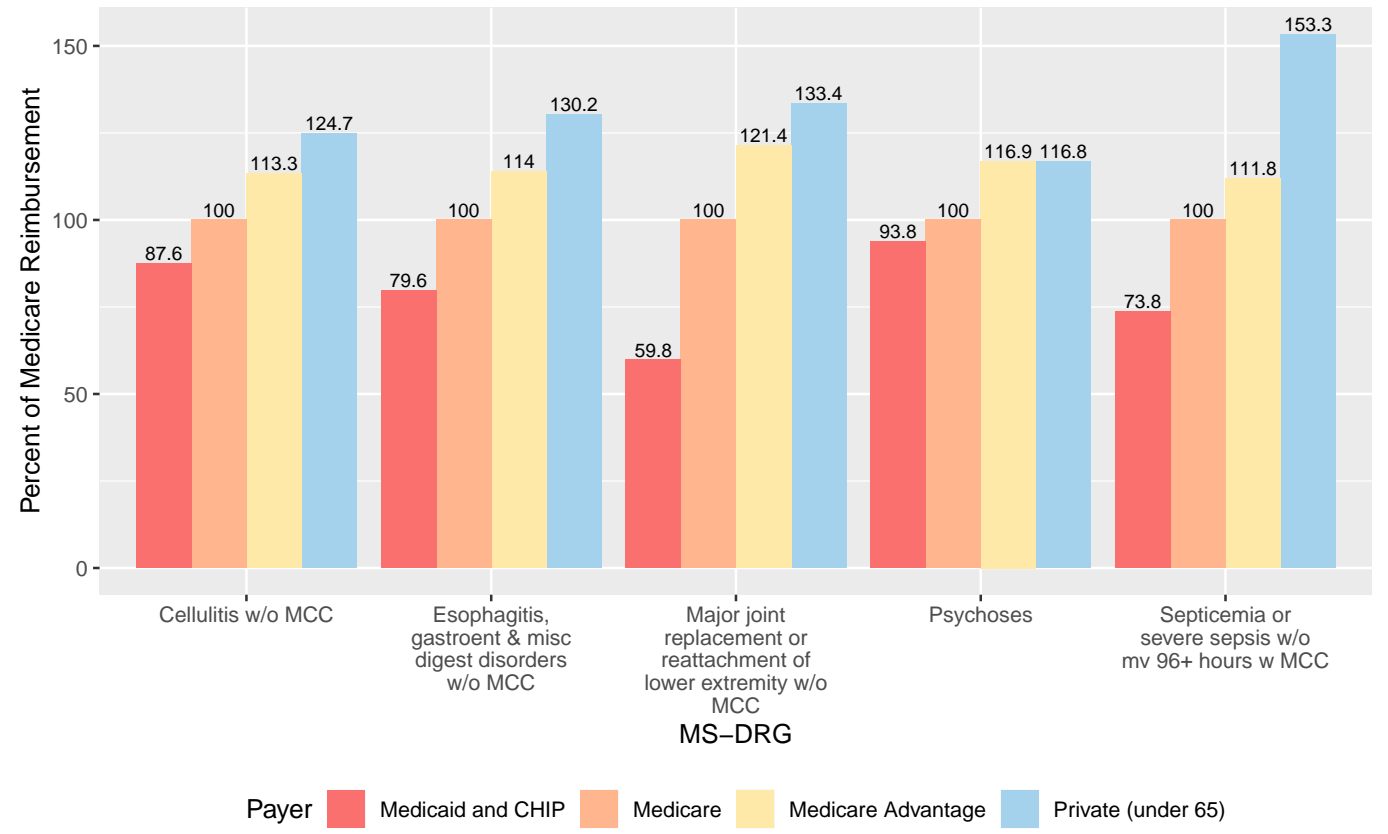




\section{E.1 Hospital- and Risk-Adjusted Negotiated Prices by Private-Payers}

In the following tables, Insurers 1-60 mask, at random, the names of the insurers we study. For a complete list of the insurers - and their subsidiaries - included in the analysis, see Appendix Table 17.

Table 18: Vaginal Delivery w/o Complicating Diagnoses

\begin{tabular}{|c|c|c|c|c|c|c|c|}
\hline \multirow[b]{3}{*}{ Payer } & \multicolumn{3}{|c|}{ Price } & \multicolumn{3}{|c|}{ Percent Discount from Charge } & \multirow[b]{3}{*}{$\mathrm{N}$} \\
\hline & \multicolumn{2}{|c|}{ Mean } & \multirow[b]{2}{*}{ Std. Dev. } & \multicolumn{2}{|c|}{ Mean } & \multirow[b]{2}{*}{ Std. Dev } & \\
\hline & Residuals & Adj. Price & & Residuals & Adj. Discount & & \\
\hline Insurer 58 & $2,557.40$ & $7,924.84$ & $3,390.08$ & -19.03 & 37.24 & 19.46 & 89 \\
\hline Insurer 29 & $1,221.17$ & $6,588.61$ & $2,599.46$ & -6.29 & 49.99 & 19.65 & 204 \\
\hline Insurer 16 & 938.72 & $6,306.16$ & $3,554.23$ & -5.47 & 50.81 & 19.86 & 1,729 \\
\hline Insurer 13 & 689.39 & $6,056.83$ & $1,739.28$ & -4.64 & 51.63 & 17.53 & 554 \\
\hline Insurer 47 & 537.11 & $5,904.55$ & $1,485.89$ & -2.09 & 54.19 & 17.43 & 2,746 \\
\hline Insurer 1 & 488.96 & $5,856.40$ & $2,992.38$ & -4.62 & 51.66 & 18.95 & 12,085 \\
\hline Insurer 21 & 477.73 & $5,845.17$ & $2,030.69$ & -7.90 & 48.37 & 26.04 & 955 \\
\hline Insurer 46 & 461.22 & $5,828.66$ & $1,283.03$ & -2.65 & 53.63 & 28.04 & 434 \\
\hline Insurer 30 & 413.78 & $5,781.21$ & $2,491.09$ & -4.21 & 52.06 & 28.84 & 21,748 \\
\hline Insurer 12 & 284.10 & $5,651.54$ & $1,274.51$ & -5.21 & 51.07 & 25.76 & 1,960 \\
\hline Insurer 40 & 248.79 & $5,616.23$ & $1,369.15$ & -3.15 & 53.12 & 15.87 & 4,647 \\
\hline Insurer 56 & 246.20 & $5,613.64$ & $1,431.99$ & -2.74 & 53.54 & 19.65 & 880 \\
\hline Insurer 37 & 240.29 & $5,607.73$ & $1,334.59$ & -2.39 & 53.89 & 15.08 & 1,554 \\
\hline Insurer 20 & 190.07 & $5,557.51$ & $3,486.34$ & 0.71 & 56.99 & 31.51 & 28,933 \\
\hline Insurer 35 & 166.66 & $5,534.10$ & $2,588.93$ & -1.05 & 55.23 & 17.35 & 2,041 \\
\hline Insurer 42 & 158.58 & $5,526.02$ & $1,184.27$ & -2.14 & 54.14 & 16.45 & 710 \\
\hline Insurer 23 & 123.43 & $5,490.87$ & $2,292.31$ & -0.37 & 55.91 & 18.31 & 110 \\
\hline Insurer 51 & 74.92 & $5,442.36$ & $1,459.23$ & -1.09 & 55.19 & 13.20 & 1,160 \\
\hline Insurer 54 & 24.16 & $5,391.60$ & $2,071.24$ & -0.17 & 56.11 & 18.86 & 2,255 \\
\hline Insurer 32 & 23.24 & $5,390.67$ & $2,847.12$ & -0.43 & 55.85 & 17.05 & 2,853 \\
\hline Insurer 44 & 10.04 & $5,377.48$ & $1,640.57$ & -0.63 & 55.65 & 23.34 & 291 \\
\hline Insurer 26 & -34.95 & $5,332.49$ & $2,508.84$ & -0.13 & 56.14 & 22.77 & 4,178 \\
\hline Insurer 3 & -129.52 & $5,237.92$ & $2,447.21$ & 0.42 & 56.70 & 18.83 & 35,166 \\
\hline Insurer 4 & -131.57 & $5,235.87$ & $1,417.03$ & 0.79 & 57.06 & 14.70 & 1,921 \\
\hline Insurer 19 & -132.48 & $5,234.96$ & $1,656.19$ & 1.20 & 57.48 & 17.17 & 2,648 \\
\hline Insurer 52 & -133.84 & $5,233.60$ & $2,311.26$ & 3.39 & 59.67 & 25.22 & 76 \\
\hline Insurer 41 & -141.58 & $5,225.85$ & $2,260.36$ & 0.53 & 56.81 & 18.10 & 13,410 \\
\hline Insurer 9 & -151.09 & $5,216.35$ & $1,074.64$ & 0.95 & 57.23 & 13.10 & 173 \\
\hline Insurer 61 & -186.04 & $5,181.40$ & $1,935.97$ & 2.26 & 58.53 & 19.44 & 6,449 \\
\hline Insurer 38 & -203.95 & $5,163.49$ & $1,729.96$ & 2.58 & 58.86 & 15.65 & 71 \\
\hline Insurer 28 & -318.77 & $5,048.67$ & $1,035.02$ & 4.48 & 60.75 & 12.23 & 175 \\
\hline Insurer 17 & -335.34 & $5,032.10$ & $3,821.13$ & 4.32 & 60.60 & 16.22 & 5,399 \\
\hline Insurer 53 & -432.88 & $4,934.56$ & $2,388.92$ & 6.82 & 63.09 & 17.93 & 2,115 \\
\hline Insurer 15 & -457.98 & $4,909.46$ & $2,171.04$ & 2.41 & 58.69 & 21.44 & 18,375 \\
\hline Insurer 24 & -484.36 & $4,883.07$ & $1,591.91$ & 5.01 & 61.29 & 13.67 & 2,881 \\
\hline Insurer 59 & -576.55 & $4,790.89$ & $2,732.33$ & 6.09 & 62.37 & 19.47 & 117 \\
\hline Insurer 45 & -587.09 & $4,780.35$ & $1,181.11$ & 6.96 & 63.24 & 21.08 & 593 \\
\hline Insurer 2 & -706.11 & $4,661.33$ & $1,363.07$ & 8.56 & 64.84 & 23.36 & 700 \\
\hline Insurer 18 & -743.01 & $4,624.43$ & $1,680.87$ & 6.39 & 62.67 & 13.44 & 1,603 \\
\hline Insurer 49 & -915.08 & $4,452.36$ & $1,771.42$ & 7.45 & 63.72 & 12.64 & 2,628 \\
\hline Insurer 50 & $-1,319.75$ & $4,047.69$ & $2,192.45$ & 9.41 & 65.69 & 12.28 & 1,103 \\
\hline Insurer 11 & $-2,226.09$ & $3,141.35$ & $1,682.43$ & 9.58 & 65.85 & 8.29 & 426 \\
\hline
\end{tabular}

Table 19: Cesarean Section w/o CC/MCC

\begin{tabular}{|c|c|c|c|c|c|c|c|}
\hline \multirow[b]{3}{*}{ Payer } & \multicolumn{3}{|c|}{ Price } & \multicolumn{3}{|c|}{ Percent Discount from Charge } & \multirow[b]{3}{*}{$\mathrm{N}$} \\
\hline & \multicolumn{2}{|c|}{ Mean } & \multirow[b]{2}{*}{ Std. Dev. } & \multicolumn{2}{|c|}{ Mean } & \multirow[b]{2}{*}{ Std. Dev } & \\
\hline & Residuals & Adj. Price & & Residuals & Adj. Discount & & \\
\hline Insurer 29 & $2,531.43$ & $10,598.06$ & $2,832.83$ & -10.50 & 49.14 & 15.53 & 83 \\
\hline Insurer 16 & $1,724.78$ & $9,791.41$ & $5,898.26$ & -5.30 & 54.33 & 18.00 & 419 \\
\hline Insurer 13 & $1,536.69$ & $9,603.32$ & $2,560.78$ & -8.47 & 51.17 & 16.86 & 131 \\
\hline Insurer 46 & $1,224.16$ & $9,290.79$ & $1,789.97$ & -11.66 & 47.97 & 20.43 & 194 \\
\hline Insurer 1 & $1,067.14$ & $9,133.76$ & $3,885.97$ & -5.18 & 54.45 & 15.68 & 5,627 \\
\hline Insurer 42 & 883.28 & $8,949.90$ & $1,990.87$ & -4.60 & 55.04 & 12.09 & 217 \\
\hline
\end{tabular}


Table 19: Cesarean Section w/o CC/MCC (continued)

\begin{tabular}{|c|c|c|c|c|c|c|c|}
\hline \multirow[b]{3}{*}{ Payer } & \multicolumn{3}{|c|}{ Price } & \multicolumn{3}{|c|}{ Percent Discount from Charge } & \multirow[b]{3}{*}{$\mathrm{N}$} \\
\hline & \multicolumn{2}{|c|}{ Mean } & \multirow[b]{2}{*}{ Std. Dev. } & \multicolumn{2}{|r|}{ Mean } & \multirow[b]{2}{*}{ Std. Dev } & \\
\hline & Residuals & Adj. Price & & Residuals & Adj. Discount & & \\
\hline Insurer 47 & 707.49 & $8,774.11$ & $1,941.35$ & -1.92 & 57.71 & 15.76 & 1,364 \\
\hline Insurer 12 & 505.91 & $8,572.54$ & $1,623.10$ & -5.70 & 53.93 & 21.82 & 790 \\
\hline Insurer 21 & 494.11 & $8,560.73$ & $2,153.78$ & -5.35 & 54.28 & 22.49 & 467 \\
\hline Insurer 30 & 470.58 & $8,537.21$ & $3,175.87$ & -3.57 & 56.06 & 47.78 & 9,678 \\
\hline Insurer 40 & 457.71 & $8,524.34$ & $2,715.82$ & -0.60 & 59.04 & 45.22 & 1,666 \\
\hline Insurer 32 & 446.89 & $8,513.52$ & $7,932.98$ & -1.26 & 58.37 & 11.61 & 1,391 \\
\hline Insurer 37 & 417.94 & $8,484.57$ & $1,784.90$ & -2.77 & 56.87 & 9.40 & 638 \\
\hline Insurer 51 & 334.78 & $8,401.40$ & $2,170.54$ & -2.60 & 57.04 & 12.11 & 439 \\
\hline Insurer 35 & 189.57 & $8,256.20$ & $1,569.13$ & -0.57 & 59.07 & 11.63 & 1,099 \\
\hline Insurer 19 & 122.47 & $8,189.10$ & $2,341.29$ & -0.96 & 58.67 & 13.57 & 1,065 \\
\hline Insurer 44 & 103.88 & $8,170.51$ & $1,834.84$ & -1.25 & 58.38 & 13.78 & 118 \\
\hline Insurer 24 & 79.92 & $8,146.54$ & $2,624.76$ & -0.62 & 59.02 & 12.44 & 1,806 \\
\hline Insurer 20 & -54.03 & $8,012.60$ & $3,852.42$ & 1.83 & 61.46 & 14.98 & 11,514 \\
\hline Insurer 56 & -54.39 & $8,012.24$ & $1,886.17$ & 0.44 & 60.07 & 14.26 & 231 \\
\hline Insurer 54 & -59.88 & $8,006.74$ & $3,297.94$ & -0.19 & 59.45 & 17.47 & 1,018 \\
\hline Insurer 26 & -88.20 & $7,978.42$ & $3,629.58$ & -0.26 & 59.37 & 21.73 & 1,710 \\
\hline Insurer 41 & -205.81 & $7,860.82$ & $2,643.62$ & 0.42 & 60.05 & 15.95 & 5,977 \\
\hline Insurer 17 & -233.79 & $7,832.84$ & $6,069.64$ & 2.98 & 62.61 & 13.09 & 2,279 \\
\hline Insurer 3 & -266.66 & $7,799.97$ & $3,349.32$ & 0.61 & 60.25 & 24.92 & 14,277 \\
\hline Insurer 15 & -337.05 & $7,729.58$ & $2,827.63$ & 1.16 & 60.79 & 9.40 & 8,416 \\
\hline Insurer 45 & -367.96 & 7,698.66 & $1,633.23$ & 2.69 & 62.32 & 14.29 & 142 \\
\hline Insurer 9 & -421.41 & $7,645.21$ & $1,558.72$ & 2.61 & 62.24 & 9.94 & 114 \\
\hline Insurer 28 & -438.73 & $7,627.89$ & $1,591.77$ & 3.85 & 63.49 & 10.59 & 59 \\
\hline Insurer 4 & -628.25 & $7,438.37$ & $2,083.34$ & 2.23 & 61.86 & 12.47 & 651 \\
\hline Insurer 61 & -683.68 & $7,382.94$ & $2,384.45$ & 4.86 & 64.49 & 14.80 & 2,449 \\
\hline Insurer 53 & -775.25 & $7,291.37$ & $2,485.20$ & 5.99 & 65.62 & 34.62 & 872 \\
\hline Insurer 2 & -869.39 & $7,197.23$ & $2,121.56$ & 8.57 & 68.20 & 22.68 & 278 \\
\hline Insurer 18 & $-1,163.87$ & $6,902.76$ & $1,622.27$ & 9.09 & 68.73 & 9.96 & 582 \\
\hline Insurer 49 & $-1,713.00$ & $6,353.62$ & $1,978.71$ & 9.10 & 68.74 & 11.57 & 924 \\
\hline Insurer 50 & $-1,888.85$ & $6,177.77$ & $2,129.07$ & 9.81 & 69.44 & 13.84 & 400 \\
\hline Insurer 11 & $-4,128.31$ & $3,938.31$ & $2,388.80$ & 12.58 & 72.21 & 7.07 & 193 \\
\hline
\end{tabular}

Table 20: Major Joint Replacement or Reattachment of Lower Extremity w/o MCC

\begin{tabular}{|c|c|c|c|c|c|c|c|c|}
\hline \multirow[b]{3}{*}{ Payer } & \multicolumn{3}{|c|}{ Price } & \multicolumn{4}{|c|}{ Percent Discount from Charge } & \multirow[b]{3}{*}{$\mathrm{N}$} \\
\hline & \multicolumn{2}{|c|}{ Mean } & \multirow[b]{2}{*}{ Std. Dev. } & \multicolumn{3}{|c|}{ Mean } & \multirow[b]{2}{*}{ Std. Dev } & \\
\hline & Residuals & Adj. Price & & Residuals & Adj. & Discount & & \\
\hline Insurer 2 & $4,198.25$ & $27,786.28$ & $5,855.70$ & -14.32 & & 38.66 & 22.93 & 213 \\
\hline Insurer 1 & $3,591.56$ & $27,179.60$ & $10,666.88$ & -4.91 & & 48.07 & 17.69 & 3,404 \\
\hline Insurer 4 & $2,909.08$ & $26,497.12$ & $5,238.84$ & -9.22 & & 43.76 & 14.18 & 743 \\
\hline Insurer 13 & $2,388.54$ & $25,976.57$ & $6,401.91$ & -7.09 & & 45.89 & 19.31 & 82 \\
\hline Insurer 30 & $2,291.69$ & $25,879.73$ & $9,225.60$ & -4.42 & & 48.56 & 17.07 & 5,411 \\
\hline Insurer 47 & $2,095.92$ & $25,683.96$ & $5,283.01$ & -4.55 & & 48.43 & 11.48 & 1,647 \\
\hline Insurer 19 & $1,938.39$ & $25,526.43$ & $5,680.97$ & -4.44 & & 48.54 & 14.59 & 689 \\
\hline Insurer 41 & $1,350.78$ & $24,938.82$ & $7,649.60$ & -2.54 & & 50.44 & 14.26 & 4,416 \\
\hline Insurer 42 & $1,288.81$ & $24,876.85$ & $4,059.48$ & -1.92 & & 51.06 & 10.10 & 161 \\
\hline Insurer 51 & $1,181.56$ & $24,769.60$ & $5,420.12$ & -2.56 & & 50.42 & 9.57 & 356 \\
\hline Insurer 40 & $1,134.37$ & $24,722.41$ & $4,958.97$ & -2.51 & & 50.47 & 22.83 & 787 \\
\hline Insurer 16 & $1,116.55$ & $24,704.59$ & $7,379.41$ & -6.36 & & 46.62 & 18.04 & 108 \\
\hline Insurer 12 & 393.99 & $23,982.03$ & $4,430.45$ & -1.60 & & 51.38 & 19.03 & 530 \\
\hline Insurer 61 & 144.48 & $23,732.52$ & $6,360.69$ & -0.16 & & 52.82 & 15.74 & 2,766 \\
\hline Insurer 37 & -44.94 & $23,543.10$ & $4,508.34$ & -0.17 & & 52.81 & 8.29 & 635 \\
\hline Insurer 21 & -145.01 & $23,443.03$ & $4,989.29$ & -1.37 & & 51.61 & 20.03 & 329 \\
\hline Insurer 56 & -322.24 & $23,265.80$ & $4,814.28$ & 1.53 & & 54.51 & 15.21 & 197 \\
\hline Insurer 53 & -359.34 & $23,228.70$ & $8,056.13$ & 1.45 & & 54.43 & 13.91 & 834 \\
\hline Insurer 32 & -503.47 & $23,084.56$ & $11,038.77$ & 3.95 & & 56.92 & 16.60 & 547 \\
\hline Insurer 35 & -567.35 & $23,020.68$ & $5,212.38$ & 1.54 & & 54.52 & 9.75 & 593 \\
\hline Insurer 20 & -663.92 & $22,924.11$ & $8,878.84$ & 1.79 & & 54.77 & 14.86 & 8,516 \\
\hline Insurer 3 & -682.58 & $22,905.46$ & $9,052.46$ & 1.23 & & 54.21 & 30.76 & 8,152 \\
\hline Insurer 15 & $-1,075.43$ & $22,512.61$ & $5,342.92$ & 1.08 & & 54.06 & 30.25 & 1,846 \\
\hline Insurer 45 & $-1,139.32$ & $22,448.72$ & $3,130.19$ & 3.38 & & 56.36 & 13.57 & 167 \\
\hline
\end{tabular}


Table 20: Major Joint Replacement or Reattachment of Lower Extremity w/o MCC (continued)

\begin{tabular}{|c|c|c|c|c|c|c|c|}
\hline \multirow[b]{3}{*}{ Payer } & \multicolumn{3}{|c|}{ Price } & \multicolumn{3}{|c|}{ Percent Discount from Charge } & \multirow[b]{3}{*}{$\mathrm{N}$} \\
\hline & \multicolumn{2}{|c|}{ Mean } & \multirow[b]{2}{*}{ Std. Dev. } & \multicolumn{2}{|c|}{ Mean } & \multirow[b]{2}{*}{ Std. Dev } & \\
\hline & Residuals & Adj. Price & & Residuals & Adj. Discount & & \\
\hline Insurer 33 & $-1,602.03$ & $21,986.01$ & $6,468.17$ & 2.84 & 55.82 & 9.50 & 93 \\
\hline Insurer 26 & $-1,704.06$ & $21,883.97$ & $5,901.67$ & 3.44 & 56.42 & 12.48 & 2,330 \\
\hline Insurer 44 & $-1,767.84$ & $21,820.20$ & $3,590.54$ & 4.34 & 57.32 & 8.31 & 161 \\
\hline Insurer 29 & $-2,061.20$ & $21,526.84$ & $13,725.74$ & 4.95 & 57.93 & 27.77 & 54 \\
\hline Insurer 24 & $-2,172.38$ & $21,415.66$ & $5,325.83$ & 3.66 & 56.64 & 8.79 & 1,892 \\
\hline Insurer 54 & $-4,140.69$ & $19,447.35$ & $11,894.92$ & 7.90 & 60.88 & 27.30 & 1,887 \\
\hline Insurer 17 & $-4,506.37$ & $19,081.67$ & $12,394.97$ & 5.22 & 58.20 & 10.64 & 1,192 \\
\hline Insurer 11 & $-5,118.84$ & $18,469.20$ & $8,629.51$ & 10.43 & 63.41 & 16.11 & 120 \\
\hline Insurer 49 & $-5,292.07$ & $18,295.97$ & $7,575.93$ & 9.67 & 62.65 & 24.29 & 102 \\
\hline Insurer 46 & $-6,779.57$ & $16,808.47$ & $4,707.35$ & 20.03 & 73.01 & 15.34 & 141 \\
\hline Insurer 50 & $-6,856.93$ & $16,731.11$ & $6,876.61$ & 10.68 & 63.66 & 10.33 & 86 \\
\hline Insurer 6 & $-8,215.15$ & $15,372.89$ & $10,403.25$ & 12.85 & 65.83 & 18.53 & 98 \\
\hline Insurer 18 & $-11,822.51$ & $11,765.53$ & $7,512.23$ & 19.68 & 72.66 & 16.95 & 88 \\
\hline
\end{tabular}

Table 21: Cesarean Section w CC/MCC

\begin{tabular}{|c|c|c|c|c|c|c|c|c|}
\hline \multirow[b]{3}{*}{ Payer } & \multicolumn{3}{|c|}{ Price } & \multicolumn{4}{|c|}{ Percent Discount from Charge } & \multirow[b]{3}{*}{$\mathrm{N}$} \\
\hline & \multicolumn{2}{|c|}{ Mean } & \multirow[b]{2}{*}{ Std. Dev. } & \multicolumn{3}{|c|}{ Mean } & \multirow[b]{2}{*}{ Std. Dev } & \\
\hline & Residuals & Adj. Price & & Residuals & Adj. & Discount & & \\
\hline Insurer 16 & $2,947.92$ & $13,754.28$ & $13,919.87$ & -4.94 & & 49.76 & 21.34 & 344 \\
\hline Insurer 51 & $1,689.24$ & $12,495.60$ & $6,841.95$ & -8.97 & & 45.73 & 17.34 & 407 \\
\hline Insurer 13 & $1,669.47$ & $12,475.82$ & $3,394.22$ & -3.79 & & 50.91 & 17.79 & 175 \\
\hline Insurer 47 & $1,475.83$ & $12,282.18$ & $5,581.54$ & -5.33 & & 49.37 & 18.87 & 907 \\
\hline Insurer 21 & $1,320.13$ & $12,126.49$ & $13,163.90$ & -5.09 & & 49.61 & 26.19 & 204 \\
\hline Insurer 1 & $1,280.62$ & $12,086.97$ & $10,003.82$ & -2.88 & & 51.82 & 78.98 & 3,122 \\
\hline Insurer 42 & $1,024.46$ & $11,830.81$ & $2,884.96$ & -5.87 & & 48.83 & 17.03 & 104 \\
\hline Insurer 32 & 937.89 & $11,744.25$ & $14,105.55$ & -0.32 & & 54.38 & 14.42 & 597 \\
\hline Insurer 12 & 796.84 & $11,603.19$ & $2,931.39$ & -6.08 & & 48.62 & 26.48 & 265 \\
\hline Insurer 4 & 757.23 & $11,563.58$ & $2,930.01$ & -3.00 & & 51.70 & 12.81 & 395 \\
\hline Insurer 37 & 693.89 & $11,500.24$ & $3,685.35$ & -3.64 & & 51.06 & 14.61 & 306 \\
\hline Insurer 24 & 607.98 & $11,414.34$ & $5,008.88$ & -2.93 & & 51.77 & 16.65 & 730 \\
\hline Insurer 30 & 556.38 & $11,362.74$ & $7,923.13$ & -2.23 & & 52.47 & 82.05 & 5,370 \\
\hline Insurer 40 & 555.51 & $11,361.86$ & $5,759.50$ & -4.53 & & 50.17 & 73.22 & 1,218 \\
\hline Insurer 35 & 324.09 & $11,130.44$ & $4,125.14$ & -1.27 & & 53.43 & 16.74 & 510 \\
\hline Insurer 19 & 255.90 & $11,062.25$ & $5,165.75$ & -0.49 & & 54.21 & 17.31 & 893 \\
\hline Insurer 44 & 81.32 & $10,887.67$ & $2,853.34$ & -3.50 & & 51.20 & 46.08 & 59 \\
\hline Insurer 20 & -26.45 & $10,779.90$ & $11,024.82$ & 2.59 & & 57.29 & 27.58 & 6,756 \\
\hline Insurer 41 & -166.78 & $10,639.57$ & $9,820.60$ & 2.75 & & 57.45 & 109.68 & 3,755 \\
\hline Insurer 2 & -226.60 & $10,579.76$ & $2,718.70$ & 0.14 & & 54.84 & 27.95 & 81 \\
\hline Insurer 54 & -267.83 & $10,538.52$ & $10,490.19$ & 5.02 & & 59.72 & 116.32 & 657 \\
\hline Insurer 15 & -282.63 & $10,523.72$ & $5,179.66$ & 1.05 & & 55.75 & 10.26 & 4,581 \\
\hline Insurer 26 & -397.24 & $10,409.11$ & $6,830.31$ & -0.33 & & 54.37 & 20.18 & 1,285 \\
\hline Insurer 46 & -425.94 & $10,380.41$ & $2,319.74$ & 4.76 & & 59.46 & 31.36 & 71 \\
\hline Insurer 3 & -426.58 & $10,379.77$ & $35,202.02$ & -3.09 & & 51.61 & 595.58 & 8,415 \\
\hline Insurer 53 & -526.38 & $10,279.97$ & $5,623.73$ & 5.38 & & 60.08 & 18.28 & 490 \\
\hline Insurer 61 & -526.51 & $10,279.84$ & $5,363.14$ & 2.59 & & 57.29 & 24.92 & 1,774 \\
\hline Insurer 56 & -691.85 & $10,114.50$ & $1,992.46$ & 4.49 & & 59.19 & 12.08 & 95 \\
\hline Insurer 17 & $-1,018.63$ & $9,787.72$ & $15,006.35$ & 7.22 & & 61.92 & 23.19 & 1,120 \\
\hline Insurer 49 & $-1,585.75$ & $9,220.60$ & $6,431.96$ & 8.21 & & 62.91 & 15.69 & 820 \\
\hline Insurer 18 & $-2,847.80$ & $7,958.55$ & $7,317.81$ & 17.85 & & 72.55 & 15.22 & 498 \\
\hline Insurer 50 & $-4,521.60$ & $6,284.76$ & $6,161.24$ & 13.65 & & 68.35 & 13.50 & 389 \\
\hline Insurer 11 & $-6,127.42$ & $4,678.93$ & $2,496.59$ & 13.23 & & 67.93 & 7.29 & 81 \\
\hline
\end{tabular}


Table 22: Psychoses

\begin{tabular}{|c|c|c|c|c|c|c|c|c|}
\hline \multirow[b]{3}{*}{ Payer } & \multicolumn{3}{|c|}{ Price } & \multicolumn{4}{|c|}{ Percent Discount from Charge } & \multirow[b]{3}{*}{$\mathrm{N}$} \\
\hline & \multicolumn{2}{|c|}{ Mean } & \multirow[b]{2}{*}{ Std. Dev. } & \multicolumn{3}{|c|}{ Mean } & \multirow[b]{2}{*}{ Std. Dev } & \\
\hline & Residuals & Adj. Price & & Residuals & Adj. & Discount & & \\
\hline Insurer 24 & $2,917.01$ & $8,923.19$ & $7,209.27$ & -18.93 & & 36.37 & 25.06 & 559 \\
\hline Insurer 13 & $2,695.34$ & $8,701.52$ & $6,341.58$ & -20.53 & & 34.77 & 31.95 & 201 \\
\hline Insurer 30 & $1,021.55$ & $7,027.73$ & $6,061.38$ & -6.61 & & 48.69 & 35.88 & 3,579 \\
\hline Insurer 12 & 962.24 & $6,968.42$ & $2,933.69$ & -13.27 & & 42.02 & 36.36 & 1,154 \\
\hline Insurer 32 & 812.93 & $6,819.11$ & $9,160.66$ & -0.15 & & 55.15 & 18.13 & 175 \\
\hline Insurer 35 & 792.81 & $6,798.99$ & $5,447.39$ & -11.39 & & 43.90 & 53.25 & 515 \\
\hline Insurer 15 & 550.31 & $6,556.49$ & $4,188.37$ & -1.42 & & 53.87 & 11.39 & 2,549 \\
\hline Insurer 44 & 501.65 & $6,507.83$ & $2,246.61$ & -8.37 & & 46.93 & 42.48 & 674 \\
\hline Insurer 19 & 332.79 & $6,338.97$ & $4,265.64$ & -1.23 & & 54.06 & 107.86 & 883 \\
\hline Insurer 16 & 324.85 & $6,331.03$ & $3,320.16$ & -1.64 & & 53.66 & 11.89 & 1,919 \\
\hline Insurer 51 & 271.58 & $6,277.76$ & $3,340.69$ & -4.28 & & 51.02 & 20.88 & 543 \\
\hline Insurer 41 & 185.13 & $6,191.31$ & $3,127.50$ & -3.25 & & 52.05 & 32.47 & 2,682 \\
\hline Insurer 26 & 139.62 & $6,145.80$ & $3,057.76$ & -7.54 & & 47.76 & 49.65 & 1,357 \\
\hline Insurer 61 & 138.77 & $6,144.95$ & $7,033.08$ & -2.40 & & 52.90 & 35.07 & 1,805 \\
\hline Insurer 17 & 65.10 & $6,071.28$ & $4,920.12$ & -3.39 & & 51.90 & 14.92 & 517 \\
\hline Insurer 20 & 47.23 & $6,053.41$ & $6,687.59$ & 0.81 & & 56.11 & 27.05 & 5,474 \\
\hline Insurer 4 & -18.18 & $5,988.00$ & $11,233.61$ & 0.40 & & 55.69 & 21.33 & 95 \\
\hline Insurer 53 & -45.38 & $5,960.80$ & $4,654.74$ & 8.31 & & 63.60 & 28.94 & 158 \\
\hline Insurer 47 & -239.65 & $5,766.53$ & $3,809.43$ & 4.77 & & 60.07 & 16.74 & 380 \\
\hline Insurer 1 & -261.50 & $5,744.68$ & $5,257.46$ & 3.24 & & 58.54 & 24.25 & 2,578 \\
\hline Insurer 50 & -591.94 & $5,414.24$ & $3,542.65$ & -3.74 & & 51.56 & 26.71 & 177 \\
\hline Insurer 21 & -634.63 & $5,371.55$ & $2,967.99$ & 5.43 & & 60.73 & 13.47 & 484 \\
\hline Insurer 18 & -692.54 & $5,313.64$ & $3,862.42$ & -0.71 & & 54.59 & 47.78 & 244 \\
\hline Insurer 49 & -702.23 & $5,303.94$ & $3,429.02$ & 0.90 & & 56.19 & 28.39 & 588 \\
\hline Insurer 3 & $-1,002.98$ & $5,003.20$ & $3,183.45$ & 8.56 & & 63.85 & 19.00 & 7,445 \\
\hline Insurer 6 & $-1,098.25$ & $4,907.92$ & $3,157.84$ & 10.54 & & 65.83 & 26.44 & 279 \\
\hline Insurer 54 & $-1,195.32$ & $4,810.86$ & $4,940.73$ & 8.75 & & 64.05 & 27.01 & 1,423 \\
\hline Insurer 46 & $-1,417.87$ & $4,588.31$ & $1,979.35$ & 15.59 & & 70.88 & 18.87 & 158 \\
\hline
\end{tabular}


Table 23: Pearson Correlation in Inpatient Risk-Adj. Residuals between Types of Coverage by MS-DRG

(Observations at provider-payer level)

\begin{tabular}{|c|c|c|c|}
\hline & $\begin{array}{c}\text { Private } \\
\text { (under 65) }\end{array}$ & Medicare & $\begin{array}{l}\text { Medicare } \\
\text { Advantage }\end{array}$ \\
\hline \multicolumn{4}{|c|}{ Esophagitis, gastroent and misc digest disorders w/o $M C C$} \\
\hline Medicare & $0.32 * * *$ & & \\
\hline Medicare Advantage & $0.62^{* * *}$ & $0.54^{* * *}$ & \\
\hline Medicaid and CHIP & $0.64^{* * *}$ & $0.34^{* * *}$ & $0.46^{* * *}$ \\
\hline \multicolumn{4}{|c|}{ Major joint replacement or reattachment of lower extremity w/o MCC } \\
\hline Medicare & $0.13^{*}$ & & \\
\hline Medicare Advantage & $0.64^{* * *}$ & $0.45^{* * *}$ & \\
\hline Medicaid and CHIP & $0.26^{* *}$ & -0.11 & 0.18 \\
\hline \multicolumn{4}{|l|}{ Cellulitis w/o $M C C$} \\
\hline Medicare & $0.21^{* * *}$ & & \\
\hline Medicare Advantage & $0.60^{* * *}$ & $0.63^{* * *}$ & \\
\hline Medicaid and CHIP & $0.57^{* * *}$ & $0.21^{* *}$ & $0.32^{* *}$ \\
\hline \multicolumn{4}{|c|}{ Septicemia or severe sepsis w/o mv $96+$ hours $w M C C$} \\
\hline Medicare & $0.51^{* * *}$ & & \\
\hline Medicare Advantage & $0.67 * * *$ & $0.71 * * *$ & \\
\hline Medicaid and CHIP & $0.49 * * *$ & $0.26^{* * *}$ & $0.42^{* * *}$ \\
\hline \multicolumn{4}{|l|}{ Psychoses } \\
\hline Medicare & $0.56^{* * *}$ & & \\
\hline Medicare Advantage & $0.66^{* * *}$ & $0.50 * * *$ & \\
\hline Medicaid and CHIP & $0.27^{* *}$ & $0.22 *$ & $0.36^{*}$ \\
\hline
\end{tabular}

Notes: ${ }^{*} \mathrm{p}<0.1 ;{ }^{* *} \mathrm{p}<0.05 ;{ }^{* * *} \mathrm{p}<0.01$. The $\mathrm{p}$-values are reported for a two-tailed test. A unit of analysis is a provider-payer. Price residuals are obtained by equation (1), which removes variation in prices due to differences in observable patient severity and year-specific hospital effects. 
Table 24: Pearson Correlation in Inpatient Risk-Adj. Residuals between Private Payers by MSDRG

(Observations at provider-payer level)

\begin{tabular}{|c|c|c|c|c|}
\hline & Insurer A & Insurer B & Insurer $\mathrm{C}$ & Insurer D \\
\hline \multicolumn{5}{|c|}{ Vaginal delivery $w / o$ complicating diagnoses } \\
\hline Insurer B & $0.56^{* * *}$ & & & \\
\hline Insurer $\mathrm{C}$ & $0.61 * * *$ & $0.63^{* * *}$ & & \\
\hline Insurer D & $0.58^{* * *}$ & $0.60^{* * *}$ & $0.61^{* * *}$ & \\
\hline Insurer $\mathrm{E}$ & $0.62^{* * *}$ & -0.57 & $0.63^{* * *}$ & $0.70^{* * *}$ \\
\hline \multicolumn{5}{|c|}{ Cesarean section $w / o C C / M C C$} \\
\hline Insurer B & $0.36^{* *}$ & & & \\
\hline Insurer $\mathrm{C}$ & $0.47^{* * *}$ & $0.45^{* * *}$ & & \\
\hline Insurer D & $0.72^{* * *}$ & 0.26 & $0.66^{* * *}$ & \\
\hline Insurer E & $0.64^{* *}$ & 0.55 & $0.85^{* * *}$ & $0.85^{* * *}$ \\
\hline \multicolumn{5}{|c|}{ Major joint replacement or reattachment of lower extremity $w / o$} \\
\hline Insurer B & $0.34^{* *}$ & & & \\
\hline Insurer $\mathrm{C}$ & $0.65^{* * *}$ & 0.07 & & \\
\hline Insurer D & $0.55^{* * *}$ & 0.29 & $0.53^{* * *}$ & \\
\hline Insurer $\mathrm{E}$ & 0.04 & 0.08 & $0.82^{* * *}$ & 0.39 \\
\hline \multicolumn{5}{|c|}{ Cesarean section $w C C / M C C$} \\
\hline Insurer B & $0.39^{* *}$ & & & \\
\hline Insurer $\mathrm{C}$ & $0.22^{*}$ & $0.54^{* * *}$ & & \\
\hline Insurer D & 0.01 & 0.04 & $0.63^{* * *}$ & \\
\hline Insurer E & 0.04 & $0.94^{* *}$ & $0.76^{* * *}$ & $0.75^{* *}$ \\
\hline \multicolumn{5}{|l|}{ Psychoses } \\
\hline Insurer B & $0.42 *$ & & & \\
\hline Insurer $\mathrm{C}$ & $0.48^{* * *}$ & $0.85^{* * *}$ & & \\
\hline Insurer D & $0.33^{*}$ & -0.45 & 0.10 & \\
\hline Insurer $\mathrm{E}$ & 0.19 & -0.20 & -0.12 & -0.09 \\
\hline \multicolumn{5}{|c|}{ Esophagitis, gastroent and misc digest disorders w/o $M C C$} \\
\hline Insurer B & $0.82^{* * *}$ & & & \\
\hline Insurer $\mathrm{C}$ & $0.46^{* * *}$ & $0.64^{* * *}$ & & \\
\hline Insurer D & $0.57^{* * *}$ & $0.63^{* *}$ & $0.81^{* * *}$ & \\
\hline Insurer E & $0.44^{*}$ & -0.63 & $0.67^{* *}$ & $0.72^{* *}$ \\
\hline
\end{tabular}

\begin{tabular}{|c|c|c|c|c|}
\hline \multicolumn{5}{|c|}{ Vaginal delivery $w$ complicating diagnoses } \\
\hline Insurer B & 0.23 & & & \\
\hline Insurer $\mathrm{C}$ & $0.74^{* * *}$ & $0.60^{* * *}$ & & \\
\hline Insurer D & $0.61 * * *$ & 0.36 & $0.77^{* * *}$ & \\
\hline Insurer $\mathrm{E}$ & -0.27 & $0.97^{* *}$ & $0.81^{* *}$ & 0.79 \\
\hline \multicolumn{5}{|c|}{ Uterine and adnexa proc for non-malignancy $w / o C C / M C C$} \\
\hline Insurer B & $0.48^{* *}$ & & & \\
\hline Insurer $\mathrm{C}$ & $0.39^{* *}$ & $0.67 * * *$ & & \\
\hline
\end{tabular}




\begin{tabular}{ccccc}
\hline & Insurer A & Insurer B & Insurer C & Insurer D \\
\hline Insurer D & 0.08 & -0.55 & $0.74^{* * *}$ & \\
Insurer E & 0.33 & 0.66 & $0.93^{* * *}$ & $0.89^{* * *}$ \\
\hline Cellulitis w/o & MCC & & & \\
Insurer B & $0.74^{* * *}$ & & & \\
Insurer C & 0.16 & $0.74^{*}$ & & \\
Insurer D & $0.57^{* *}$ & 0.64 & $0.83^{* * *}$ & \\
Insurer E & 0.47 & - & 0.62 & 0.94 \\
\hline
\end{tabular}

Perc cardiovasc proc $w$ drug-eluting stent $w / o$ MCC

Insurer B $\quad 0.08$

Insurer $\mathrm{C} \quad 0.76^{* * *} \quad 0.28$

$\begin{array}{llll}\text { Insurer D } & 0.57^{* *} & 0.99^{*} & 0.62^{* *}\end{array}$

$\begin{array}{llll}\text { Insurer } \mathrm{E} & -0.18 & 0.45 & 0.18\end{array}$

$O . R$. procedures for obesity $w / o C C / M C C$

Insurer B 0.33

Insurer C $\quad 0.57^{* * *} \quad-0.25$

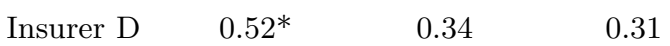

$\begin{array}{lllll}\text { Insurer } \mathrm{E} & 0.51 & - & 0.81^{*} & 0.65\end{array}$

Notes: ${ }^{*} \mathrm{p}<0.1 ;{ }^{* *} \mathrm{p}<0.05 ;{ }^{* * *} \mathrm{p}<0.01$. The $\mathrm{p}$-values are reported for a two-tailed test. A unit of analysis is a provider-payer. Price residuals are obtained by equation (1), which removes variation in prices due to differences in observable patient severity and year-specific hospital effects. Insurers A-E mask the names of the five largest U.S. private insurers (Aetna, Anthem, Cigna, Humana, and UnitedHealthcare). 
Table 25: Relationship between Inpatient Prices and Insurer's Market Share - Robustness to Medical Classification Code Specificity

\begin{tabular}{|c|c|c|c|c|}
\hline \multirow[b]{3}{*}{ Panel A } & \multicolumn{4}{|c|}{ Dependent variable: } \\
\hline & \multicolumn{2}{|c|}{ Price } & \multicolumn{2}{|c|}{$\log$ (Price) } \\
\hline & $(1)$ & $(2)$ & $(3)$ & $(4)$ \\
\hline Insurer's Market Share & $\begin{array}{c}-72.360^{* * *} \\
(17.486)\end{array}$ & $\begin{array}{c}-81.478^{* * *} \\
(19.769)\end{array}$ & $\begin{array}{c}-0.005^{* *} \\
(0.002)\end{array}$ & $\begin{array}{c}-0.006^{* * *} \\
(0.002)\end{array}$ \\
\hline Age & $\begin{array}{c}2.937 \\
(6.511)\end{array}$ & $\begin{array}{c}5.316 \\
(3.972)\end{array}$ & $\begin{array}{c}0.003^{* * *} \\
(0.001)\end{array}$ & $\begin{array}{l}0.003^{* * *} \\
(0.0004)\end{array}$ \\
\hline Male & $\begin{array}{c}228.526^{* * *} \\
(67.682)\end{array}$ & $\begin{array}{c}203.912^{* * *} \\
(61.057)\end{array}$ & $\begin{array}{c}0.005 \\
(0.005)\end{array}$ & $\begin{array}{c}0.002 \\
(0.004)\end{array}$ \\
\hline Length of Stay & $\begin{array}{c}1,229.932^{* * *} \\
\quad(167.579)\end{array}$ & $\begin{array}{c}1,223.609^{* * *} \\
(168.932)\end{array}$ & $\begin{array}{c}0.066^{* * *} \\
(0.008)\end{array}$ & $\begin{array}{c}0.065^{* * *} \\
(0.008)\end{array}$ \\
\hline Charlson comorbidity dummies & Yes & Yes & Yes & Yes \\
\hline ICD-9/10 fixed effects & Yes & Yes & Yes & Yes \\
\hline Year fixed effects & Yes & Yes & Yes & Yes \\
\hline Provider fixed effects & No & Yes & No & Yes \\
\hline Observations & 496,737 & 496,737 & 496,737 & 496,737 \\
\hline $\mathrm{R}^{2}$ & 0.471 & 0.512 & 0.495 & 0.579 \\
\hline \multirow[t]{2}{*}{ Adjusted $\mathrm{R}^{2}$} & 0.468 & 0.509 & 0.492 & 0.577 \\
\hline & \multicolumn{4}{|c|}{ Dependent variable: } \\
\hline Panel B & \multicolumn{2}{|c|}{ Risk-Adj. Price } & \multicolumn{2}{|c|}{$\log ($ Risk-Adj. Price $)$} \\
\hline Insurer's Market Share & $\begin{array}{c}-72.302^{* * *} \\
(17.185)\end{array}$ & $\begin{array}{c}-81.823^{* * *} \\
(19.487)\end{array}$ & $\begin{array}{c}-0.005^{* * *} \\
(0.002)\end{array}$ & $\begin{array}{c}-0.007^{\text {*** }} \\
(0.002)\end{array}$ \\
\hline ICD-9/10 fixed effects & Yes & Yes & Yes & Yes \\
\hline Year fixed effects & Yes & Yes & Yes & Yes \\
\hline Provider fixed effects & No & Yes & No & Yes \\
\hline Observations & 496,737 & 496,737 & 488,684 & 488,684 \\
\hline $\mathrm{R}^{2}$ & 0.415 & 0.461 & 0.445 & 0.537 \\
\hline Adjusted $R^{2}$ & 0.411 & 0.457 & 0.441 & 0.534 \\
\hline
\end{tabular}

Note:

${ }^{*} \mathrm{p}<0.1 ;{ }^{* *} \mathrm{p}<0.05 ;{ }^{* * *} \mathrm{p}<0.01$ 
Table 26: 25 Most Common MS-DRGs for Inpatient Visits

\begin{tabular}{|c|c|c|c|c|c|}
\hline \multicolumn{2}{|l|}{ All Patients } & \multicolumn{2}{|l|}{ TM and MA Patients } & \multicolumn{2}{|l|}{ Private (under 65) patients } \\
\hline & $\mathrm{N}$ & & $\mathrm{N}$ & & $\mathrm{N}$ \\
\hline Normal newborn & $1,566,635$ & $\begin{array}{l}\text { Major joint replacement or reattachment } \\
\text { of lower extremity w/o MCC }\end{array}$ & 195,754 & Normal newborn & 484,298 \\
\hline $\begin{array}{l}\text { Vaginal delivery w/o complicating } \\
\text { diagnoses }\end{array}$ & $1,447,989$ & $\begin{array}{l}\text { Septicemia or severe sepsis w/o mv } 96+ \\
\text { hours w MCC }\end{array}$ & 136,247 & $\begin{array}{l}\text { Vaginal delivery w/o complicating } \\
\text { diagnoses }\end{array}$ & 474,276 \\
\hline $\begin{array}{l}\text { Major joint replacement or reattachment } \\
\text { of lower extremity w/o MCC }\end{array}$ & 639,975 & Heart failure \& shock w MCC & 94,257 & Cesarean section w/o CC/MCC & 197,940 \\
\hline Psychoses & 603,193 & $\begin{array}{l}\text { Esophagitis, gastroent \& misc digest } \\
\text { disorders w/o MCC }\end{array}$ & 88,524 & Neonate w other significant problems & 132,441 \\
\hline Cesarean section w/o CC/MCC & 559,804 & Heart failure \& shock w CC & 87,435 & Cesarean section w $\mathrm{CC} / \mathrm{MCC}$ & 121,419 \\
\hline Neonate w other significant problems & 463,049 & Psychoses & 86,657 & $\begin{array}{l}\text { Major joint replacement or reattachment } \\
\text { of lower extremity w/o MCC }\end{array}$ & 119,673 \\
\hline $\begin{array}{l}\text { Esophagitis, gastroent \& misc digest } \\
\text { disorders w/o MCC }\end{array}$ & 446,179 & $\begin{array}{l}\text { Kidney \& urinary tract infections w/o } \\
\text { MCC }\end{array}$ & 70,649 & Psychoses & 99,718 \\
\hline $\begin{array}{l}\text { Septicemia or severe sepsis w/o mv } 96+ \\
\text { hours w MCC }\end{array}$ & 385,411 & Rehabilitation w $\mathrm{CC} / \mathrm{MCC}$ & 65,673 & $\begin{array}{l}\text { Esophagitis, gastroent \& misc digest } \\
\text { disorders w/o MCC }\end{array}$ & 89,371 \\
\hline Cesarean section w $\mathrm{CC} / \mathrm{MCC}$ & 359,725 & Renal failure w CC & 64,879 & $\begin{array}{l}\text { Vaginal delivery w complicating } \\
\text { diagnoses }\end{array}$ & 77,617 \\
\hline Cellulitis w/o MCC & 275,122 & Simple pneumonia \& pleurisy w CC & 62,452 & $\begin{array}{l}\text { Uterine \& adnexa proc for } \\
\text { non-malignancy w/o CC/MCC }\end{array}$ & 66,028 \\
\hline $\begin{array}{l}\text { Vaginal delivery w complicating } \\
\text { diagnoses }\end{array}$ & 250,247 & G.I. hemorrhage w $\mathrm{CC}$ & 61,657 & Cellulitis w/o MCC & 49,313 \\
\hline Heart failure \& shock w CC & 234,977 & $\begin{array}{l}\text { Chronic obstructive pulmonary disease } \\
\text { w MCC }\end{array}$ & 57,400 & $\begin{array}{l}\text { Perc cardiovasc proc w drug-eluting } \\
\text { stent } \mathrm{w} / \mathrm{O} \mathrm{MCC}\end{array}$ & 40,097 \\
\hline $\begin{array}{l}\text { Kidney \& urinary tract infections w/o } \\
\text { MCC }\end{array}$ & 232,406 & Pulmonary edema \& respiratory failure & 56,205 & $\begin{array}{l}\text { O.R. procedures for obesity w/o } \\
\text { CC/MCC }\end{array}$ & 35,764 \\
\hline Heart failure \& shock w MCC & 226,609 & Simple pneumonia \& pleurisy w MCC & 55,584 & Full term neonate w major problems & 35,707 \\
\hline Simple pneumonia \& pleurisy w CC & 208,468 & Cellulitis w/o MCC & 52,485 & Prematurity w/o major problems & 35,651 \\
\hline $\begin{array}{l}\text { Misc disorders of nutrition, metabolism, } \\
\text { fluids/electrolytes w/o MCC }\end{array}$ & 206,522 & $\begin{array}{l}\text { Intracranial hemorrhage or cerebral } \\
\text { infarction w CC or tpa in } 24 \mathrm{hrs}\end{array}$ & 52,343 & Spinal fusion except cervical w/o MCC & 34,215 \\
\hline Renal failure w CC & 201,105 & Renal failure w $\mathrm{MCC}$ & 50,844 & $\begin{array}{l}\text { Other antepartum diagnoses w medical } \\
\text { complications }\end{array}$ & 32,823 \\
\hline $\begin{array}{l}\text { Perc cardiovasc proc w drug-eluting } \\
\text { stent } \mathrm{w} / \mathrm{o} \mathrm{MCC}\end{array}$ & 190,429 & $\begin{array}{l}\text { Misc disorders of nutrition, metabolism, } \\
\text { fluids/electrolytes w/o MCC }\end{array}$ & 50,818 & $\begin{array}{l}\text { Circulatory disorders except ami, w card } \\
\text { cath w/o MCC }\end{array}$ & 32,785 \\
\hline Rehabilitation w CC/MCC & 189,546 & $\begin{array}{l}\text { Septicemia or severe sepsis w/o mv ¿96 } \\
\text { hours w MCC }\end{array}$ & 50,185 & Seizures w/o MCC & 32,618 \\
\hline
\end{tabular}


Table 26: 25 Most Common MS-DRGs for Inpatient Visits (continued)

\begin{tabular}{|c|c|c|c|c|c|}
\hline \multicolumn{2}{|l|}{ All Patients } & \multicolumn{2}{|l|}{ TM and MA Patients } & \multicolumn{2}{|l|}{ Private (under 65) patients } \\
\hline & $\mathrm{N}$ & & $\mathrm{N}$ & & $\mathrm{N}$ \\
\hline $\begin{array}{l}\text { Circulatory disorders except ami, w card } \\
\text { cath w/o MCC }\end{array}$ & 187,142 & $\begin{array}{l}\text { Chronic obstructive pulmonary disease } \\
\text { w CC }\end{array}$ & 49,773 & $\begin{array}{l}\text { Septicemia or severe sepsis w/o mv } 96+ \\
\text { hours w MCC }\end{array}$ & 29,544 \\
\hline Chest pain & 183,901 & Syncope \& collapse & 49,230 & $\begin{array}{l}\text { Misc disorders of nutrition, metabolism, } \\
\text { fluids/electrolytes w/o MCC }\end{array}$ & 29,339 \\
\hline G.I. hemorrhage w CC & 173,674 & $\begin{array}{l}\text { Circulatory disorders except ami, w card } \\
\text { cath w/o MCC }\end{array}$ & 49,044 & Bronchitis \& asthma w/o CC/MCC & 28,784 \\
\hline Pulmonary edema \& respiratory failure & 171,560 & $\begin{array}{l}\text { Perc cardiovasc proc } \mathrm{w} \text { drug-eluting } \\
\text { stent } \mathrm{w} / \mathrm{o} \mathrm{MCC}\end{array}$ & 47,695 & $\begin{array}{l}\text { Alcohol/drug abuse or dependence w/o } \\
\text { rehabilitation therapy w/o MCC }\end{array}$ & 27,725 \\
\hline Red blood cell disorders w/o MCC & 166,322 & $\begin{array}{l}\text { Cardiac arrhythmia \& conduction } \\
\text { disorders } w / o \mathrm{CC} / \mathrm{MCC}\end{array}$ & 45,862 & Chest pain & 27,524 \\
\hline $\begin{array}{l}\text { Septicemia or severe sepsis w/o mv } 96+ \\
\text { hours w/o MCC }\end{array}$ & 156,381 & $\begin{array}{l}\text { Cardiac arrhythmia \& conduction } \\
\text { disorders w } \mathrm{CC}\end{array}$ & 45,529 & $\begin{array}{l}\text { Laparoscopic cholecystectomy w/o c.d.e. } \\
\text { w/o MCC/MCC }\end{array}$ & 24,916 \\
\hline
\end{tabular}




\section{References}

[1] American Council on Aging. 2017. "Medicaid By State: Alternative Names and Contact Information," https: //www.medicaidplanningassistance.org/state-medicaid-resources/ (accessed March 29, 2020).

[2] American Hospital Association. 2019. AHA Hospital Statistics, 2019 edition. Chicago, IL.

[3] American Hospital Association. 2020. "AHA to Appeal Court Decision on Public Disclosure of Negotiated Rates." https://www . aha.org/news/headline/2020-06-23-aha-appeal-court-decision-public-disclosure-negotia ted-rates (accessed June 23, 2020).

[4] Baker, Laurence, M. Kate Bundorf, Aileen M. Devlin, and Daniel P. Kessler. 2016. "Medicare Advantage Plans Pay Hospitals Less Than Traditional Medicare Pays." Health Affairs, 35 (8): 1444-1451.

[5] Baker, Laurence, M. Kate Bundorf, Aileen Devlin, and Daniel P. Kessler. 2019. "Why Don't Commercial Health Plans Use Prospective Payment?" American Journal of Health Economics, 5 (4): 465-480.

[6] Berenson, Robert A., Jonathan H. Sunshine, David Helms, and Emily Lawton. 2015. "Why Medicare Advantage Plans Pay Hospitals Traditional Medicare Prices." Health Affairs, 34 (8): 1289-1295.

[7] Brooks, John M., Avi Dor, and Herbert S. Wong. 1997. "Hospital-Insurer Bargaining: An Empirical Investigation of Appendectomy Pricing." Journal of Health Economics, 16 (4): 417-434.

[8] Burns, Lawton R., and Mark V. Pauly. 2018. "Transformation of the Health Care Industry: Curb Your Enthusiasm?" The Milbank Quarterly, 96 (1): 57-109.

[9] Clemens, Jeffrey, and Joshua D. Gottlieb. 2017. "In the Shadow of a Giant: Medicare's Influence on Private Physician Payments." Journal of Political Economy, 125 (1): 1-39.

[10] Clemens, Jeffrey, Joshua D. Gottlieb, and Tímea Laura Molnár. 2017. "Do Health Insurers Innovate? Evidence from the Anatomy of Physician Payments." Journal of Health Economics, 55: 153-167.

[11] Congressional Budget Office. 2013. "A Premium Support System for Medicare: Analysis of Illustrative Options." Washington, D.C.: CBO.

[12] Cooper, Zach, Stuart V. Craig, Martin Gaynor, and John Van Reenen. 2019. "The Price Ain't Right? Hospital Prices and Health Spending on the Privately Insured." The Quarterly Journal of Economics, 134 (1): 51-107.

[13] Craig, Stuart V., Keith Marzilli Ericson, and Amanda Starc. 2018. "How Important Is Price Variation Between Health Insurers?" NBER Working Paper No. 25190.

[14] Curto, Vilsa, Liran Einav, Amy Finkelstein, Jonathan Levin, and Jay Bhattacharya. 2019. "Health Care Spending and Utilization in Public and Private Medicare." American Economic Journal: Applied Economics, 11 (2): $302-332$.

[15] Cutler, David M., Mark McClellan, and Joseph P. Newhouse. 2000. "How Does Managed Care Do It?" RAND Journal of Economics, 31 (3): 526-548.

[16] Gaynor, Martin, and Robert Town. 2011. "Competition in Health Care Markets" in Mark V. Pauly, Thomas G. McGuire, Pedro P. Barros, eds., Handbook of Health Economics (Volume 2). Oxford, U.K: North Holland, 499-637.

[17] Ginsburg, Paul B. 2010. "Wide Variation in Hospital and Physician Payment Rates Evidence of Provider Market Power." Center for Studying Health System Change, HSC Research Brief No. 16.

[18] HCUPnet, Healthcare Cost and Utilization Project. Agency for Healthcare Research and Quality, Rockville, MD.

[19] Maeda, Jared Lane K., and Lyle Nelson. 2018. "How Do the Hospital Prices Paid by Medicare Advantage Plans and Commercial Plans Compare With Medicare Fee-for-Service Prices?" INQUIRY: The Journal of Health Care Organization, Provision, and Financing, 55: 1-8. 
[20] McKellar, Michael R., Sivia Naimer, Mary B. Landrum, Teresa B. Gibson, Amitabh Chandra, and Michael Chernew. 2013. "Insurer Market Structure and Variation in Commercial Health Care Spending." Health Services Research, 499 (3): 878-892.

[21] Melnick, Glenn A., Yu-Chu Shen, and Vivian Y. Wu. 2011. "The Increased Concentration Of Health Plan Markets Can Benefit Consumers Through Lower Hospital Prices." Health Affairs, 30 (99): 1728-1733.

[22] Moriya, Asako S., William B. Vogt, and Martin Gaynor. 2010. "Hospital Prices and Market Structure in the Hospital and Insurance Industries." Health Economics, Policy and Law, 5 (4): 459-479.

[23] Pauly, Mark V. 1998. "Managed Care, Market Power, and Monopsony." Health Services Research, 33 (5): $1439-$ 1460.

[24] Pelech, Daria M. 2018. "Prices for Physicians' Services in Medicare Advantage and Commercial Plans." Medical Care Research and Review, Advance online publication. doi:10.1177/1077558718780604

[25] Quan, Hude, Vijaya Sundararajan, Patricia Halfon, Andrew Fong, Bernard Burnand, Jean-Christophe Luthi, L. Duncan Saunders, Cynthia A. Beck, Thomas E. Feasby, and William A. Ghali. 2005. "Coding Algorithms for Defining Comorbidities in ICD-9-CM and ICD-10 Administrative Data." Medical Care, 43 (11): 1130-1139.

[26] Robinson, JC. 2011. "Hospital Market Concentration, Pricing, and Profitability in Orthopedic Surgery and Interventional Cardiology." American Journal of Managed Care, 17 (6): 241-248.

[27] Romley, John A., Sarah Axeen, Darius N. Lakdawalla, Michael E. Chernew, Jay Bhattacharya, and Dana P. Goldman. 2015. "The Relationship between Commercial Health Care Prices and Medicare Spending and Utilization." Health Services Research, 50 (3): 883-896.

[28] Scheffler, Richard M., and Daniel R. Arnold. 2017. "Insurer Market Power Lowers Prices In Numerous Concentrated Provider Markets." Health Affairs, 36 (9): 1539-1546.

[29] Sorenson, Alan T. 2003. "Insurer-Hospital Bargaining: Negotiated Discounts in Post-Deregulation Connecticut." The Journal of Industrial Economics, 51 (4): 469-490.

[30] Staten, William, John Umbeck, and William Dunkelberg. 1987. "Market Share and the Illusion of Power: Can Blue Cross Force Hospitals to Discount?" Journal of Health Economics, 6 (1): 43-58.

[31] Staten, William, John Umbeck, and William Dunkelberg. 1988. "Market Share/Market Power Revisited: A New Test for an Old Theory." Journal of Health Economics, 7 (1): 73-83.

[32] Town, Robert J., and Gregory Vistnes. 2001. "Hospital Competition in HMO Networks." Journal of Health Economics, 20 (5): 733-753.

[33] Town, Robert J. Roger Feldman, and John Kralewski. 2011. "Market Power and Contract Form: Evidence from Physician Group Practices." International Journal of Health Care Finance and Economics, 11: 115-132.

[34] U.S. Centers for Medicare \& Medicaid Services. 2019. "CY 2020 Hospital Outpatient Prospective Payment System (OPPS) Policy Changes: Hospital Price Transparency Requirements (CMS-1717-F2)." CMS Newsroom. https://www.cms.gov/newsroom/fact-sheets/cy-2020-hospital-outpatient-prospective-payment-systemopps-policy-changes-hospital-price (accessed April 1, 2020).

[35] U.S. Centers for Medicare \& Medicaid Services. 2020. "Medicaid and CHIP program names in your state." https://www.healthcare.gov/medicaid-chip-program-names/ (accessed March 29, 2020).

[36] U.S. Department of Health \& Human Services. 2009. "Medicaid Program Names" published in "Homelessness Data in Health and Human Services Mainstream Programs: Final Report," Winter. https://aspe.hhs.gov/dat aset/medicaid-program-names (accessed March 29, 2020).

[37] White, Chapin, and Christopher Whaley. 2019. "Prices Paid to Hospitals by Private Health Plans Are High Relative to Medicare and Vary Widely." RAND Corporation Research Report, https://www.rand.org/content /dam/rand/pubs/research_reports/RR3000/RR3033/RAND_RR3033.pdf (accessed March 29, 2020). 
[38] Wu, Vivian Y. 2009. "Managed Care's Price Bargaining with Hospitals." Journal of Health Economics, 28 (2): 350-360. 